Aus dem Institut für Diagnostische und Interventionelle Neuroradiologie (Prof. Dr. med. M. Knauth)

der Medizinischen Fakultät der Universität Göttingen

\title{
Untersuchung zum prognostischen Wert der Ganzhirn-Volumen-Perfusions-CT bei Patienten mit akuter zerebraler Ischämie
}

\author{
INAUGURAL-DISSERTATION \\ zur Erlangung des Doktorgrades \\ der Medizinischen Fakultät \\ der Georg-August-Universität zu Göttingen
}

vorgelegt von

Sarah Mareike Finger (geb. Fischer)

aus

Göttingen

Göttingen 2016 
Dekan:

1. Berichterstatter:

2. Berichterstatter/in:

3. Berichterstatter/in:
Prof. Dr. med. H. K. Kroemer

Prof. Dr. med. P. Schramm

PD Dr. med. J. Liman

Prof. Dr. med. T. Meyer

Tag der mündlichen Prüfung: $\quad$ 03.11.2016 


\section{Inhaltsverzeichnis}

\section{Abkürzungsverzeichnis}

1 Einleitung ............................................................................................................. 1

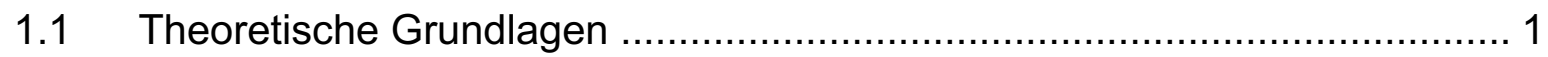

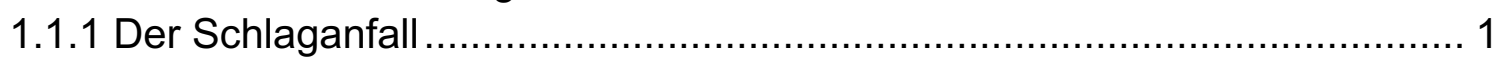

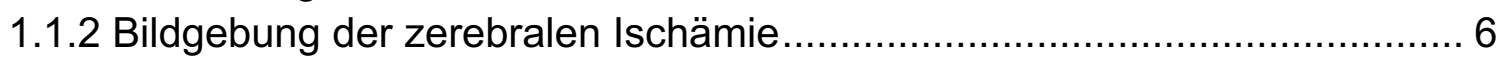

1.2 Fragestellung und Hypothesen ............................................................ 17

2 Material und Methoden .................................................................................................... 18

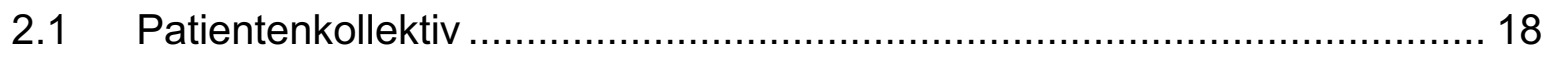

2.2 Durchführung der CT-Untersuchungen.................................................. 19

2.2.1 Durchführung der VPCT-Untersuchungen im akuten Stadium ................ 19

2.2.2 Anfertigung der Follow-up-Bilder zur Bestimmung des finalen

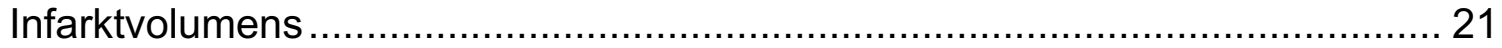

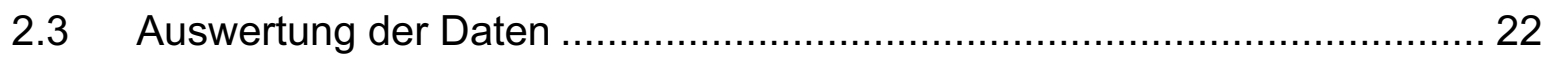

2.3.1 Beurteilung der CT-Perfusions-Untersuchungen im Akutstadium............. 22

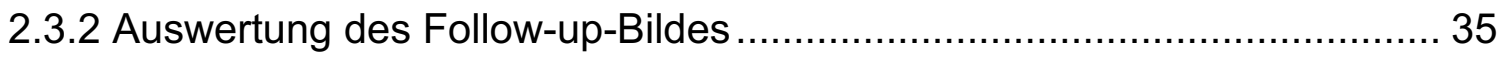

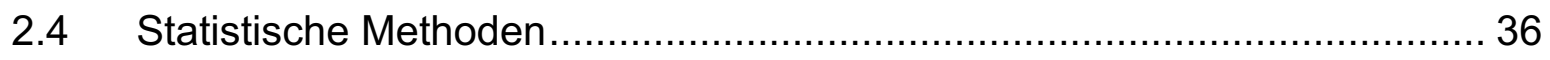

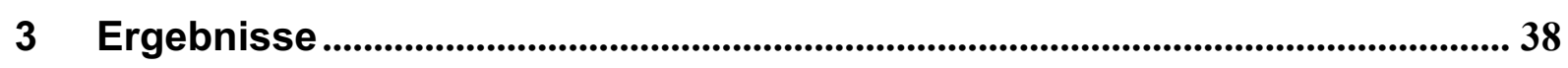

3.1 Analysen des Patientenkollektivs .................................................... 38

3.2 Statistische Reliabilität der Definition von Infarktgewebe ......................... 39

3.3 Prognostischer Wert der Parameter im Bezug auf das Follow-up-

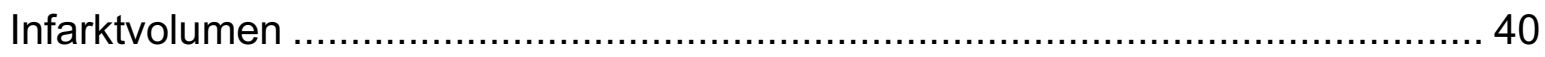

3.3.1 Korrelation der Prädiktoren mit dem Follow-up-Infarktvolumen im

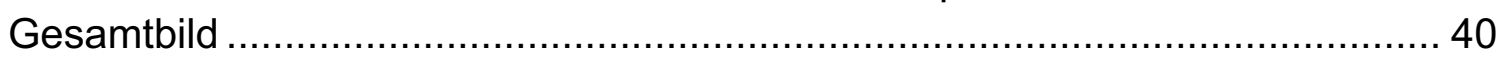

3.3.2 Korrelation der Prädiktoren mit dem Follow-up-Volumen bei Patienten mit/ ohne Gefäßverschluss: ........................................................................ 46

3.3.3 Korrelation der Prädiktoren mit dem Follow-up-Volumen bei Patienten mit

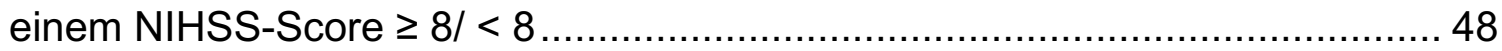

3.4 Zusammenhang zwischen weiteren klinischen Parametern und dem Follow-

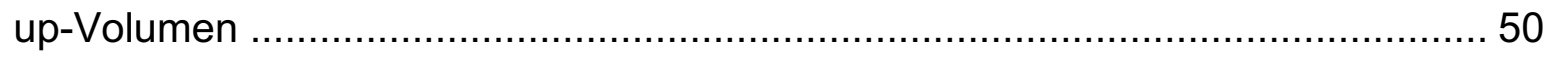

3.4.1 Zusammenhang zwischen dem Alter/ Geschlecht der Patienten und dem Follow-up-Volumen ................................................................................ 50

3.4.2 Zusammenhang zwischen Patienten mit einem Gefäßverschluss/ keinem Gefäßverschluss und dem Follow-up-Volumen ........................................... 51

3.5 Korrelation der Kombination aus NVT + TAR mit dem CBF .................... 53

4 Diskussion. 
4.1 Patientenkollektiv und Studiengrundlagen ........................................ 54

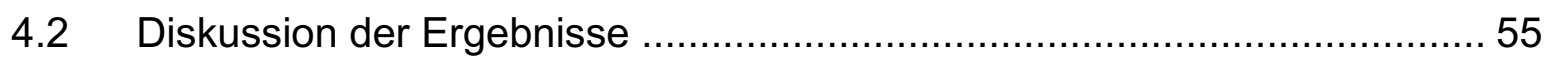

4.2.1. Prognostischer Wert der Perfusionsparameter im Bezug auf das Follow-

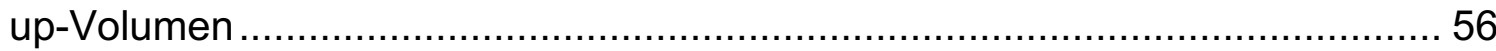

4.2.2 Dichotomisierung des Patientenkollektivs ..................................... 59

4.2.3. Limitationen der Methodik ................................................................ 61

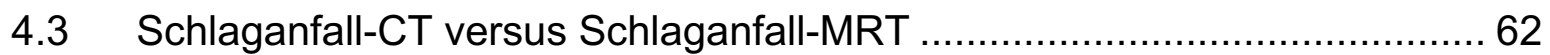

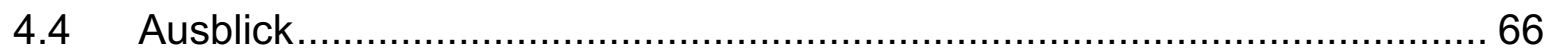

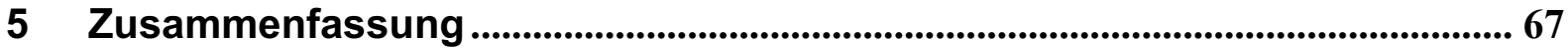

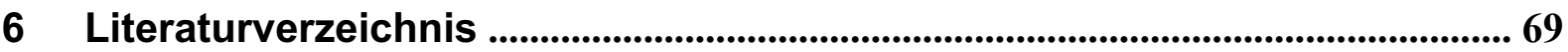

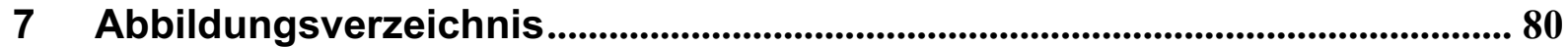

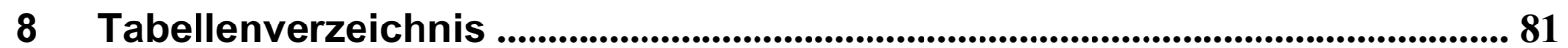

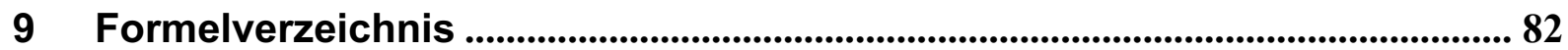

Anhang

Auswertungstabelle 


\section{Abkürzungsverzeichnis}

Abb.

$\mathrm{ACl}$

ASPECTS

CBF

CBV

CBV $(P)$

CSF

CT

CTA

DIAS

DWI

EPI

kV

mAs

mGy

$\mathrm{mmHg}$

$\mathrm{mSv}$

MRT

MRA

MTT

NIHSS

NINDS

NVT

PCT

PRIND

PWI

ROI

rt-PA
Abbildung

Arteria carotis interna

Alberta Stroke Program Early CT Score

zerebraler Blutfluss

zerebrales Blutvolumen

zerebrales Blutvolumen (nach Patlak)

cerebrospinal fluid

Computertomograph/ ie

Computertomographie-Angiographie

Desmoteplase in Acute Ischemic Stroke trial

diffusion weighted imaging

Echo Planar Imaging

Kilovolt

Milli-Ampere-Sekunde

Milli-Gray

Millimeter-Quecksilbersäule

Milli-Sievert

Magnetresonanztomographie

magnetic resonance angiography

mean transit time

National Institute of Health Stroke Scale

The National Institute of Neurological Disorders and Stroke

non viable tissue

Perfusions-CT

prolongiertes reversibles ischämisches neurologisches Defizit

perfusion weighted imaging

region of interest

recombinant tissue plasminogen activator 
TIA

transitorisch ischämische Attacke

TAR

tissue at risk

TTD

time to drain

TTP

time to peak

UMG

Universitätsmedizin Göttingen

VPCT

Volumen-Perfusions-Computertomographie

WHO

World Health Organization 


\section{$1 \quad$ Einleitung}

\subsection{Theoretische Grundlagen}

\subsubsection{Der Schlaganfall}

\subsubsection{Einführung:}

Nach Studienergebnissen von Heuschmann et al. (2010) ereignen sich in Deutschland jährlich rund 196.000 erstmalige Schlaganfälle. Die mit einem Schlaganfall häufig verbundene frühzeitige Invalidität und die dabei entstehenden Kosten stellen dabei ein gesellschaftliches Problem dar (Bogousslavsky et al. 2000).

Die WHO (1988) definiert einen Schlaganfall als ein sich rasch entwickelndes fokales oder globales Ereignis mit Zeichen einer Störung der Hirnfunktion. Die Symptome dauern dabei mindestens 24 Stunden an oder führen direkt zum Tod. Andere Ursachen müssen ausgeschlossen sein (eigene Übersetzung).

Abhängig von der Dauer des ischämischen Ereignisses spricht man entweder von einer transitorisch-ischämischen Attacke (TIA), einem prolongierten reversiblen ischämischen neurologischen Defizit (PRIND) oder einem zerebralen Infarkt. Eine TIA beschreibt eine passagere, unter 24 Stunden andauernde Minderversorgung des zerebralen Hirngewebes ohne bleibende Symptomatik. Bei einem PRIND hingegen kann die Minderdurchblutung zwischen 24 Stunden und ungefähr 3 Wochen anhalten und sich dann wieder regulieren.

Nach Lago et al. (1998) liegt bei ungefähr 25\% der Schlaganfallpatienten ein sogenannter wake-up stroke vor, ein Ereignis, bei dem die Patienten mit einer Ischämiesymptomatik aus dem Schlaf heraus aufwachen und der Symptombeginn letztlich unklar bleibt. 
Bei Patienten, die einen Infarkt erleiden, unterscheidet man abhängig vom Schweregrad der Ischämie einen leichten (minor stroke) von einem schweren (major stroke) Schlaganfall. Ein leichter Schlaganfall wird nach Yadav et al. (1997) definiert als ein Infarkt mit funktionaler Erholung des Hirngewebes innerhalb von sieben Tagen. Ein schwerer Schlaganfall führt hingegen meist $\mathrm{zu}$ einer schwerwiegenden oder bleibenden Behinderung oder direkt zum Tod.

Der Schweregrad eines Schlaganfalls kann mit Hilfe des NIHSS-Scores angegeben werden, der sich aus dem Bewusstseinsgrad, der Motorik und Sensibilität einzelner Körperregionen des Patienten zusammensetzt. Der NIHSS-Score dient als Verlaufsparameter oder der Beurteilung der Therapieoptionen.

Bei $80 \%$ der Schlaganfallpatienten findet sich eine fokale zerebrale Ischämie, die durch den Verschluss einer Hirnarterie verursacht ist. Aber auch intrazerebrale Blutungen können in $15 \%$ der Fälle eine Schlaganfall-Symptomatik auslösen.

Zu den selteneren Ursachen für die entsprechende Symptomatik zählen die Subarachnoidalblutung, die Hypoglykämie, die Hirnvenenthrombosen, Tumoren, die postparoxysmale Parese nach Krampfanfall, das chronische Subduralhämatom, die Migräne mit Aura und psychogene Paresen.

Gemäß einem Beitrag der „WHO Task Force on Stroke and other Cerebrovascular Disorders" von 1989 gehören arterielle Hypertension, Diabetes mellitus, Adipositas, Gerinnungsstörungen, ein vorausgegangener Herzinfarkt oder Schlaganfall sowie eine bereits erlebte transitorisch ischämische Attacke (TIA) zu den häufigsten Risikofaktoren, die die Auslösung eines Schlaganfalls begünstigen.

$\mathrm{Zu}$ den Warnsignalen eines akuten Schlaganfallereignisses zählt die „American Stroke Association“ (www.Strokeassociation.org) vor allem eine plötzliche einseitige faziale oder extremitätenbetonte Schwäche und Gefühllosigkeit, eine plötzlich verwaschene oder konfuse Sprache, Sehstörungen, Balance- und Koordinationsstörungen sowie blitzartig einsetzende idiopathische Kopfschmerzen.

Auch bei einer TIA, die durch eine kurze Ischämiedauer von weniger als 24 Stunden im entsprechenden Hirngewebe verursacht ist, können diese Symptome auftreten. Diagnostisch findet sich im Fall einer TIA zwar kein Infarktgewebe, jedoch ist eine TIA eine wichtige Indikation für eine sofortige Sekundärprävention eines Schlaganfalls mit Antikoagulantien, da das Schlaganfallrisiko in den ersten Stunden nach 
einer TIA besonders hoch ist. Kleindorfer et al. (2005) fanden heraus, dass innerhalb der ersten zwei Tage nach einer TIA ein Infarktrisiko von ca. $6 \%$ besteht. Bis zum 6. Monat nach einer TIA liegt das Risiko für einen Schlaganfall sogar bei $17 \%$, wobei sich in $65 \%$ der Fälle der Infarkt bereits in den ersten 30 Tagen nach der TIA ereignete.

Bei einer zerebralen Ischämie ist das Ausmaß der Funktionsbeeinträchtigung der Hirnzellen von der Restperfusion durch Kollateralgefäße und dem lokalen Blutdruck abhängig. Synapsen, die Natrium-Kalium-Pumpe und der Energiestoffwechsel können dabei im ischämischen Hirnareal funktionell beeinflusst werden.

Ein zerebraler Blutfluss von weniger als $20 \mathrm{ml} / 100 \mathrm{~g} / \mathrm{min}$ bedingt ein minder durchblutetes Hirngewebe. Unter einem Wert von 6-10 $\mathrm{ml} / 100 \mathrm{~g} / \mathrm{min}$ ist das Hirngewebe in der Regel irreversibel geschädigt (Astrup et al. 1981, Astrup et al. 1976).

Für den zerebralen Blutfluss und für die weiteren Parameter der regionalen zerebralen Perfusion sind Grenzwerte festgelegt worden, die das Ausmaß der Ischämie vorhersagen können. Auf diese wird im Rahmen der Dissertationsarbeit noch genauer eingegangen.

\subsubsection{Die pathophysiologische Kaskade bei der regionalen zerebralen Ischä- mie:}

Die pathophysiologische Kaskade in einem zerebralen Infarktgebiet kann durch das Modell von vier verschiedenen Gewebekompartimenten beschrieben werden. $\mathrm{Zu}$ diesen Kompartimenten gehören

- das nicht beeinträchtigte Normalgewebe

- die Oligoämiezone (türkis)

- die ischämische Penumbra (gelb) und

- der im Zentrum liegende Infarktkern (rot) (siehe Abb. 1) (Baron 2001) 


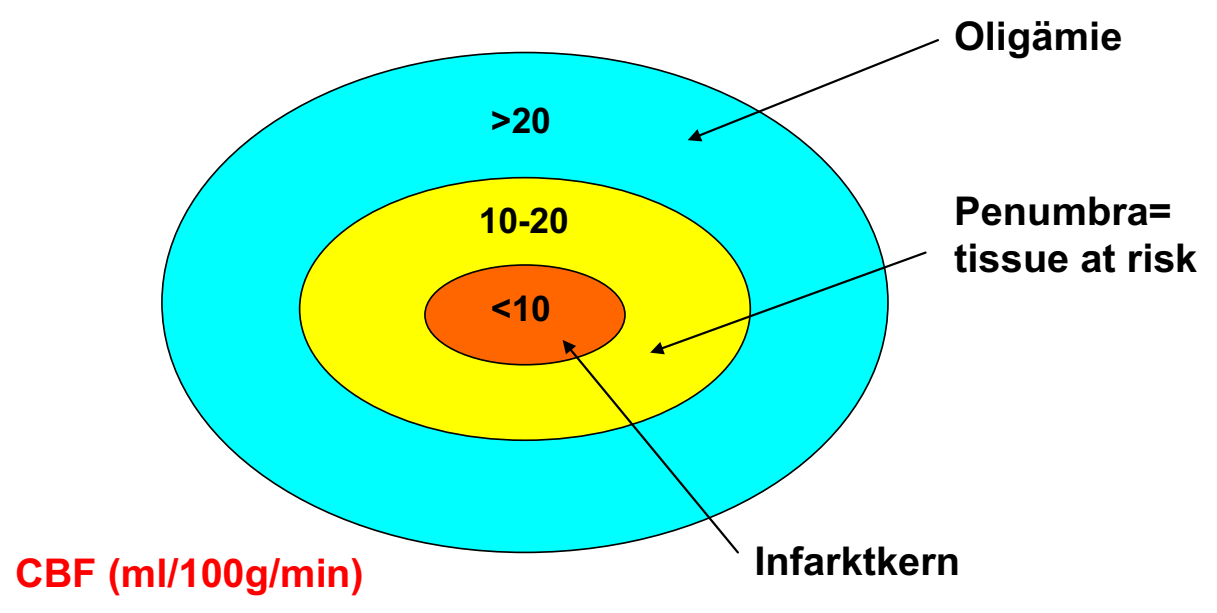

Abbildung 1: Zonen der zerebralen Ischämie

Der regionale zerebrale Blutfluss beträgt im Infarktkern 6-10 ml/100 $/ \mathrm{min}$ (Astrup et al. 1981). Der durch die Minderperfusion bedingte Funktionsverlust der Zellen führt zu einem Zusammenbruch der lonenkanalfunktion. Durch den resultierenden Wassereinstrom in die Zellen kommt es zu einem zytotoxischen Ödem, das als Surrogatmarker von irreversibel geschädigtem Gewebe gilt (Schramm 2004).

Der Infarktkern wird dabei direkt von der weniger schlecht perfundierten ischämischen Penumbra umschlossen. Nach Astrup et al. $(1977 ; 1981)$ und Lassen (1990) ist bei einem Verschluss der Arteria cerebri media in der Penumbra zwar die elektrische Funktion gestört, das extrazelluläre Kalium hingegen noch nicht erhöht, wodurch die Zellen grundsätzlich überlebensfähig sind. In diesem Gewebe beträgt der zerebrale Blutfluss weniger als $20 \mathrm{ml} / 100 \mathrm{~g} / \mathrm{min}$, liegt aber über dem kritischen Wert von 6-10 $\mathrm{ml} / 100 \mathrm{~g} / \mathrm{min}$, der zu einer irreversiblen Schädigung führt.

Die Penumbra kann sich regenerieren, wenn sie abhängig vom zerebralen Blutfluss innerhalb von zwei bis drei Stunden wieder ausreichend durchblutet wird. Jones et al. (1981) sowie Heiss und Rosner (1983) beschreiben somit ein therapeutisches Fenster von drei Stunden, in dem sich Penumbragewebe durch Reperfusion wieder komplett regenerieren kann. Ist die Reperfusion in der begrenzten Zeit nicht gewährleistet, kann sich die Penumbra zum irreversibel geschädigten Infarktgewebe umwandeln. Auf diese Weise kommt es zur Ausweitung des Infarktgebietes (Jones et al. 1981, Baron 1999). Die ischämische Penumbra beschreibt einen dynamischen Prozess. Sie existiert für einen kurzen Moment auch im Zentrum des Infarktgebietes, bevor sich dieses Gewebe entsprechend der Ischämiedauer zu einem irreversibel 
geschädigten Areal entwickelt und auch zunehmend das oligämische Nachbargewebe einbezieht (siehe Abb. 2) (Heiss 2000).

Nicht nur der zerebrale Blutfluss, sondern auch die Dauer der Ischämie im Gewebe hat einen entscheidenden Einfluss auf die Ausbildung einer irreversiblen Infarktzone. Je niedriger der zerebrale Blutfluss, desto geringer auch die zeitliche Toleranz eines Gefäßverschlusses (Garcia et al. 1983, Jones et al. 1981).
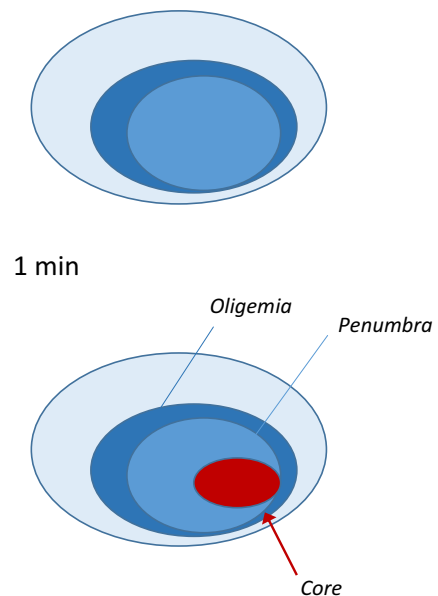

$1 \mathrm{~h}$

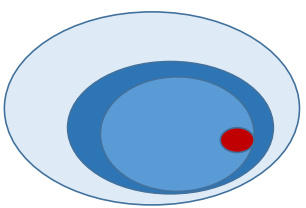

$15 \min$

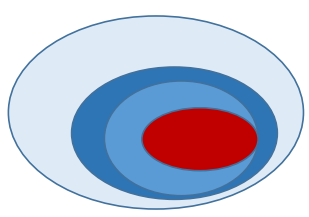

$2 \mathrm{~h}$

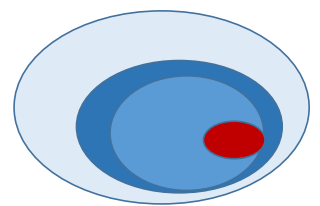

$30 \mathrm{~min}$

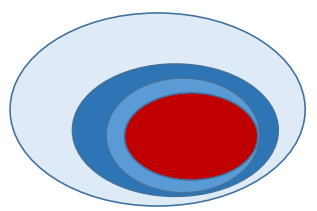

$3 \mathrm{~h}$

Abbildung 2: Veränderung des Infarktgebietes im zeitlichen Verlauf (modifiziert nach Baron 1999, S. 194). Rot: Infarktkern, hellblau: Penumbra, Dunkelblau: Oligämiezone

Die ischämische Penumbra wird von einer Oligämiezone umgeben. In diesem Bereich liegt der zerebrale Blutfluss aufgrund der Versorgung durch Gefäßkollateralen zwar unter dem Normalwert von 50-60 ml $/ 100 \mathrm{~g} / \mathrm{min}$, jedoch über dem Grenzwert der Penumbra. Die Oligoämiezone ist somit nicht unmittelbar Risikogebiet für einen zerebralen Infarkt (Astrup et al. 1981).

Die ischämische Penumbra stellt durch die Regenerierbarkeit des Gewebes einen entscheidenden Angriffspunkt für Therapieverfahren eines akuten Schlaganfalls dar (Heiss 2000). Sämtliche neuroprotektive Optionen der Therapie der akuten zerebralen Ischämie zielen auf das Gewebe der Penumbra. 


\subsubsection{Bildgebung der zerebralen Ischämie}

\subsubsection{Einführung:}

Der Schlaganfall ist eine der häufigsten Todesursachen in den Industrienationen. Die Akutversorgung der Infarktpatienten hat sich jedoch in den letzten Jahren durch die Einführung spezialisierter Einrichtungen - wie etwa den stroke units - immens verbessert.

Laut der ECASS 3-Lysestudie ist eine intravenöse Behandlung mit Alteplase bei einer akuten Ischämie in einem Zeitrahmen von bis zu 4,5 Stunden möglich (Hacke et al. 2008). Mit Desmoteplase erreichte man, wie in der DIAS-2-Studie (Desmoteplase in Acute Ischemic Stroke trial) erforscht, sogar ein Zeitfenster von bis zu neun Stunden (Hacke et al. 2005, Hacke et al. 2009), sofern eine ischämische Penumbra vorhanden war.

Die Thrombolyse stellt nach der NINDS-Studie (The National Institute of Neurological Disorders and Stroke rt-PA Stroke Study Group) von 1995 eine effektive Therapieoption bei der akuten zerebralen Ischämie dar. Ohne eine Rekanalisationstherapie ist mit dauerhaften irreversiblen Schäden von Hirngewebe zu rechnen. Die Diagnostik der dem Schlaganfall zugrunde liegenden Ursache muss dabei schnell und präzise erfolgen, um in dem engen therapeutischen Zeitfenster von aktuell bis 4,5 Stunden eine Thrombolyse-therapie bei Vorhandensein einer ischämischen Penumbra zu ermöglichen. Je größer allerdings das Zeitfenster zwischen akutem Auftreten der Ischämie-symptomatik und der Therapie ist, desto höher liegt auch das durch die Thrombolyse bedingte Blutungsrisiko (Schellinger und Köhrmann 2012, Wardlaw 2001).

Ziel der neuroradiologischen Diagnostik ist, vor der Therapie diejenigen Patienten zu identifizieren, die von einer intravenösen oder intraarteriellen Lyse profitieren (Lee et al. 2005). Patienten mit bereits großem Anteil von irreversibel geschädigtem Infarktgewebe, d.h. einer Demarkation von > 33\% des Versorgungsgebietes der Arteria cerebri media, haben ein erhöhtes Risiko einer durch die Thrombolysetherapie verursachten Reperfusionsverletzung und sind damit für die Lyse weniger gut geeignet (Hacke et al. 1995).

Von einer optimalen neuroradiologischen Ischämiediagnostik wird erwartet, die Ursache, die genaue Lokalisation und die Ausdehnung des Schlaganfalls bildgebend 
darzustellen. Des Weiteren sollte eruierbar sein, ob ein Gefäßverschluss und ein bereits irreversibel geschädigtes Areal vorliegen.

\subsubsection{Computertomographie bei der zerebralen Ischämie:}

\section{a) Allgemeines}

Die Computertomographie (CT) ist ein seit den siebziger Jahren verwendetes röntgenologisches Verfahren zur Anfertigung von Schichtaufnahmen des menschlichen Körpers. Die CT-Bilder entstehen dadurch, dass eine um den Patienten rotierende Röntgenröhre Röntgenstrahlen produziert, die nach Durchtritt durch den Körper von einem Detektorkranz absorbiert und zu überlagerungsfreien digitalen Bildern verarbeitet werden. Der Detektor misst die durch den Körper verursachte Schwächung der Röntgenstrahlen. Diese Schwächung wird in Hounsfield-Einheiten angegeben und zeigt entsprechend der Dichte des Gewebes unterschiedliche Grauwerte.

Godfrey Hounsefield entwickelte in Zusammenarbeit mit der Firma EMI den ersten CT-Scanner, der 1971 die erste Untersuchung einer Patientin ermöglichte. Siemens Medical Systems brachte 1988 zunächst den ersten einzeiligen helikalen Computertomographen für den klinischen Gebrauch auf den Markt. 1992 wurde dann das erste Zweizeilen-CT von Elscint vorgestellt. Erst 1998 folgte dann das Mehrzeilen-CT mit vier Detektorzeilen. Das Mehrzeilen-CT bot unter anderem eine schnellere Untersuchungszeit, weniger Bewegungsartefakte und eine bessere zeitliche und räumliche Auflösung durch feinere Schichtungen.

Damit war es möglich, Perfusionsuntersuchungen und CT-Angiographien des Gehirns durchzuführen (Klingenbeck-Regn et al. 1999, Klotz und König 1999).

Seit Einführung des Mehrzeilen-Spiral-CT in den neunziger Jahren sind die Perfusions-CT und die CT-Angiographie etablierte Verfahren, die in Kombination mit dem Nativ-CT wesentlicher Bestandteil der Schlaganfalldiagnostik geworden sind (Tomandl et al. 2003).

Im Folgenden werden die einzelnen Untersuchungsverfahren bei einer akuten zerebralen Ischämie kurz erläutert: 


\section{b) Nativ-Computertomographie:}

Die Nativ-Computertomographie ist eine Untersuchungsmethode ohne Kontrastmittel und wurde bis zu den späten achtziger Jahren alleinig beim akuten Schlaganfall durchgeführt. Intrakranielle Blutungen, große Tumoren oder Liquorzirkulationsstörungen können mit ihr erkannt werden.

Darüber hinaus wird die Nativ-CT auch zur Diagnostik von frühen Infarktzeichen wie das dense media sign, das insular ribbon sign, die verstrichenen unscharfen Sulci und die beginnende Dichteminderung im Infarktgebiet genutzt und ist daher in der Akutdiagnostik weiter sehr bedeutsam.

Das hyperdense Media-Zeichen (dense media sign) beschreibt eine im CT sichtbare Dichtezunahme der Arteria cerebri media. Es kann als frühes Infarktzeichen vor der Demarkierung des Infarktes auftreten. Das hyperdense Media-Zeichen ist ein Hinweis auf ein größeres ischämisches Ereignis. Bastianello et al. (1991), Tomsick et al. (1996) und Leys et al. (1992) fanden heraus, dass es bei Auftreten eines hyperdensen Media-Zeichens häufiger auch zu früher parenchymaler Hypodensität kommt. Ein weiteres frühes Infarktzeichen ist das insular ribbon sign, welches sich nach Truwit et al. (1990) innerhalb der ersten sechs Stunden nach Symptombeginn darstellen kann und die durch das sich entwickelnde frühe zytotoxische Ödem fehlende Abgrenzbarkeit des Inselrindenbandes vom Marklager meint.

Ist auf einem Nativ-CT-Bild eine Blutung oder eine andere Läsion wie z.B. ein Tumor ausgeschlossen worden, muss von einer akuten Ischämie ausgegangen werden. Jedoch ist innerhalb der ersten Stunden auf den Bildern der Nativ-CT alleine die Ausdehnung von irreversibel geschädigtem Hirngewebe nicht ausreichend einschätzbar (von Kummer et al. 1996).

Mitte der neunziger Jahre änderten sich die Anforderungen an die diagnostische Bildgebung durch eine Studie der NINDS rt-PA Stroke Study Group (1995). Die Thrombolyse mit recombinant tissue plasminogen activator (rt- PA) wurde als effiziente Behandlungsmethode bei akuter zerebraler Ischämie vorgestellt. Somit wurden die Supportivmaßnahmen von neuen therapeutischen medikamentösen Interventionen abgelöst. Damit waren höhere Ansprüche an die Bildgebung in der Akutdiagnostik bei einer akuten zerebralen Ischämie unerlässlich (Beauchamp et al. 1999). 
Die Schlaganfall-Diagnostik mittels CT hat einer Diagnostik mit dem MRT gegenüber den Vorteil, dass Computertomographen im Gegensatz zu Magnetresonanztomographen weiter verbreitet und generell auch in kleineren Kliniken verfügbar sind (Handschu et al. 2001). Außerdem sind beatmete Patienten und solche, die einer intensivmedizinischen Betreuung bedürfen, häufig nicht für eine schnelle MRTUntersuchung geeignet. Die Untersuchungsdauer ist zudem mit dem CT kürzer.

\section{c) CT-Angiographie:}

In der Schlaganfalldiagnostik wird heute zusätzlich zur Nativ-CT häufig eine CTAngiographie (CTA) durchgeführt. Die CTA ist eine schnelle, nicht invasive Methode zur bildlichen Darstellung von Gefäßverschlüssen und Aneurysmen und kann an jedem Spiral-CT durchgeführt werden (Kalender und Polacin 1991). Sie ermöglicht die Darstellung der Lokalisation der Okklusion, der Ausdehnung des arteriellen Segment-Verschlusses und der Kollateralgefäßversorgung (Knauth et al. 1997). Schramm et al. (2002) zeigten zudem, dass die CTA-Quellbilder in Lokalisation und Ausdehnung der ischämischen Läsion in diffusionsgewichteten MRT-Bildern entsprechen und damit das irreversibel geschädigte Infarktgewebe vorhersagen können.

Das für die Untersuchung benötigte nicht-ionische Kontrastmittel ist gut verträglich und besitzt nur wenige Nebenwirkungen (Katayama et al. 1990, Doerfler 1998).

Die CTA ist nicht nur für die Akutdiagnostik von entscheidendem Wert, sondern liefert auch prognostische Hinweise über Krankheitsverlauf und Outcome (von Kummer et al. 1995). Demzufolge hilft sie bei der Entscheidung, ob eine Thrombolysetherapie erfolgen sollte oder nicht.

\section{d) Die Perfusions-Computertomographie:}

Die Perfusions-Computertomographie (PCT) ist eine kontrastmittelgestützte Untersuchung, die die Durchblutung eines Organs misst und dabei quantitative Werte über die Durchblutung liefert. Die Analyse der PCT erfolgt in der Regel anhand von Farbbildern, die entsprechende Veränderungen der Hämodynamik aufzeigen. Die dynamische Perfusions-CT kann das Ausmaß des geschädigten Gewebes viel präziser als die Nativ-CT voraussagen und auch zur genaueren Evaluation der 
Indikation einer Thrombolysetherapie verhelfen (Klotz und König 1999, Tomandl et al. 2003).

Die Prinzipien der dynamischen CT-Untersuchung unter Verwendung von jodhaltigem Kontrastmittel sind bereits Anfang der achtziger Jahre erforscht worden. 1980 stellte Axel eine computertomographische Methode zur Bestimmung des zerebralen Blutflusses vor. Grundlage dieser Forschung war die Erfassung des sogenannten First pass eines Kontrastmittelbolus durch das Hirngefäßsystem anhand repetitiver CT-Aufnahmen einer Untersuchungsschicht.

Für die zerebrale PCT ist die intravenöse Applikation von jodhaltigem Kontrastmittel notwendig. Dabei müssen zuvor Kontraindikationen wie eine Jodallergie, eine Hyperthyreose und eine Niereninsuffizienz ausgeschlossen werden. Die Verteilung des Kontrastmittels im Gehirn unterliegt dem Kompartmentmodell, die Blut-HirnSchranke beschreibt dabei eine physiologische Barriere zwischen dem Blutkreislauf und dem Zentralnervensystem. Dabei können nur lipophile, also fettlösliche Moleküle die Blut-Hirn-Schranke überwinden. Das Kompartmentmodell gibt die Verteilung eines Arzneimittels, hier des Kontrastmittels, in einem oder mehreren Kompartimenten an und dient der Berechnung der Konzentration in den Volumina. Die Perfusions-CT bietet neue diagnostische Ansätze, da bereits im sehr frühen Infarktstadium durch Berechnung der Perfusionsparameter die Ischämieregion bildlich sowie auch anhand von Messdaten dargestellt werden kann. Das Verfahren besitzt in Bezug auf die bildliche Darstellung des zerebralen Blutflusses dabei eine Sensitivität von 90\% und eine Spezifität von 100\% (Klotz und König 1999). Die durch die PCT mögliche Differenzierung in Infarktkern und Penumbra hat einen hohen Stellenwert für die Therapieentscheidung (Leiva-Salinas et al. 2011).

Die Volumina ischämischer Läsionen in der perfusionsgewichteten Bildgebung (PWI) mittels MRT stimmen signifikant mit den Volumina der ischämischen Läsionen im PCT überein (Schramm 2004).

In der Vergangenheit war es mittels PCT nicht möglich, das gesamte Gehirnvolumen mit einem Kontrastmittelbolus zu untersuchen, sondern abhängig von der Detektorbreite des CT-Gerätes nur ein eingeschränktes Hirnareal. Anhand der neurologischen Symptomatik wurde die darzustellende Hirnregion für die Untersuchung ausgewählt (Tomandl et al. 2003). Daher konnte bei größeren Infarkten so gut wie nie das komplette Ausmaß der Hypoperfusion erfasst oder kleinere Infarkte 
übersehen werden. Eine größere (Hirn-) Volumenabdeckung durch die PerfusionsCT war aber gerade bei größeren Mediainfarkten wünschenswert.

\section{Die Ischämieparameter:}

Zur frühzeitigen Diagnostik eines Schlaganfalls anhand der Computertomographie haben sich die Untersuchungen Nativ-CT, Perfusions-CT und CT-Angiographie als Kombination bewährt.

Für die PCT und die CTA ist die intravenöse Infusion von Kontrastmittel notwendig. Solange die Blut-Hirn-Schranke im frühen Ischämiestadium intakt ist, bleibt das zur Ischämiediagnostik verabreichte Kontrastmittel in den Gefäßen und kann nicht ins Gewebe dringen. Während des First pass des Kontrastmittelbolus durch das Gehirn werden die lokale Kontrastmittelanreicherung und damit das Gefäßsystem durch die Änderung der Dichtewerte mit Hilfe des CT bildlich dargestellt (Klotz und König 1999).

Aus der Zeit-Dichte-Kurve der PCT (siehe Abb. 3) werden für jedes untersuchte Voxel die hämodynamischen Parameter time to peak, cerebral blood flow und cerebral blood volume sowie die mean transit time errechnet.

Zur Beurteilung der regionalen Perfusion im menschlichen Hirngewebe dienen neben anderen die Parameter TTP, CBF und CBV. Den Ischämieparametern liegen unterschiedliche Konzepte zugrunde, die im Folgenden kurz erläutert werden:

\section{TTP (time to peak)}

Die TTP bezeichnet die Zeitspanne in Sekunden vom Beginn der Kontrastmittelinjektion bis zur maximalen Kontrastmittelanreicherung innerhalb eines bestimmten Areals im Hirngewebe (Reichenbach et al. 1999).

Die time to peak ist ein stabiler Parameter, der in enger Beziehung zum zerebralen Blutfluss steht und damit die Einschätzung der Gewebedurchblutung verbessert (Lassen und Perl 1979). 


\section{CBF (cerebral blood flow)}

Normalerweise beträgt der regionale zerebrale Blutfluss im Kortex 50-60 ml/100 $\mathrm{g} / \mathrm{min}$.

Eine Blutflussreduktion kann toleriert werden, solange zu ihrem Ausgleich das Sauerstoffangebot erhöht wird und die normale Stoffwechselrate konstant bleibt. Ist dies nicht gewährleistet, kommt es zu Funktionseinschränkungen der Hirnzellen. Ab einem zerebralen Blutfluss von $55 \mathrm{ml} / 100 \mathrm{~g} / \mathrm{min}$ wird die Proteinsynthese beeinträchtigt, im Bereich von $35 \mathrm{ml} / 100 \mathrm{~g} / \mathrm{min}$ beginnt die anaerobe Glykolyse und bei einem zerebralen Blutfluss von $20 \mathrm{ml} / 100 \mathrm{~g} / \mathrm{min}$ wird die Ausschüttung von Neurotransmittern und der Energiestoffwechsel dysreguliert. Erreicht der zerebrale Blutfluss einen Wert unter $10 \mathrm{ml} / 100 \mathrm{~g} / \mathrm{min}$, steigt die extrazelluläre $\mathrm{K}+$-lonenKonzentration an und führt zum Zelltod (Astrup 1977, 1981; Heiss 2000).

Eine Normalisierung des CBF kann zu einer Erholung der Zellfunktion führen.

Die Berechnung des CBF basiert auf dem Konzept des maximum slope models, welches durch Miles et al. (1991) für die Bestimmung von Organdurchblutungen am CT beschrieben wurde. Die Perfusion entspricht dabei dem Verhältnis der maximalen Steigung der Zeit-Dichte-Kurve im Gewebe zum maximalen Dichteanstieg in der ZeitDichte-Kurve in der Arterie (siehe Formel 1). Nach König et al. (2000) kann das Kontrastmittel das Kompartiment bis zu einem bestimmten Zeitpunkt nach Eintreffen des Bolus im Gewebe auf venösem Weg nicht verlassen.

Das maximum slope model veranschaulicht somit den Höchstwert in der arteriellen Kontrastmittelanreicherungskurve. Es erfordert eine schnelle intravenöse Kontrastmittelbolusinjektion, da eine Verzögerung sonst zu einer Abflachung der ZeitDichtekurve und damit zu einer Verfälschung des CBF-Werts führen würde (Klotz und König 1999)

\section{max. Anstiegsgeschwindigkeit der TAC (Gewebe)}

Perfusion $=$

max. Anstieg der TAC (arteriell)

Formel 1: Berechnung der Perfusion anhand der Zeit-Dichtekurve (König et al. 2000). TAC = time attenuation curve 


\section{CBV (cerebral blood volume)}

Das zerebrale Blutvolumen beträgt normalerweise $4-5 \mathrm{ml} / 100 \mathrm{~g}$ Gehirnmasse (Sakai et al. 1985).

Im frühen Ischämiestadium erweitert sich das Kapillarbett und der zerebrale Blutfluss nimmt ab. Das zerebrale Blutvolumen hingegen bleibt zunächst konstant, bzw. steigt durch die Autoregulationsmechanismen leicht an. Wenn die Kompensation des geringen Blutflusses nicht mehr ausreicht, sinkt auch das zerebrale Blutvolumen (König et al. 2001, Wintermark et al. 2002a). Wintermark et al. (2002a) gehen davon aus, dass bei einem zerebralen Blutvolumen von 2,5 ml/100g ein absoluter Grenzwert für irreversibel geschädigtes Hirngewebe zu setzen ist.

Das regionale CBV wird durch die maximale Anreicherungsrate bestimmt, welche das Verhältnis zwischen der maximalen Kontrastmittelkonzentration im Gewebe und der Kontrastmittelkonzentration in der abführenden Vene darstellt (siehe Formel 2) (Klotz und König 1999). Es wird auch durch die Fläche unter der Zeit-Dichte-Kurve der PCT wiedergegeben (siehe Abb. 3).

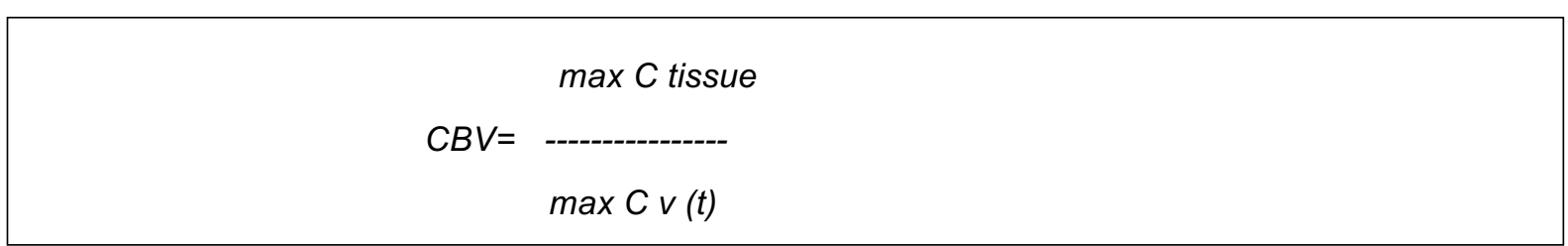

Formel 2: Formel zur Berechnung des zerebralen Blutvolumens, $C=$ Konzentration, tissue $=$ Gewebe, $v=$ Vene, $t=$ time (Zeit) (Klotz und König 1999)

Das zerebrale Blutvolumen kann alternativ auch mit einer 1983 von C.S. Patlak entwickelten Methode bestimmt werden (CBV(P)). Die Patlak-Analyse wird aus dem Kompartimentmodell hergeleitet und beschreibt den gerichteten Kontrastmitteltransport nur vom Intravaskulär- in den Extravaskulärraum. Ab einem bestimmten Zeitpunkt ist die Kontrastmittelkonzentration im Gewebe äquivalent zu der Summe aus intra- und extravaskulärer Kontrastmittelkonzentration. Die Patlak-Methode beschreibt damit die extravaskuläre Permeabilität in den interstitiellen Raum. 
Die mean transit time (MTT), die im Rahmen der Dissertationsarbeit nicht bestimmt wurde, ist als Zeitabstand zwischen arteriellem Zustrom und venösem Abfluss definiert.

TTP und MTT sind sehr sensitive Parameter zur Bewertung einer hämodynamischen Störung und sollten immer bei Beginn der Auswertung der Perfusionsdaten begutachtet werden. CBF und CBV hingegen sind wichtige Prädiktoren für das Outcome des Patienten mit einer zerebralen Ischämie (Tomandl et al. 2003). Das Verhältnis zwischen $\mathrm{CBF}$ und $\mathrm{CBV}$ gibt Aufschluss über den Umfang einer irreversiblen Störung. So ist es wichtig, dass CBF und CBV gleichzeitig analysiert werden (Schramm 2005).

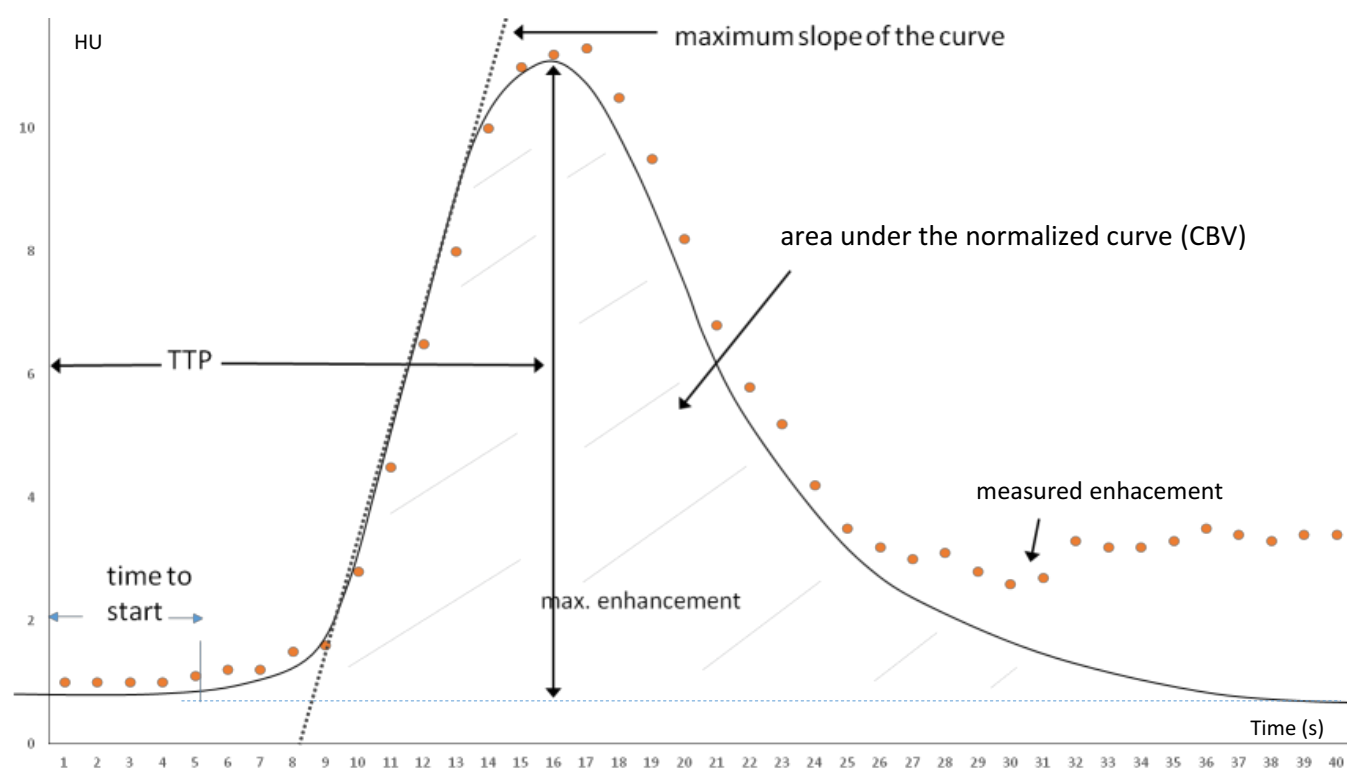

Abbildung 3: Zeit-Dichte-Kurve im normalen Hirngewebe zur Bestimmung von CBF, CBV und TTP (modifiziert nach Tomandl et al. 2003, S. 570).

\section{Die Volumen-Perfusions-Computertomographie:}

Die Volumen-Perfusions-Computertomographie (VPCT) ist eine weiterentwickelte Methode zur Darstellung der zerebralen Perfusion und damit auch der Früherkennung von Infarkten. Die VPCT hat darüber hinaus in der Tumordiagnostik bereits einen hohen Stellenwert erreicht (Xyda et al. 2012)

Bei der VPCT wird ein Multispiraldatensatz anstelle von repetitiven Einzelschichten verwendet. Das Mehrzeilen-Spiral-CT mit 4-D Spirale ermöglicht ein zeitaufgelöstes Volumenscanning und eine Abdeckung des Hirnvolumens deutlich über der Detektor- 
breite. Durch die kontinuierliche Pendelbewegung des Untersuchungstisches und die repetitiven Spiralen wird ein größerer Scanbereich erreicht und damit eine GanzhirnPerfusions-Untersuchung möglich (siehe Abb. 4). Die strahlen-empfindlichen Augenlinsen werden bei einem Abstand von ca. $2 \mathrm{~cm}$ vom Scan-bereich ausreichend geschont.

Der Scanbereich umfasst in der Z-Achse $96 \mathrm{~mm}$. Alle 1,5 Sekunden befindet sich die Spirale in der Mitte des Scanbereichs und damit des zu detektierenden Volumens.

Die Untersuchungszeit bei der VPCT beträgt nach der Lagerung des Patienten auf dem Untersuchungs-Tisch und der Kontrastmittelinjektion insgesamt 45 Sekunden.

Die Softwareapplikation ermöglicht die Errechnung von Perfusions-Parametern wie TTP, CBF, CBV und CBV(P) aus dem Satz dynamischer Volumendaten.
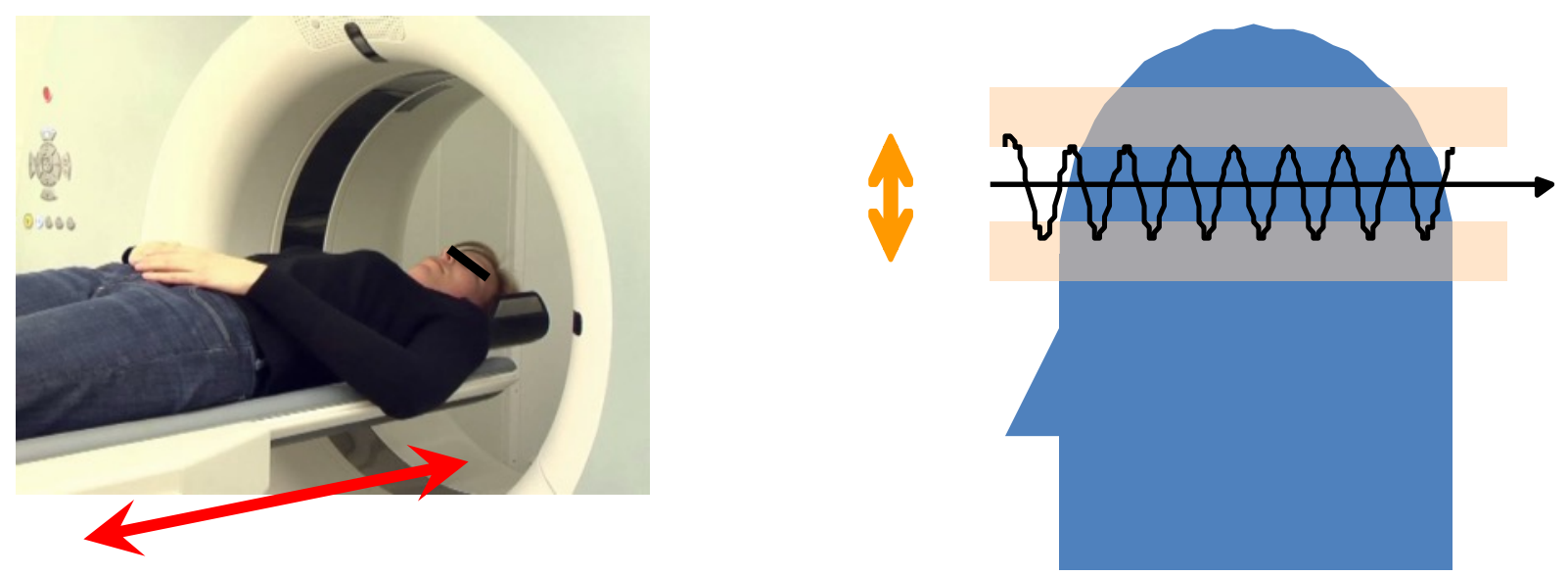

Abbildung 4: Prinzip der VPCT. Durch die Pendelbewegung des Untersuchungstisches und die repetitiven Spiralen kann das gesamte Hirn-Volumen untersucht werden. 


\subsubsection{Magnetresonanztomographie:}

Die Magnetresonanztomographie (MRT) stellt ein weiteres Verfahren in der akuten Schlaganfalldiagnostik dar. Wie die CT ist auch die MRT ein Schnittbildverfahren, allerdings kommen keine ionisierenden Strahlen zum Einsatz. Vielmehr basiert die MRT auf starken Magnetfeldern, die vor allem die Wasserstoffprotonen des menschlichen Körpers anregen und über elektrische Signale eine Bildgebung induzieren.

Bis in die frühen neunziger Jahre wurde das MRT-Verfahren hauptsächlich für die subakute Phase der Ischämie eingesetzt. Die „klassische“ T2-Wichtung zeigt jedoch erst nach sechs bis acht Stunden hyperintense ischämische Veränderungen. Mit der T1-Wichtung werden hypointense Veränderungen im Gebiet der zerebralen Ischämie ebenfalls erst außerhalb des therapeutischen Zeitfensters dargestellt (Crain et al. 1991, Mohr et al. 1995, Unger et al. 1987).

In den frühen neunziger Jahren etablierte sich durch die fortschreitende Weiterentwicklung der MRT das schnelle echoplanare Imaging (EPI). Klassische EPISequenzen für die Diagnostik sind die Diffusions (DWI)- und die Perfusions-MRT (PWI) (Le Bihan et al. 1986). Die heutzutage angewendete Kombination aus diffusionsgewichteter und perfusionsgewichteter MRT-Bildgebung sowie einer zusätzlichen Magnetresonanzangiographie (MRA) ermöglicht eine frühzeitige Darstellung des irreversibel geschädigten Infarktkerns und der Penumbra (Röther 2001).

Das Prinzip der DWI beruht auf der Tatsache, dass die ischämisch bedingte Zerstörung des Membranstoffwechsels zum Wassereinstrom in die Zellen und der Ausbildung eines zytotoxischen Ödems führt. Dadurch reduziert sich anteilig der extrazelluläre Raum und mittelbar die extrazelluläre Diffusion freier Wassermoleküle, was auf diffusionsgewichteten Sequenzen hyperintens dargestellt wird (Baird und Warach 1998, Warach et al. 1992). Diese Hyperintensität lässt sich bereits früher als sechs Stunden nach Symptombeginn bildlich darstellen (Warach et al. 1995). Mit der perfusionsgewichteten MRT identifizieren Neuroradiologen hingegen hämodynamische Veränderungen und Hirnareale mit zerebraler Hypoperfusion. Die Volumendifferenz des veränderten Gewebes aus PWI und DWI stellt über das 
PWI/DWI mismatch das tissue at risk bzW. die Penumbra dar (Rosen et al. 1989, Schellinger et al. 2000, Schlaug et al. 1999).

In den ersten 24 Stunden nach Symptombeginn sind Protonendichte-gewichtete (PD) und T2-gewichtete MRT-Bildgebungen wenig aussagekräftig (Bryan et al. 1991, Kertesz et al. 1987, Yuh et al. 1991). Das Diffusions-MRT hingegen zeigt bereits 11 Minuten nach dem ischämischen Ereignis erste Veränderungen (Hjort et al. 2005).

\subsection{Fragestellung und Hypothesen}

In der vorliegenden Dissertation wurde der prognostische Wert der GanzhirnPerfusions-Computertomographie untersucht.

Dabei war von großem Interesse, ob die Volumen-Perfusions-Computertomographie die frühe Diagnostik von akuten zerebralen Infarkten zulässt. Zudem sollte geprüft werden, ob die Identifizierung der gesamten ischämischen Penumbra mit dem VPCT-Verfahren ermöglicht werden kann.

Zur Untersuchung der Wertigkeit dieses Verfahrens sollten die PerfusionsParameter time to peak (TTP), cerebral blood flow (CBF) und cerebral blood volume (CBV) im frühen Infarktstadium mit den Volumenwerten aus dem Follow-up-Bildern intraindividuell verglichen werden. Daraus ergab sich die Fragestellung, welcher dieser Parameter den höchsten prognostischen Wert für die Ausdehnung des finalen Infarktes aufweist.

Die Dissertation wird von der Hypothese geleitet, dass die Ganzhirn-PerfusionsComputertomographie bei einem akuten Schlaganfallereignis eine hohe prognostische Wertigkeit in Bezug auf die finale Infarktgröße und die damit verbundene wahrscheinliche Prognose aufweist und dadurch zu einer zügigen sich anschließenden Therapieentscheidung verhelfen kann. 


\section{Material und Methoden}

\subsection{Patientenkollektiv}

Die konsekutive Aufnahme der Patienten in die prospektive Studie erstreckte sich über den Zeitraum von August 2008 bis Juni 2009. Die Schlaganfallpatienten waren für die Datenerhebung geeignet, wenn sie folgende Kriterien erfüllten: Im initialen Nativ-CT des Gehirns Fehlen von Blutungen oder Tumoren sowie keine Demarkation eines Infarktes. Es wurden Patienten in die Untersuchung integriert, die bei notfallmäßiger Aufnahme das klinische Bild einer akuten Ischämie boten. 21 Patienten befanden sich dabei in einem Zeitfenster von $<6$ Stunden nach Symptombeginn, fünf Patienten waren zuvor als sogenannte wake-up strokes mit unbeobachtetem Symptombeginn aufgefunden worden. Außerdem war bei zwei weiteren Patienten ein Zeitfenster von $>6$ Stunden nach Symptombeginn zu verzeichnen. Im Nativ-CT zeigte sich bei den beiden letzteren genannten Gruppen noch keine Demarkation des Infarktes, sodass sie ebenfalls in die Datenerfassung aufgenommen werden konnten. Ein weiteres Kriterium war, dass bei den Patienten mindestens 24 Stunden nach der im akuten Stadium erfolgten GanzhirnperfusionsCT darüber hinaus als Follow up eine zerebrale Nativ-CT (oder in 2 Fällen auch eine MRT) zur Bestimmung des final demarkierten Infarktvolumens angefertigt worden sein sollte.

Grundsätzliche Voraussetzungen zur Durchführung der kontrastmittelgestützten VPCT waren die Volljährigkeit der Patienten und der Ausschluss einer Allergie gegen jodhaltige Röntgenkontrastmittel. Bei Patientinnen im gebärfähigen Alter wurde vor Studieneinschluss eine Schwangerschaft ausgeschlossen.

Eine schriftliche Genehmigung der lokalen Ethikkommission lag vor.

Die in die Studie eingeschlossenen Patienten wurden mit Symptomen eines akuten Schlaganfalls über die neurologische Notaufnahme in die Abteilung Neuroradiologie zur Schlaganfalldiagnostik weitergeleitet. Im Rahmen des Stroke-Managements der UMG wurden die Patienten mittels Nativ-CT, einer Ganzhirn-Perfusions-CT und arterieller CT-Angiographie des Schädels untersucht. Die Perfusions-CT-Bilder der 
akuten Phase wurden zur Auswertung verwendet und mit den Nativ-CT-Aufnahmen, die mindestens 24 Stunden später zur Verlaufskontrolle angefertigt wurden, verglichen.

Die Perfusions-CT fand bei den ausgewählten Patienten innerhalb der ersten sechs Stunden nach Symptombeginn statt; dieser Zeitraum wurde gewählt, weil sich innerhalb der ersten sechs Stunden auf der Nativ-CT-Aufnahme des Gehirns in der Mehrzahl der Fälle noch keine demarkierte Ischämie erkennen lässt (Grotta et al. 1999).

Für die Auswertung der Daten erfolgte eine Dichotomisierung der Patienten hinsichtlich des klinischen Schweregrads des Schlaganfalls. Anhand der Skalierung des National Institute of Health Stroke Scale, bei dem verschiedene neurologische Symptome zu verschiedenen Punktzahlen führen, folgte entsprechend der Schwere der Symptomatik eine Aufteilung der Patienten in eine Gruppe mit einem NIHSSScore $<8$ und eine Gruppe mit einem NIHSS-Score $\geq 8$. Patienten mit einem NIHSSScore $<8(n=7)$ wurden zu der Gruppe mit einem minor stroke gezählt. Patienten mit einem NIHSS-Score $\geq 8$ gehörten zu der Gruppe mit einem major stroke und damit zu einem schweren Schlaganfall. Yadav et al. (1997) definierten einen leichten Schlaganfall als ein neu aufgetretenes neurologisches Defizit, das sich entweder nach sieben Tagen vollständig zurückgebildet hat oder einen NIHSS $\leq 3$ anzeigt. Ein schwerer Schlaganfall hingegen stellt ein neu aufgetretenes neurologisches Defizit dar, welches nach sieben Tagen noch weiterhin besteht und einen NIHSS $\geq 4$ aufweist.

Darüberhinaus erfolgte eine Einteilung des Patientenkollektivs in eine Patientengruppe, bei der eine Rekanalisationstherapie erfolgt war, sowie in eine Gruppe ohne Thrombolysetherapie.

\subsection{Durchführung der CT-Untersuchungen}

\subsubsection{Durchführung der VPCT-Untersuchungen im akuten Stadium}

Die Untersuchung erfolgte mit einem 128-Zeilen-CT-Gerät (Somatom Definition AS + , Siemens AG, Erlangen). Für die Auswertung der Bilder wurde die separate 
Workstation syngo Multi Modality Workplace 2008B sowie die Softwareapplikation Volume Perfusion-CT Neuro von Siemens verwendet.

Nach Lagerung der Patienten auf dem CT-Tisch erfolgte zunächst die Nativ-CT, welche mit 120 kV 358 mAs (Schädelbasis) bzw. 420 mAs (Rest des Schädels) durchgeführt wurde.

Im Anschluss erhielten die Patienten eine Volumen-Perfusions-CT mit jodhaltigem Kontrastmittel (Imeron 400ß; (BRACCO Imaging, Wirkstoff: Imeprol 400)) sowie einen darauffolgenden $\mathrm{NaCl}$-Bolus (siehe Tabelle 1). Die Injektionsverzögerung nach dem Start betrug 4 Sekunden.

Für die Infusion erhielt der Patient eine 16-18G-Braunüle antecubital.

\begin{tabular}{|l|l|}
\hline $36 \mathrm{ml}$ Imeprol 400 & Flussrate: $6 \mathrm{ml} / \mathrm{s}$ \\
\hline $20 \mathrm{ml} \mathrm{NaCl}$ & Flussrate: $5 \mathrm{ml} / \mathrm{s}$ \\
\hline
\end{tabular}

Tabelle 1: Protokoll der Infusionen

Zur Anfertigung der Bilder erfolgte zunächst ein repetitiver Scan von 30 aufeinander folgenden Einzelspiralen. Das Sampling betrug dabei 1,5 Sekunden. So gelang eine Abdeckung von $96 \mathrm{~mm}$ in der Z-Achse. Somit konnte das komplette Gehirn und auch Teile des Kleinhirns erfasst werden. Die 30 Einzelspiralen wurden jeweils mit $1,5 \mathrm{~mm}, 5 \mathrm{~mm}$ und $10 \mathrm{~mm}$ Schichtdicke automatisch rekonstruiert. Bei einer Röhrenspannung von $80 \mathrm{kV}$ ergab sich für die VPCT eine effektive Dosis von 5,2 mSv.

Die arterielle CT-Angiographie erfolgte ebenfalls mittels intravenöser Gabe von Imeron $400 \AA$ und $\mathrm{NaCl}$ und umfasste einen Scanbereich vom Vertex bis zum Aortenbogen (siehe Tabelle 2). Es wurden axiale Quellbilder mit Schichtdicken von $1,5 \mathrm{~mm}$ sowie axiale und koronare MIP-Rekonstruktionen mit $10 \mathrm{~mm}$-Schichtdicken angefertigt. Die Untersuchung benötigte bei $120 \mathrm{kV}$ eine effektive Dosis von 3,1 mSv. 


\begin{tabular}{|l|l|}
\hline $40 \mathrm{ml}$ lomeprol 400 & Flussrate: $5 \mathrm{ml} / \mathrm{s}$ \\
\hline $25 \mathrm{ml}$ lomeprol 400 & Flussrate: $2,5 \mathrm{ml} / \mathrm{s}$ \\
\hline $20 \mathrm{ml} \mathrm{NaCl}$ & Flussrate: $2,5 \mathrm{ml} / \mathrm{s}$ \\
\hline
\end{tabular}

Tabelle 2: Protokoll der Infusionen bei der CTA

Der genaue Ablauf und die Zeitangaben für die einzelnen Untersuchungen sind in Abbildung 5 zusammengefasst.

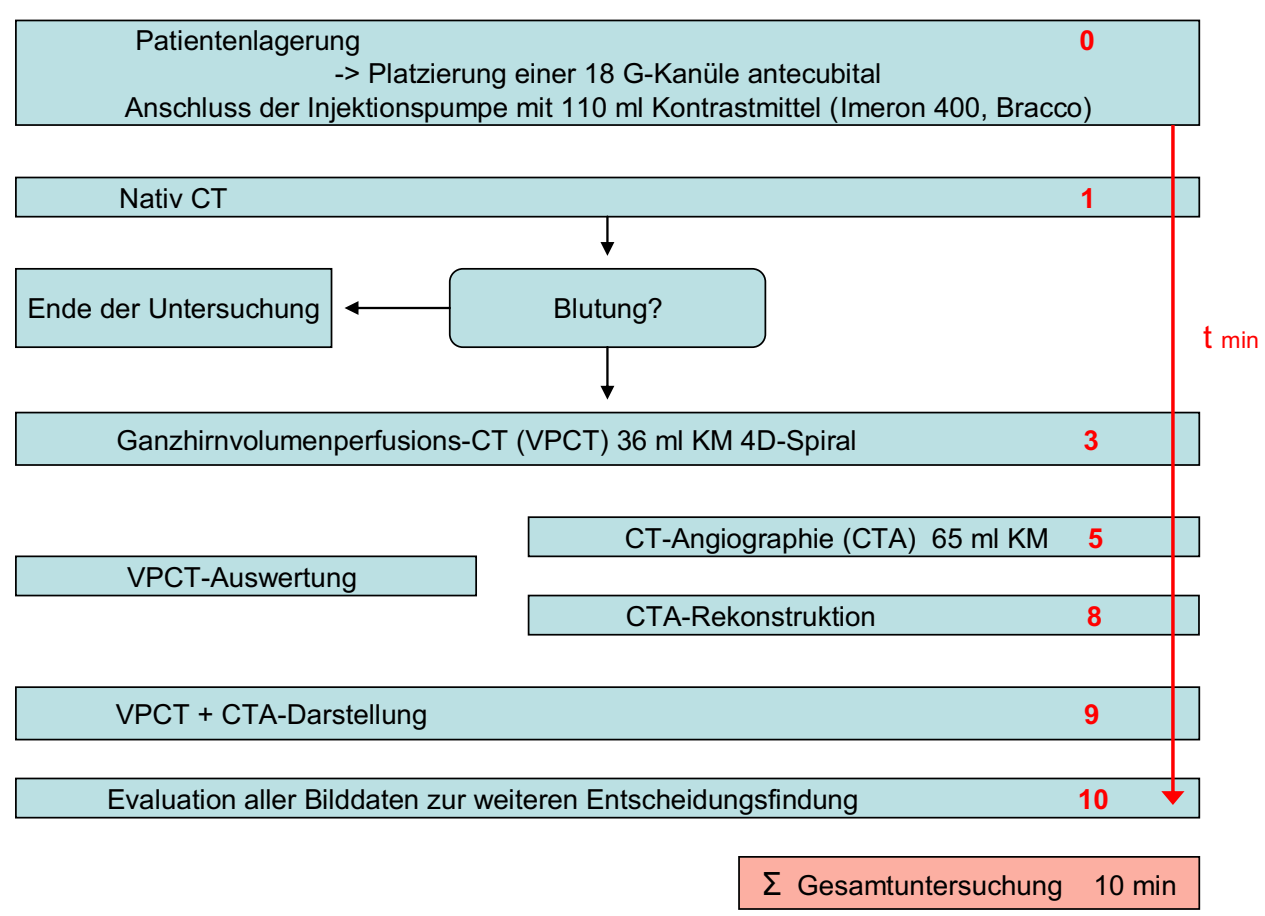

Abbildung 5: Protokoll der CT Untersuchungen

\subsubsection{Anfertigung der Follow-up-Bilder zur Bestimmung des finalen Infarktvo- lumens}

Für die Bestimmung des finalen Infarktvolumens wurden entweder Nativ-CT-Bilder oder MRT-Bilder der jeweiligen Patienten verwendet. Diese Aufnahmen wurden frühestens 24 Stunden nach der initialen CT-Untersuchung angefertigt, da erst nach diesem Zeitraum eine definitive Infarktvolumenbestimmung anhand einer Dichteminderung auf den CT-Aufnahmen möglich ist. 
Die Aufnahmen der Nativ-CT wurden wie im akuten Stadium bei $120 \mathrm{kV}$ und einer Dosis von 358 mAs (Schädelbasis) und 420 mAs (Rest des Schädels) angefertigt.

Die MRT-Bilder des Schädels für die Follow-up-Vergleichsbilder wurden mit einem Magnetom Tim Trio von Siemens (3 Tesla Feldstärke) erstellt.

\subsection{Auswertung der Daten}

\subsubsection{Beurteilung der CT-Perfusions-Untersuchungen im Akutstadium}

2.3.1.1 Vorbereitungsschritte für die Ausmessung der Ischämie-Volumina:

Für die Auswertung mit der 3D-Perfusions-Software wurden zunächst alle axialen $5 \mathrm{~mm}$-Spiral-Datensätze in die VPCT-Neuro-Anwendungskarte (Syngo VolumenPerfusion CT Neuro, Siemens, Forchheim, Deutschland) der Workstation geladen.

Das Programm startete nach Wahl der Auto-Schlaganfall-Funktion aufeinanderfolgend eine automatische Bewegungskorrektur (siehe Abb. 6), eine Segmentierung (siehe Abb. 7), bei der automatisiert der Schädelknochen aus dem Bilddatensatz entfernt wurde, und legte ein arterielles und ein venöses Referenzgefäß fest (siehe Abb. 8). Diese mussten kontrolliert und gegebenenfalls neu definiert werden. Der Schwellenwert für die Gefäßerkennung musste zudem angepasst werden. Auch die Symmetrieebene, die das Gehirn in eine rechte und eine linke Hemisphäre unterteilt, wurde automatisch festgelegt und benötigte bei Ungenauigkeit eine Korrektur. Dies ermöglichte in der späteren Auswertung einen Vergleich von normalisierter „gesunder“ und „kranker“ Hemisphäre (siehe Abb. 14).

Hiernach wurden durch Anwahl der Berechnungsfunktion die PerfusionsparameterBilder und die Auswertungsparameter angezeigt. 


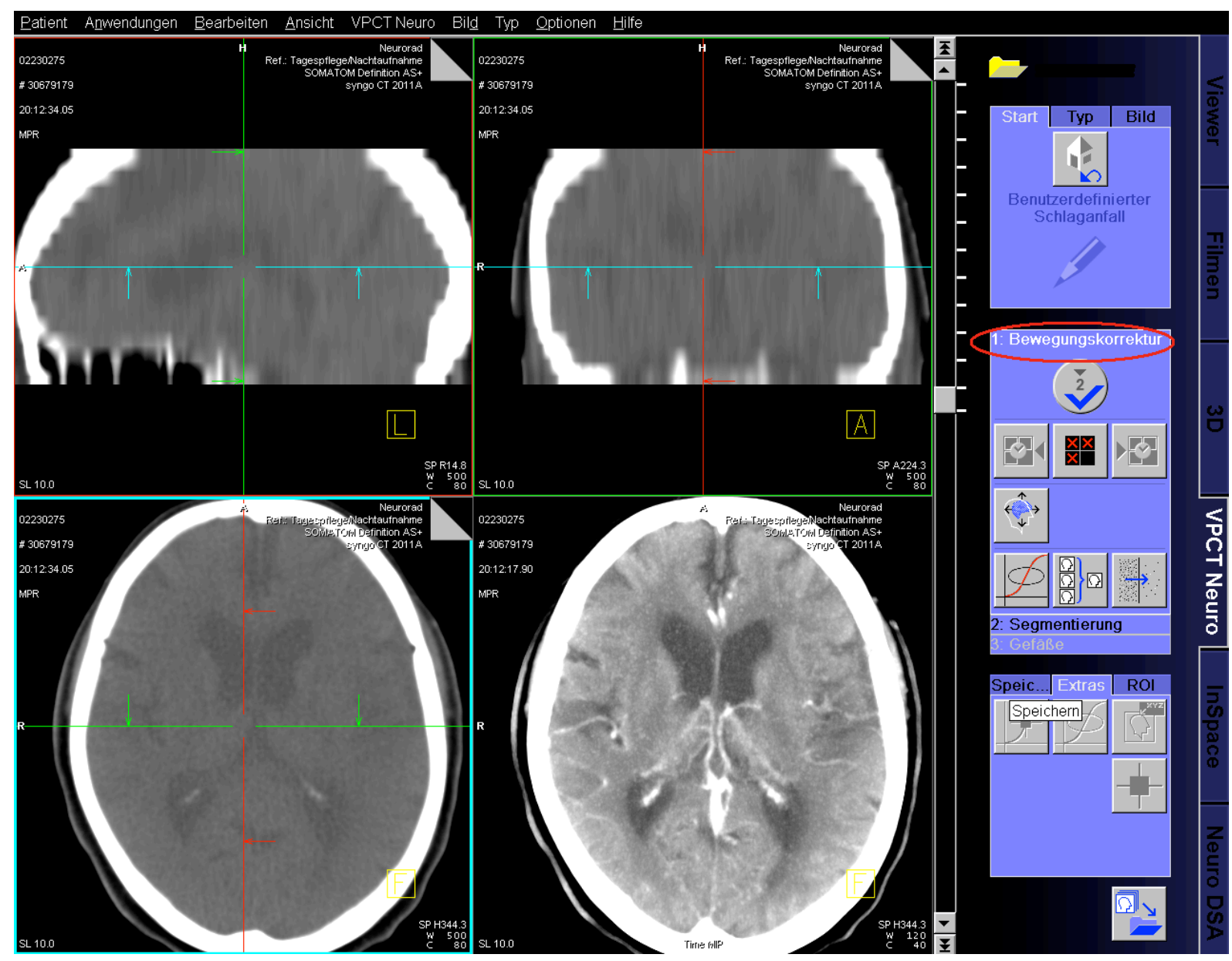

Abbildung 6: Schritt 1 - Bewegungskorrektur. 


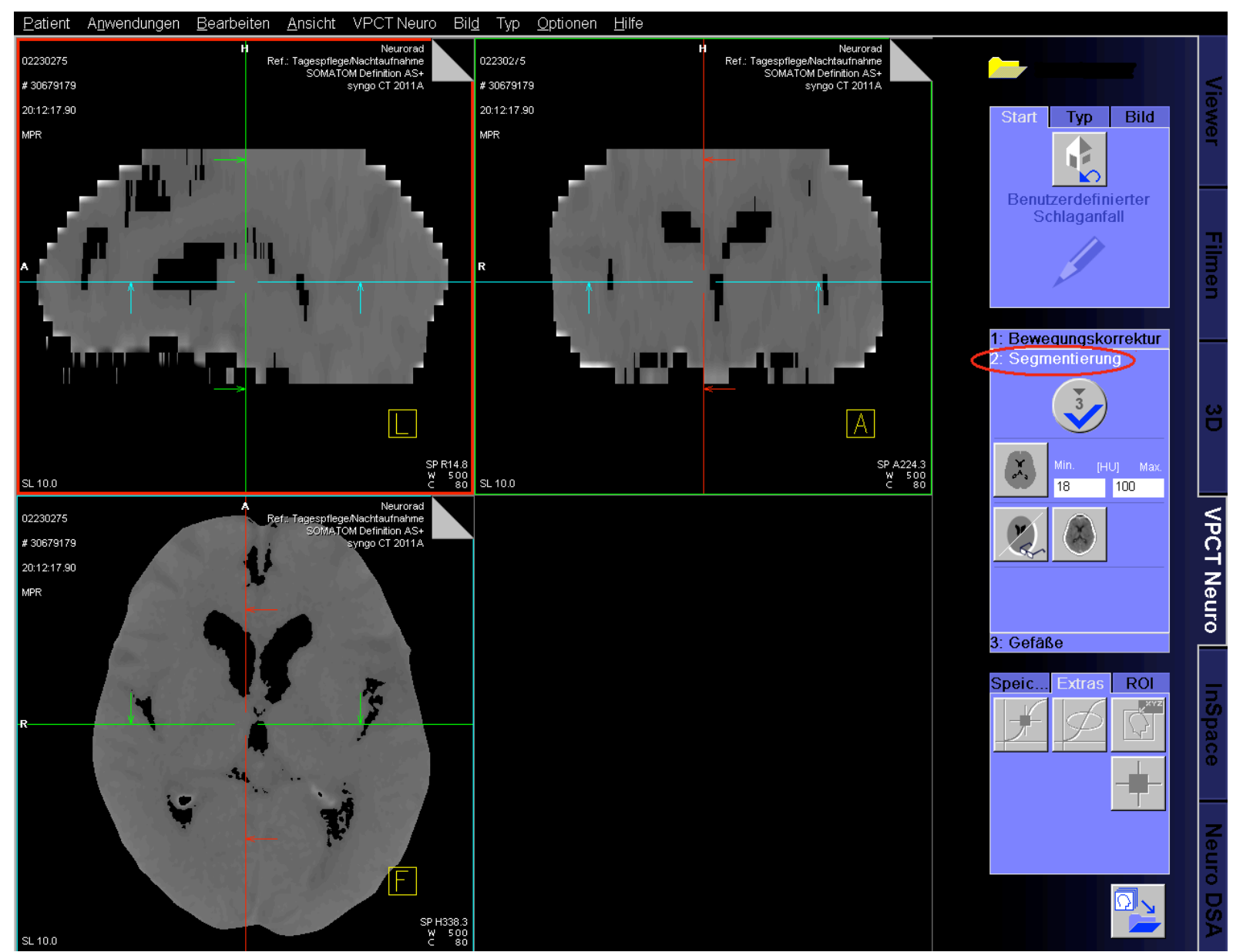

Abbildung 7: Schritt 2 - Segmentierung . Entfernung des Schädelknochens aus dem Bilddatensatz. 


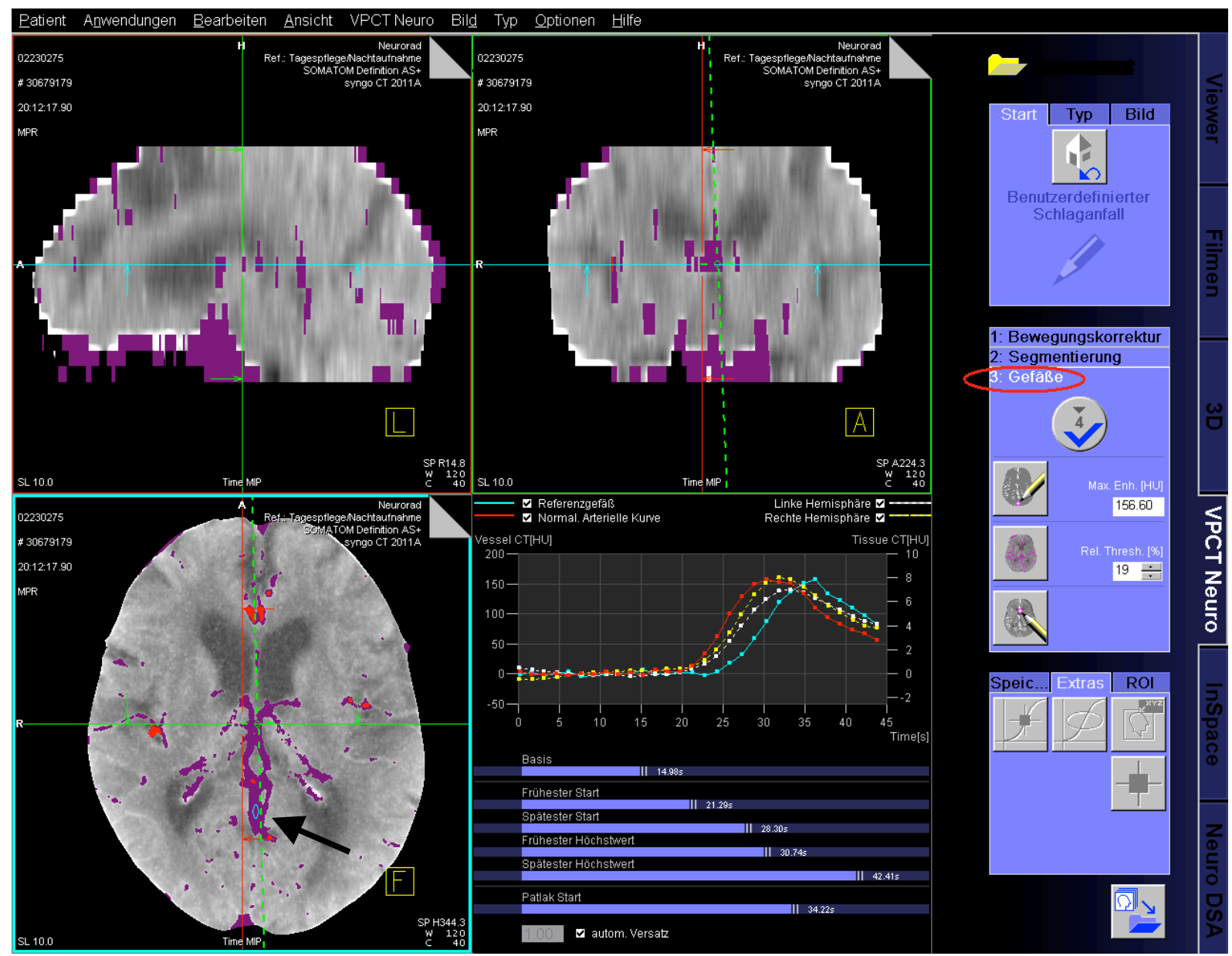

Abbildung 8: Schritt 3 - Festlegung der arteriellen und venösen Referenzgefäße für die spätere Datenberechnung.

Aus dem Satz der Volumendaten konnten damit die Parameterbilder cerebral blood flow (CBF), cerebral blood volume (CBV) und time to peak (TTP) erstellt werden.

Die berechneten Ergebnisbilder wurden dann zunächst in einem 3x3-Multiparameter-Übersichtslayout dargestellt.

Durch Anwahl einer einzelnen Parameterkarte, wie z.B. dem CBF-Bilddatensatz, gelangte man in das 3D-Parameter-Ansicht-Ergebnislayout, welches zur Bestimmung der Volumina diente. In diesem Layout wurden eine axiale, eine sagittale und eine koronare Ansicht übersichtlich auf dem Bildschirm zusammengestellt.

Die benutzerdefinierten Schwellenwerte für die CBF und die CBV machten eine farbliche Darstellung der Infarktgebiete auf den Parameterkarten möglich. Anhand der erweiterten ROI-Funktion konnte man die farblich markierten Infarktareale umfahren. 


\subsubsection{Die Parameter:}

Bei jedem Patienten wurden Bilder der TTP, CBF, CBV und des CBV(P) ausgewertet. Einzelheiten zu den Parametern wurden bereits in der Einleitung beschrieben und werden in Tabelle 3 nochmals kurz erläutert.

Die Beispielbilder (Abb. 9-12) zeigen eine große zerebrale Ischämie einer 68jährigen Patientin mit einer proximalen Stenose der Arteria carotis interna (ACl) rechts.

\begin{tabular}{|c|c|c|}
\hline Parameter & Einheit & Definition \\
\hline TTP & Sekunden [s] & $\begin{array}{l}\text { Die time to peak (TTP) beschreibt die Zeit [s] vom } \\
\text { Anfang der Kontrastmittelinjektion bis zum } \\
\text { maximalen Kontrastenhancement innerhalb einer } \\
\text { zerebralen region of interest. }\end{array}$ \\
\hline CBF & $\begin{array}{l}\mathrm{ml} / 100 \mathrm{ml} \\
\text { Hirngewebe/min }\end{array}$ & $\begin{array}{l}\text { Der cerebral blood flow (CBF) basiert auf dem } \\
\text { maximalen Steigungsmodell und beschreibt die } \\
\text { Blutversorgung des Gehirns in einer bestimmten } \\
\text { Zeit. }\end{array}$ \\
\hline CBV & $\begin{array}{l}\mathrm{ml} / 100 \mathrm{~g} \\
\text { Gehirnmasse }\end{array}$ & $\begin{array}{l}\text { Das cerebral blood volume (CBV) ist der Anteil } \\
\text { des Blutes pro Maßeinheit der Gehirnmasse, } \\
\text { physiologisch: } 4-5 \mathrm{ml} / 100 \mathrm{~g} \text { ). }\end{array}$ \\
\hline $\mathrm{CBV}(\mathrm{P})$ & $\begin{array}{l}\mathrm{ml} / 100 \mathrm{~g} \\
\text { Gehirnmasse }\end{array}$ & $\begin{array}{l}\text { Das cerebral blood volume berechnet nach der } \\
\text { Patlak-Methode. }\end{array}$ \\
\hline
\end{tabular}

Tabelle 3: Parameter der regionalen zerebralen Perfusion. 


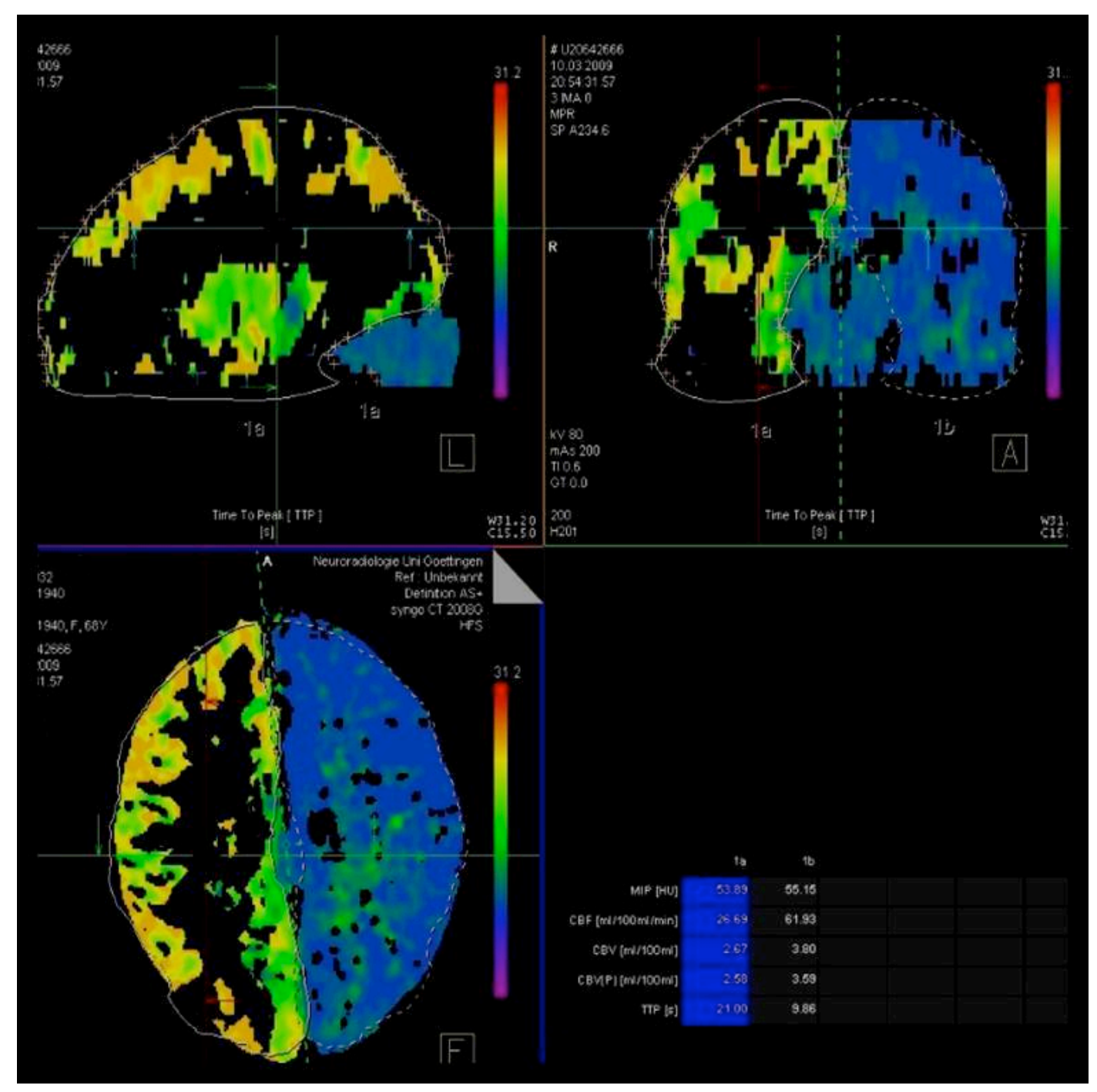

Abbildung 9: TTP. Die TTP bezeichnet die Zeitspanne in Sekunden vom Beginn der Kontrastmittelinjektion bis zur maximalen Kontrastmittelanreicherung innerhalb eines bestimmten Hirnareals. Die rechtshirnige Infarktregion ist grün-orange dargestellt und zeigt die verlängerte Zeitspanne der Kontrastmittelanreicherung, die gesunde linksseitige Hirnregion ist blau-grün dargestellt. Voxel, innerhalb derer während der Meßzeit kein Peak erreicht wird, bleiben schwarz. 


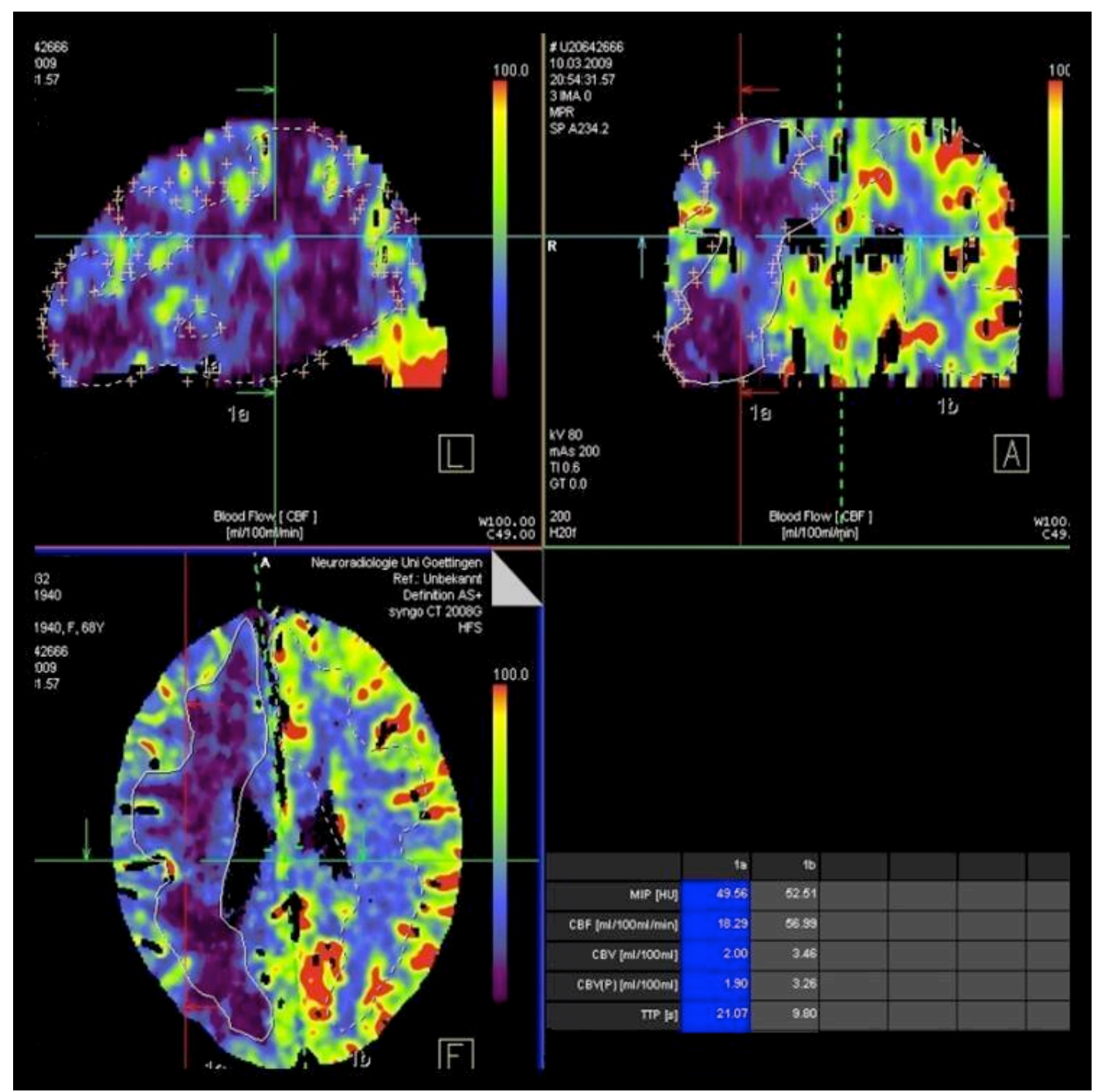

Abbildung 10: CBF. Normalerweise beträgt der regionale zerebrale Blutfluss im Kortex 50-60 ml/100 $\mathrm{g} / \mathrm{min}$. Die Berechnung des CBF basiert auf dem Konzept des maximum slope models. Die Infarktregion ist blau-lila dargestellt und zeigt den verminderten Blutfluss an. 


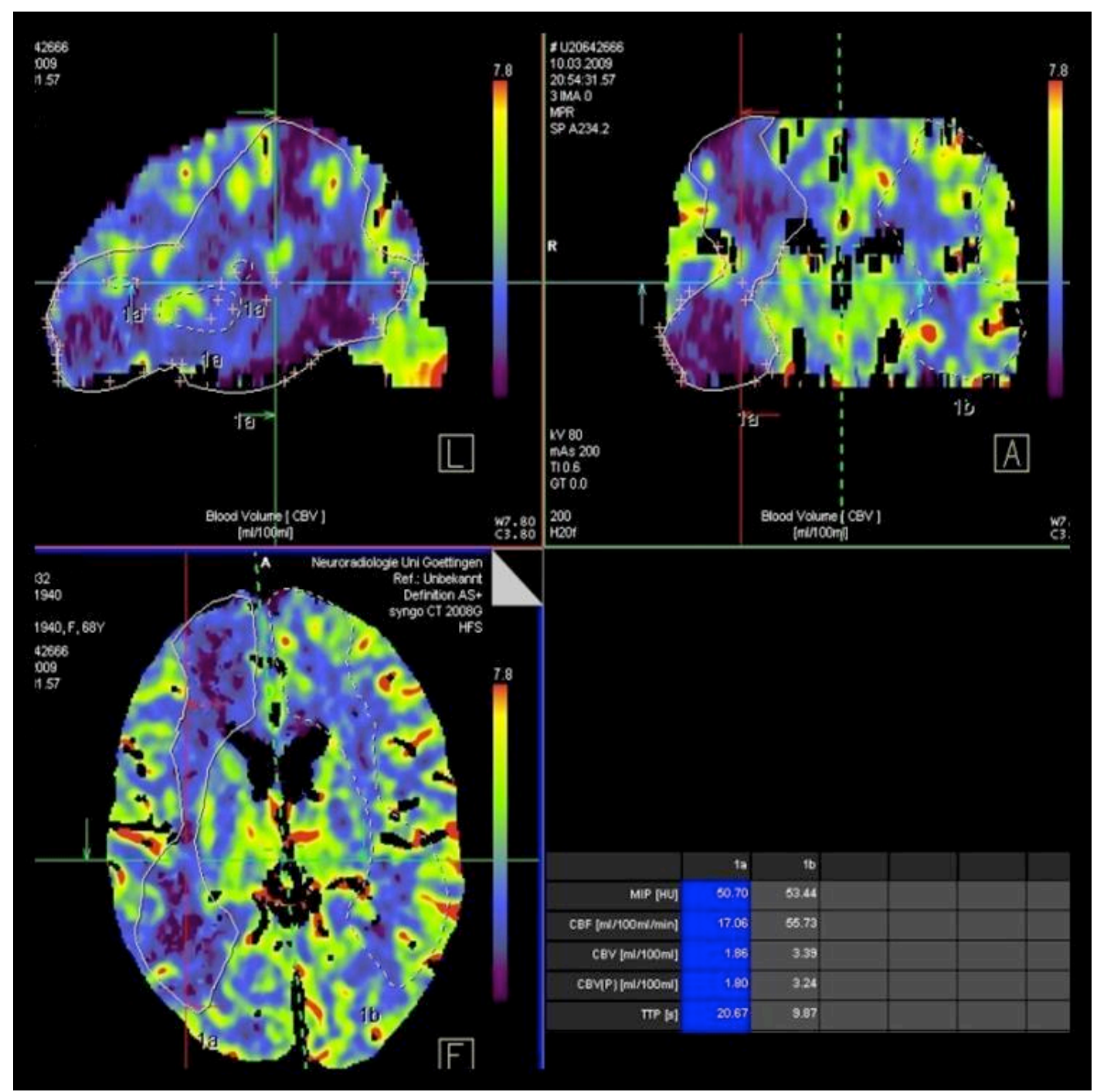

Abbildung 11: CBV. Das zerebrale Blutvolumen beträgt normalerweise 4-5 ml/100g Gehirnmasse. Das Infarktvolumen ist blau-lila dargestellt und zeigt das minderperfundierte Hirngewebe. 


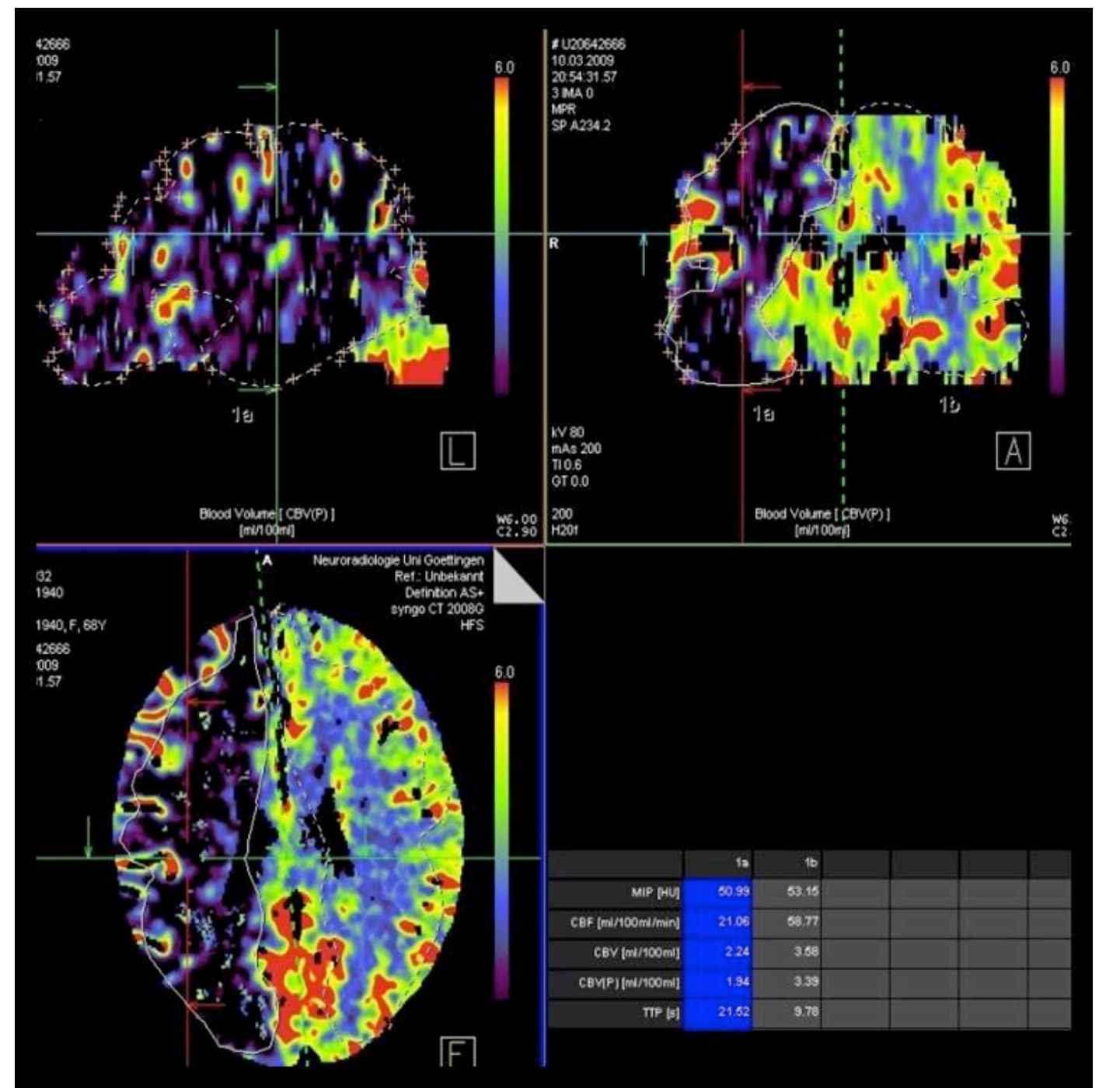

Abbildung 12: CBV $(P)$. Das Infarktvolumen, nach Patlak bestimmt, ist hier schwarz-lila dargestellt.

Die Farbskala der einzelnen Parameterbilder reicht von blau über grün, gelb bis rot und ist je nach Parameterkarte unterschiedlich zu interpretieren.

Der gesunde gut durchblutete Kortex (graue Substanz) wird im CBF- und CBVParameterbild grün-gelb, die Gefäße rot dargestellt. Das physiologische weniger perfundierte gesunde Hirnmark (weiße Substanz) wird blau-grün angezeigt. Entsprechend wird eine verminderte regionale zerebrale Perfusion blau, eine mäßige bis gute Perfusion grün-gelb und eine sehr gute Perfusion (= Gefäße) auf diesen Karten rot dargestellt.

Im TTP-Parameterbild wird die gut perfundierte Hirnrinde blau codiert. Die Farbskala entspricht hier der Zeit der maximalen Anreicherungsrate des Kontrastmittels und zeigt die physiologische kurze TTP blau an. Ist eine Hirnregion grün oder gar gelb oder rot, zeigt dies eine verlängerte TTP an. 


\subsubsection{Markierung der region of interest (ROI):}

Nach der Fensterung des Farbbildes eines Parameters wurde zunächst in der sagittalen und koronaren Ansicht das farblich angezeigte Areal der regionalen pathologischen Perfusionsveränderung auf einem Ergebnisbild markiert. In der axialen Ansicht wurde dann folgend auf jedem der pathologisch farblich markierten Schichtbilder die ROI eingezeichnet (siehe Abb. 13). Die Auswertungsparameter für die ROI wurden berechnet und tabellarisch dargestellt. Die Auswertungstabelle umfasste den Mittelwert und die Standardabweichung des jeweiligen Wertes für TTP, CBF und CBV sowie das jeweilige Volumen der Läsion.

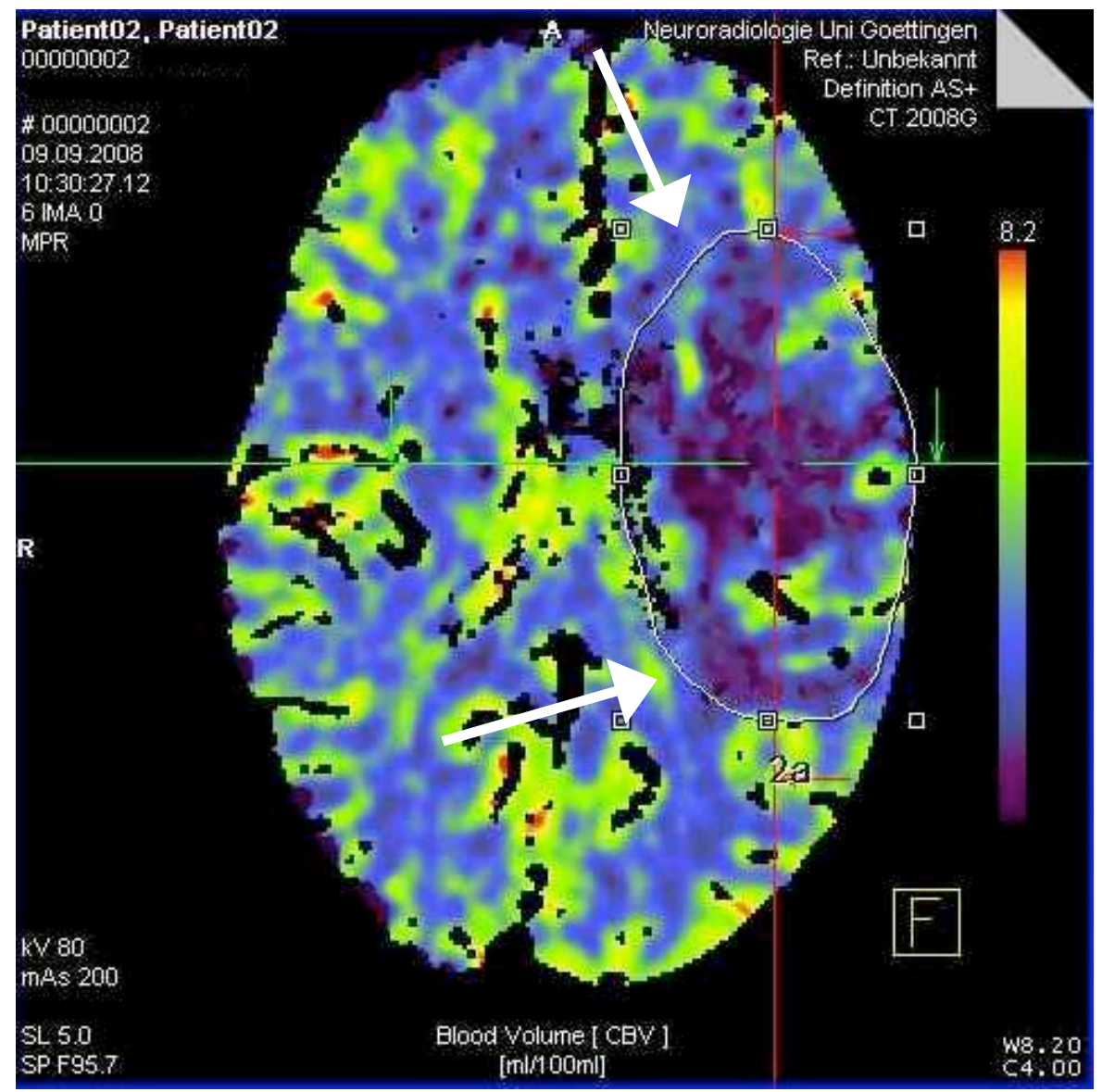

Abbildung 13: Einzeichnen der region of interest (ROI) in der axialen Schicht.

Der Vergleich beider Großhirnhemisphären wurde in der Tabelle der Auswertungsparameter berücksichtigt (siehe Abb. 14 und 15). Man erhielt somit Vergleichswerte für die gesunde und die pathologisch veränderte Gehirnhälfte mit identischem ROIVolumen. 


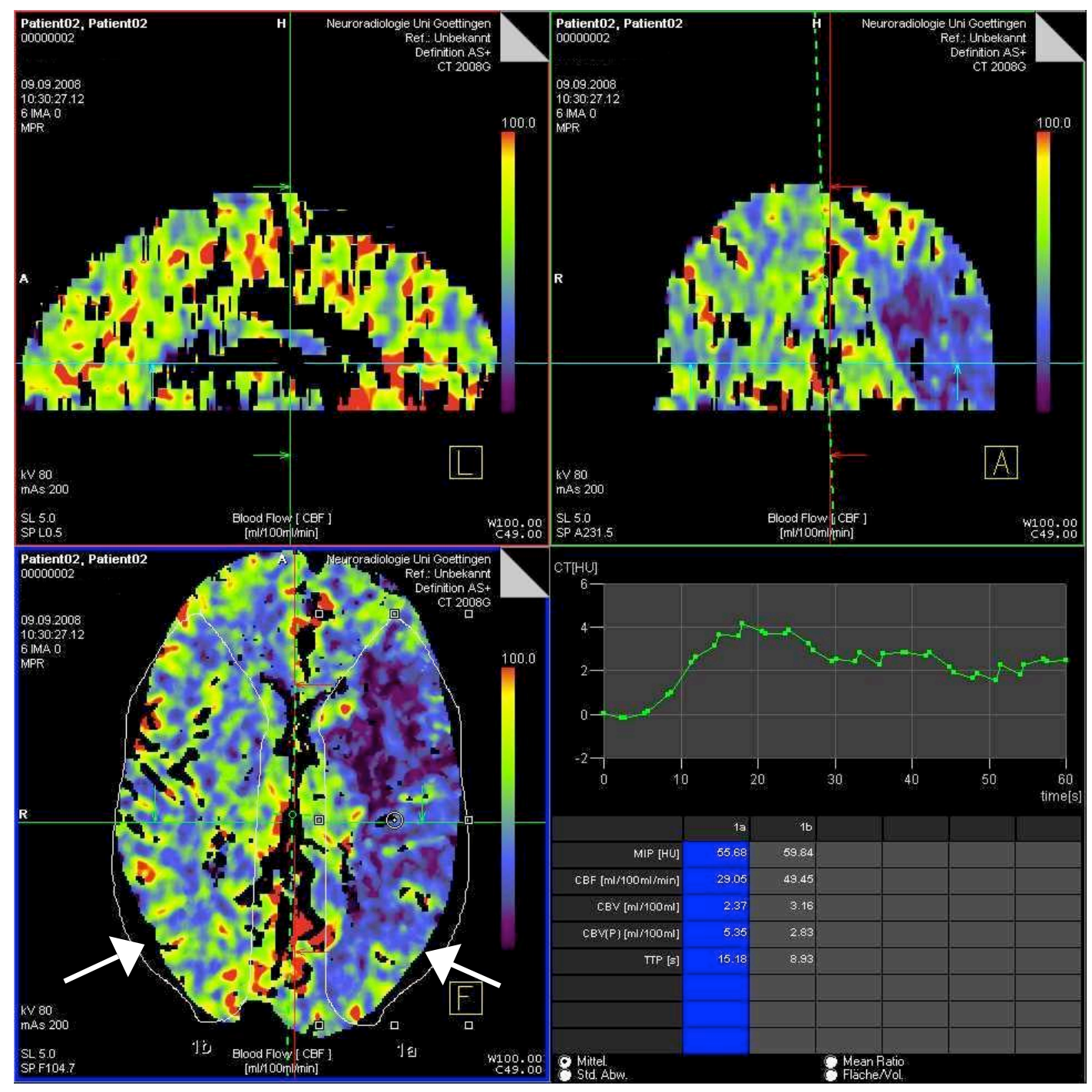

Abbildung 14: Vergleich der beiden Hemisphären anhand einer ROI. Die rechte Hemisphäre ist gesund, die linke Hemisphäre zeigt das Infarktgebiet. 


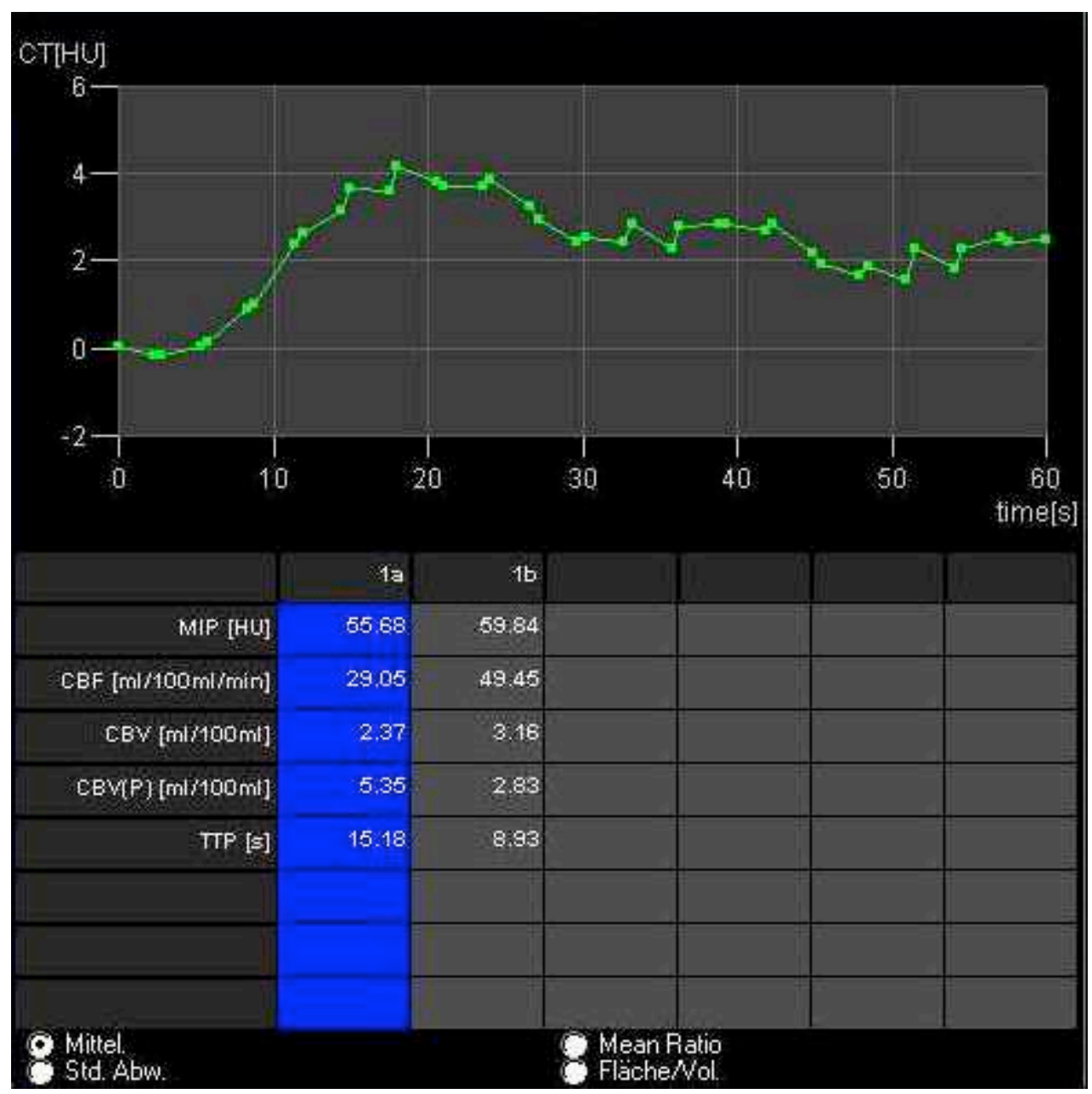

Abbildung 15: Tabelle der Parameterdaten im Hemisphärenvergleich. 1a: Infarktgebiet, 1b: Werte der gespiegelten ROI auf der gesunden Hemisphärenseite (hier als Mittelwert angezeigt).

Bei drei Patienten war das Infarktareal nicht nur auf eine Hemisphäre beschränkt, sodass ein Vergleich nur mit manuell eingezeichneter ROI im gesunden Gewebe durchgeführt werden konnte. Die Volumina von gesunder und kranker Seite waren somit zwar näherungsweise identisch, aber nicht exakt deckungsgleich.

Die Entscheidung, wann ein Gewebe als pathologisch gekennzeichnet werden musste, wurde anhand der oben bereits erwähnten farblichen Markierung gefällt und entsprach der klinisch praktizierten Vorgehensweise unter Alltagsbedingungen. 


\subsubsection{Erweiterte ROI-Analyse:}

Um die Genauigkeit der Darstellung der manuell definierten ROI-Volumina erweitern zu können, wurde über die Multiparameter-Gewebeauswertung eine erweiterte ROIAnalyse durchgeführt. Hierbei wurde innerhalb der ROI, die auf den Ergebnisbildern der TTP-Parameterkarten eingezeichnet worden waren, und deren Volumina sämtliche (auch geringe) Verzögerungen des Blut- und Kontrastmittelanflutens erfassten, eine weitere farbkodierte Auswertung durchgeführt. Innerhalb der manuell gewählten ROI wurden automatisiert alle Voxel gelb codiert, in denen der Messwert für das regionale CBF weniger als 20,0 ml/100 g Hirngewebe/min betrug; die Voxel, innerhalb derer zusätzlich das regionale CBV unter 0,8 ml/100 ml Hirngewebe betrug, wurden rot codiert. So ergab sich eine auf quantitativen Messwerten beruhende Farbskala von gelbem tissue at risk (TAR) oder Penumbra und rotem irreparabel geschädigtem Kerninfarkt (non viable tissue, NVT). Die Volumina dieser rot und gelb farbcodierten Bezirke wurden zusätzlich quantifiziert (siehe Abb. 16). 


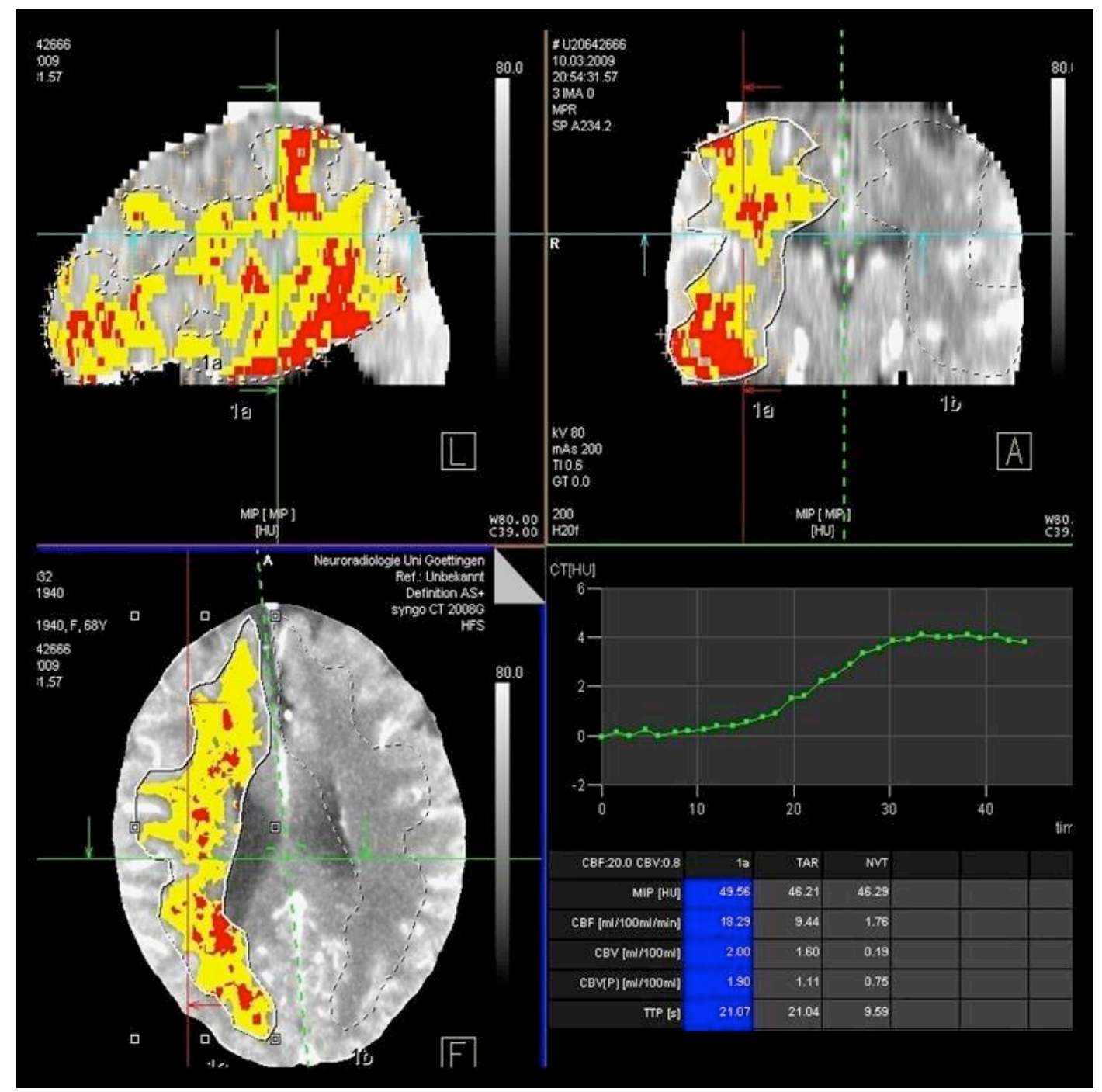

Abbildung 16: Die erweiterte ROI-Analyse. Das non viable tissue (NVT) entspricht dem Infarktkern und ist hier rot, das der Penumbra entsprechende tissue at risk (TAR) ist gelb dargestellt.

\subsubsection{Auswertung des Follow-up-Bildes}

Die Kontrollbestimmung des finalen Infarktvolumens erfolgte mit zwei unterschiedlichen Verfahren. Die Auswertung der Nativ-CT-Bilder wurde anhand der CT-Volumen-Anwendungskarte der syngo Multi Modality Workplace 2008B von Siemens durchgeführt. Dazu wurde das Infarktgebiet in den einzelnen Schichten manuell umzeichnet und zu einem Volumenwert berechnet (siehe Abb. 17).

In zwei Fällen erfolgte die Auswertung des finalen Infarktvolumens anhand von diffusionsgewichteten MRT-Bilddaten. Auf diesen axialen Bildern wurde das Infarktgebiet auf den einzelnen Schichten eingezeichnet. Das Volumen wurde bestimmt, 
indem die einzelnen ROI-Flächenwerte mit den jeweiligen Schichtdicken multipliziert und zu einem Gesamtvolumen addiert wurden.

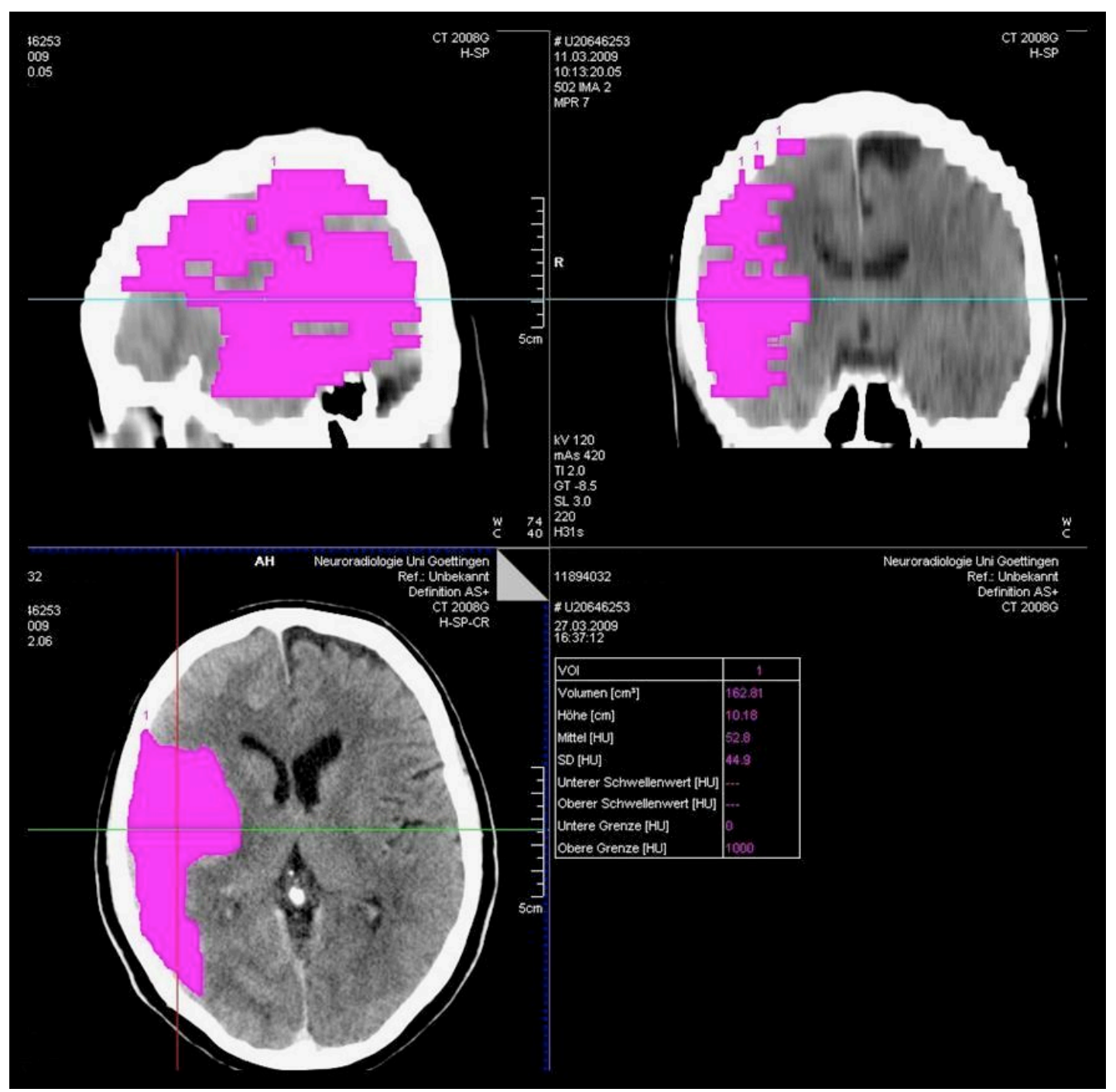

Abbildung 17: Das Follow-up-Bild. Markierung der Demarkation des Infarktes auf einem VerlaufsNativ-CT-Bild.

\subsection{Statistische Methoden}

Der Zusammenhang zwischen den Prädiktoren - also den Parametern, die das Ausmaß des späteren Infarktvolumens in unterschiedlicher Genauigkeit vorhersagen können - und dem tatsächlichen Infaktvolumen mit und ohne Einteilung in Untergruppen wurde zuerst mit einfachen Regressionsanalysen beschrieben. Die vier Prädiktoren wurden anschließend in einer multiplen Regression kombiniert, wobei die endgültige Regressionsgleichung mit einer Variablenselektion schrittweise ermittelt 
wurde. Die Regressionsgüte wurde durch das Bestimmtheitsmaß $\mathrm{R}^{2}$ und die mittlere absolute Abweichung zwischen vorhergesagtem und echtem Wert beschrieben.

Der Zusammenhang zwischen gesunder Hemisphäre und Infarktseite wurde mit dem Pearson's Korrelationskoeffizient $\rho$ bestimmt. Der Zusammenhang zwischen dem Alter und dem Follow-up-Volumen sowie zwischen (NVT + TAR) und CBF wurde ebenfalls mit Pearson's $\rho$ untersucht. Das Follow-up-Infarktvolumen zwischen Männern und Frauen sowie zwischen Patienten mit bzw. ohne arteriellen Gefäßverschluss wurde mit dem Mann-Whitney-U-Test verglichen.

Als Signifikanzniveau für statistische Tests wurde $\alpha=5 \%$ festgelegt. Alle Analysen wurden mit der freien Software R (Version 2.8, www.r-project.org) vorgenommen. 


\section{Ergebnisse}

\subsection{Analysen des Patientenkollektivs}

In die Studie wurden von August 2008 bis Juni 2009 konsekutiv insgesamt 28 Patienten eingeschlossen. Das Altersintervall der Patienten lag zwischen 21 und 88 Jahren. Das Durchschnittsalter betrug 70 Jahre. Zum Kollektiv zählten 16 weibliche und 12 männliche Patienten.

Die Ein- bzw. Ausschlusskriterien für die Aufnahme in die Studie sind dem Methodikteil zu entnehmen.

Das durchschnittliche Zeitfenster zwischen dem Auftreten der ersten Symptome und der CT-Erstuntersuchung lag bei 3,2 Stunden. Bei 21 Patienten lag das Zeitfenster unter sechs Stunden, bei fünf Patienten hingegen waren der Symptombeginn und somit auch das exakte Zeitfenster unklar. Zwei Patienten mit Infarktereignissen erhielten eine Akutdiagnostik nach mehr als 6 Stunden nach Symptomauftritt. Das Zeitintervall von der ersten CT-Untersuchung bis zur Follow-up-Untersuchung lag im Durchschnitt bei 72 Stunden. Bei einer Patientin lag das Zeitintervall nur bei 30 Minuten. Die kurzfristige Nativ-CT-Kontrolle wurde notfallmäßig durchgeführt, da sich die Patientin klinisch deutlich verschlechtert hatte.

Das Follow-up-CT der einzelnen Patienten wurde durchschnittlich drei Tage nach dem initialen VPCT angefertigt. Zwei Patienten erhielten keine Verlaufskontrolle, da ein Infarkt in der initialen Bildgebung ausgeschlossen werden konnte.

Das Follow-up-Infarktvolumen wurde bei 24 Patienten auf Nativ-CT-Aufnahmen und bei zwei Patienten auf MRT-Bildern bestimmt.

Die erhobenen Messwerte für jeden Patienten sind der Excel-Tabelle im Anhang zu entnehmen.

Von den 28 Patienten hatten 19 Patienten einen in der CT-Angiographie erkennbaren Verschluss einer intrakraniellen Arterie, bei neun Patienten fand sich kein Gefäßverschluss. Mindestens 19 Patienten litten an einer akuten Ischämie im Versorgungsgebiet der Arteria zerebri media (im M1- oder M2-Segment), bei sieben Patienten führte man den Mediainfarkt auf einen Verschluss der $\mathrm{ACl}$ zurück. Des 
Weiteren wurden als Ursache für die Ischämiesymptomatik arterielle Verschlüsse der Arteria cerebri anterior, der Arteria cerebri posterior sowie der lenticulo-striatalen Äste, der Kleinhirnarterien und der Rami ad pontem gefunden. In vier Fällen bestand eine Thrombose der Arteria basilaris.

Insgesamt 15 Patienten erhielten eine akute, gewichtsadaptierte intravenöse Lysetherapie, drei Patienten einen intraarteriellen Stent im Bereich der ACl oder der Arteria vertebralis.

Im Rahmen der weiteren Analyse wurden 21 Patienten einer Gruppe mit einem NIHSS-Score von $\geq 8$ (im Akutstadium) sowie 7 Patienten einer Gruppe mit einem NIHSS-Score von $<8$ zugeteilt.

\subsection{Statistische Reliabilität der Definition von Infarktgewebe}

Mit Hilfe der ROI-Funktion wurden die Perfusionsdefizite auf den Ergebnisbildern markiert. Diese Ischämiebereiche konnten visuell oder voxelbasiert automatisiert bestimmt werden. Das innerhalb der ROI-Markierung befindliche Gewebevolumen konnte so entsprechend errechnet werden.

Um die manuelle Messgenauigkeit zu überprüfen, wurde eine statistische Qualitätskontrolle der Mittelwerte der einzelnen Prädiktoren angefertigt.

Die Mittelwerte $(\mathrm{m})$ der manuell erarbeiteten Prädiktoren TTP, CBF, CBV und $\mathrm{CBV}(\mathrm{P})$ zeigen im Vergleich der gesunden Seite mit der Infarktseite einen signifikanten Unterschied ( $p=<0,01$ ). Die größte Korrelation findet sich hier beim TTP (Pearson's $p=0,76)$ (Abb. 18).

Es zeigt sich statistisch eine signifikante Verschiebung zwischen gesunder und kranker Seite: Die TTP-Werte der kranken Seite sind deutlich höher, bei den anderen drei Parametern liegen die Werte der erkrankten Hemisphäre deutlich unter denen der gesunden (siehe Abb. 18). 

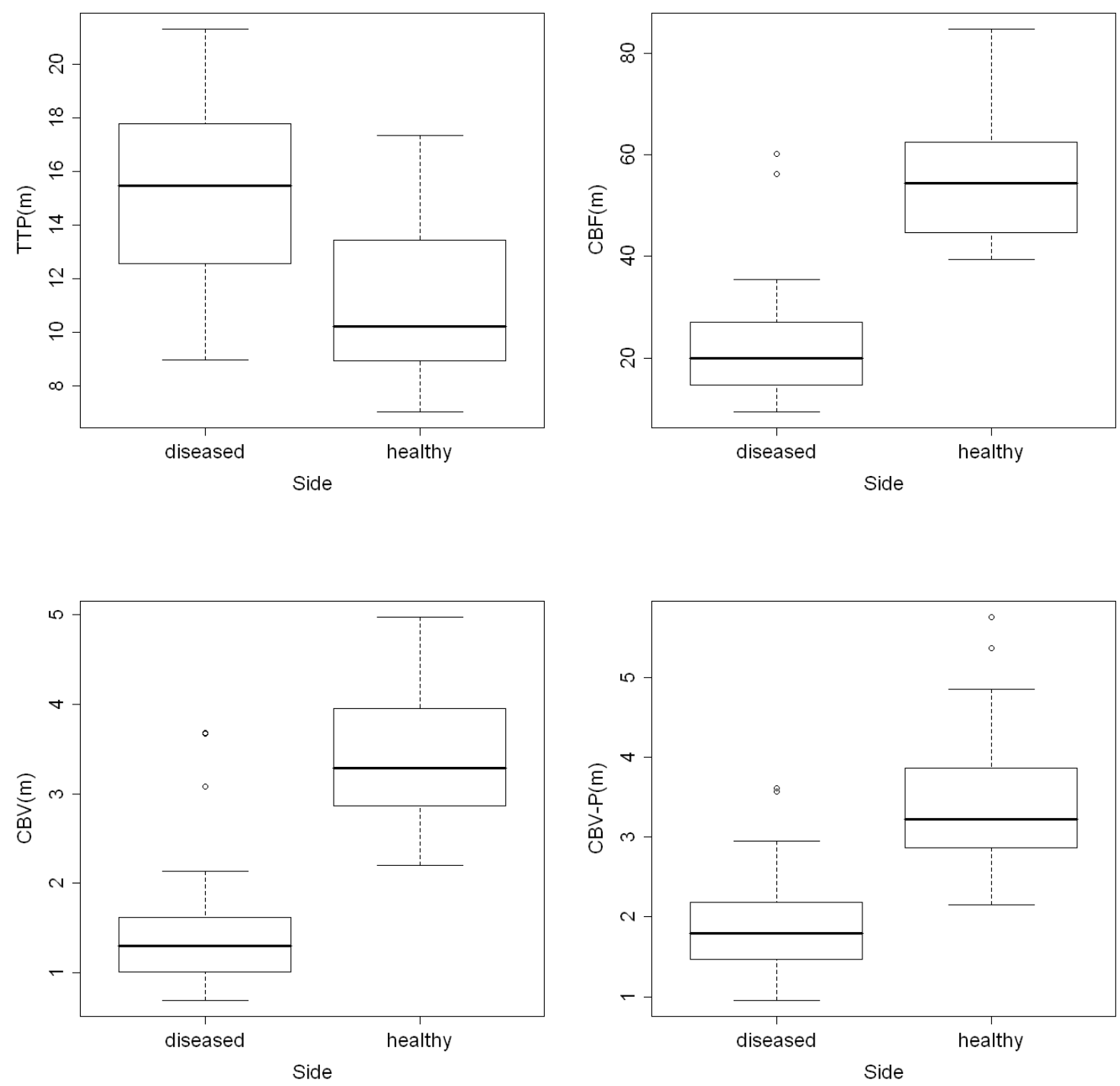

Abbildung 18: Vergleich der Kenngrößen zwischen gesunder Seite und Infarktseite.

\subsection{Prognostischer Wert der Parameter im Bezug auf das Follow- up-Infarktvolumen}

\subsubsection{Korrelation der Prädiktoren mit dem Follow-up-Infarktvolumen im Ge-} samtbild

Um eine mögliche Korrelation nachweisen zu können, wurden die Läsionsvolumina der einzelnen Parameter im Akutstadium jeweils mit dem dazugehörigen Follow-upInfarktvolumen verglichen. Es wurde ermittelt, welcher der vier Prädiktoren bzw. der 
zusätzlichen bestimmten Werte für NVT und TAR die beste Voraussagekraft für das Infarktvolumen im späteren Stadium besitzt.

Die Ergebnisse zeigen, dass die Volumina der vier Prädiktoren einen starken positiven Zusammenhang zum Follow-up-Volumen und damit eine signifikante Vorhersagekraft für das Ausmaß der späteren Infarktgröße darstellen. Die Größe der Läsion auf den CBV-Parameterkarten nach dem Maximum-Slope-Modell und das ermittelte NVT und TAR als Kombination (NVT + TAR) weisen mit einer Regressionsgüte von jeweils $\mathrm{R}^{2}=0,75$ die größte positive Korrelation auf. Das Volumen der Läsionen auf den TTP-Karten hingegen zeigt die geringste Korrelation und damit Vorhersagekraft für die Größe des späteren Infarktgewebes $\left(R^{2}=0,45\right)$.

Beim CBV ergibt sich die geringste mittlere Abweichung der Werte von der Regressionsgeraden $(=22,42)$ (siehe Tabelle 4$)$.

In der multiplen Regressionsanalyse zeigte sich, dass die Kombination aller Parameter (die Parameter korrelierten stark untereinander) keine bessere Voraussagekraft ergibt als das CBV und die Addition aus NVT + TAR als einzelne Prädiktoren (siehe $\mathrm{R}^{2}-$ Werte Tabelle 4).

Die Vorhersagekraft der Prädiktoren ist beim Vergleich der Läsionsvolumina allerdings von der Größe des Infarktgebietes abhängig. Die Abweichung von der Regressionsgeraden ist bei größeren Volumina über $150 \mathrm{~cm}^{3}$ (beim NVT sogar schon ab $100 \mathrm{~cm}^{3}$ ) erheblich größer (siehe Abb. 19-21) und beeinträchtigt somit die Regressionsgüte. 


\begin{tabular}{|c|c|c|c|c|c|}
\hline \multirow[t]{3}{*}{ Prädiktor } & \multicolumn{3}{|c|}{ Regressionskoeffizienten } & \multirow{3}{*}{$\begin{array}{l}\text { Adjustiertes } \\
\mathbf{R}^{\mathbf{2}}\end{array}$} & \multirow{3}{*}{$\begin{array}{l}\text { Mittlere } \\
\text { absolute } \\
\text { Abweichung }\end{array}$} \\
\hline & \multirow{2}{*}{$\begin{array}{l}\text { Achsenabschnitt } \\
\text { Schätzwert }\end{array}$} & \multicolumn{2}{|l|}{ Steigung } & & \\
\hline & & Schätzwert & $\mathbf{P}$ & & \\
\hline TTP Vol & -25.53 & 0.52 & $\begin{array}{l}< \\
0.01\end{array}$ & 0.45 & 53.74 \\
\hline CBF Vol & -10.68 & 1.09 & $\begin{array}{l}< \\
0.01\end{array}$ & 0.71 & 30.97 \\
\hline CBV Vol & -5.75 & 1.30 & $\begin{array}{l}< \\
0.01\end{array}$ & 0.75 & 22.42 \\
\hline $\mathrm{CBV}(\mathrm{P}) \mathrm{Vol}$ & 1.31 & 1.02 & $\begin{array}{l}< \\
0.01\end{array}$ & 0.67 & 27.13 \\
\hline NVT Vol & -1.83 & 2.04 & $\begin{array}{l}< \\
0.01\end{array}$ & 0.70 & 28.04 \\
\hline $\begin{array}{l}\text { NVT Vol + } \\
\text { TAR Vol }\end{array}$ & -18.19 & 1.34 & $\begin{array}{l}< \\
0.01\end{array}$ & 0.75 & 32.73 \\
\hline
\end{tabular}

Tabelle 4: Geschätzte Regressionsparameter für die einzelnen Prädiktoren und Beschreibung der Regressionsgüte. 
(A)
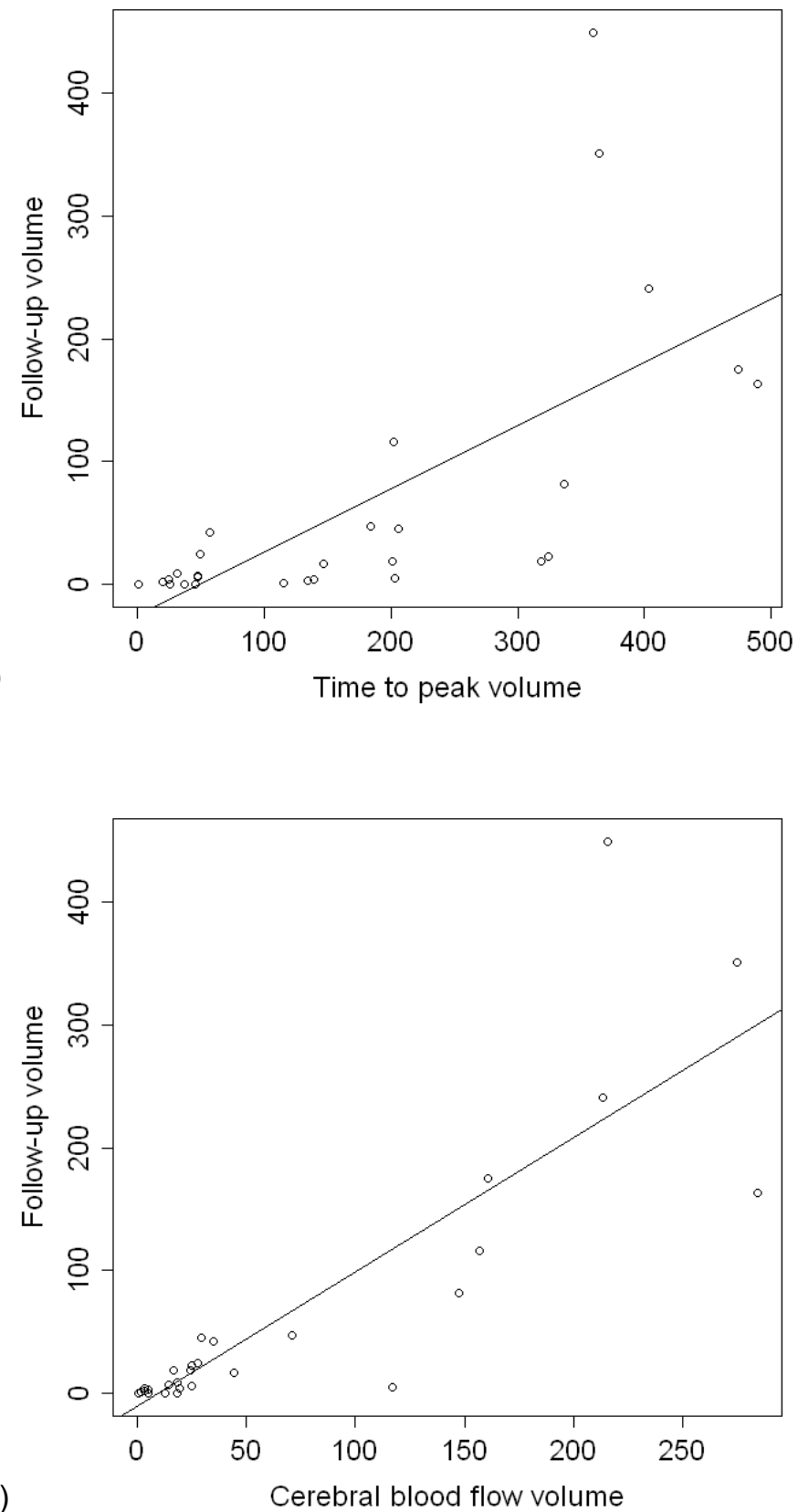

Abbildung 19: Follow-up-Messung in Abhängigkeit von TTP (A) und CBF (B). 


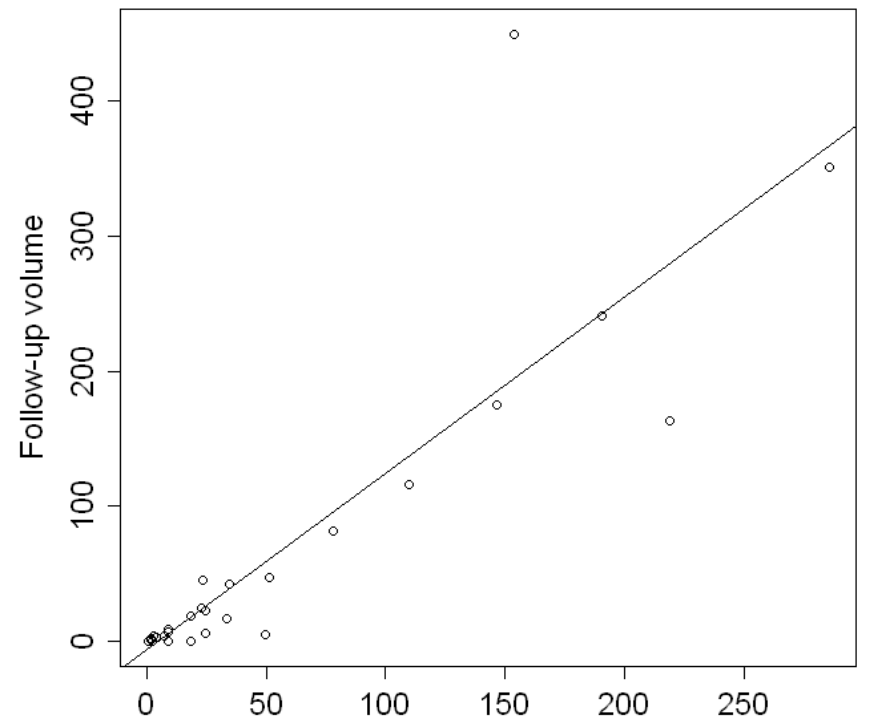

(A)

Cerebral blood volume volume

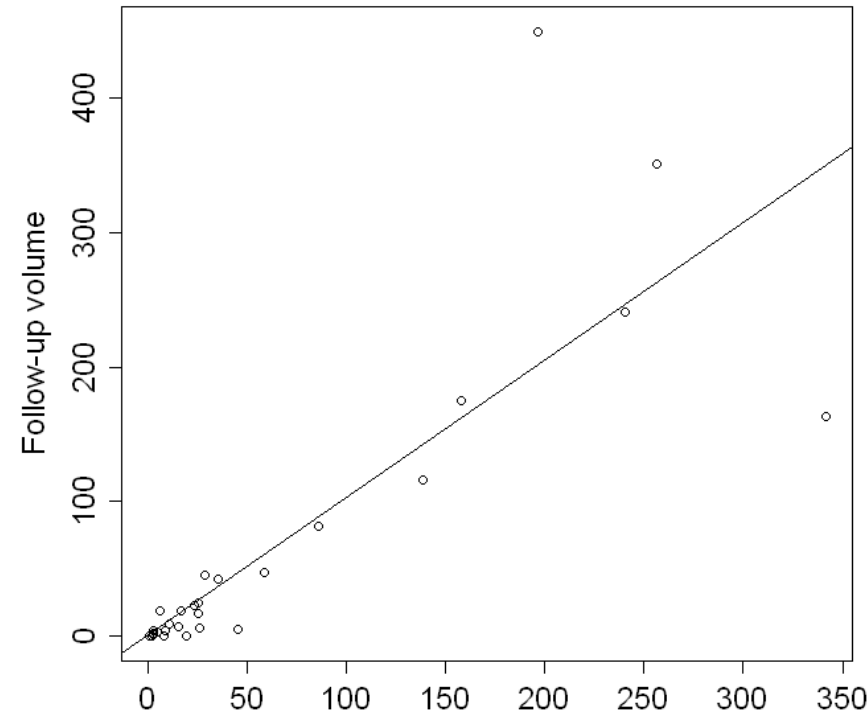

(B)

Cerebral blood volume (Patlak) volume

Abbildung 20: Follow-up-Messung in Abhängigkeit von $C B V(A)$ und $C B V(P)(B)$. 


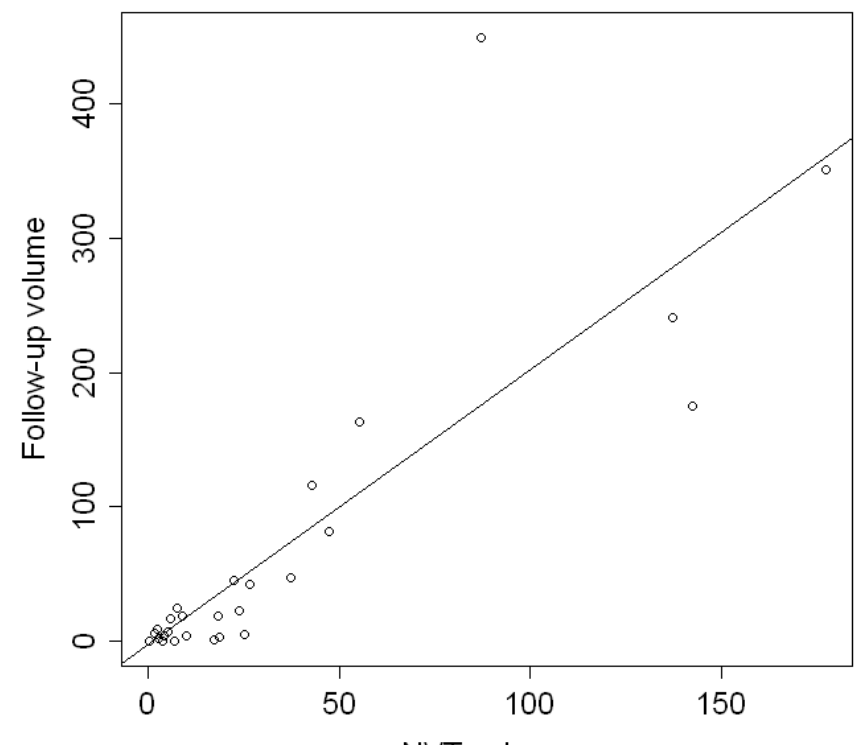

(A)

NVT volume

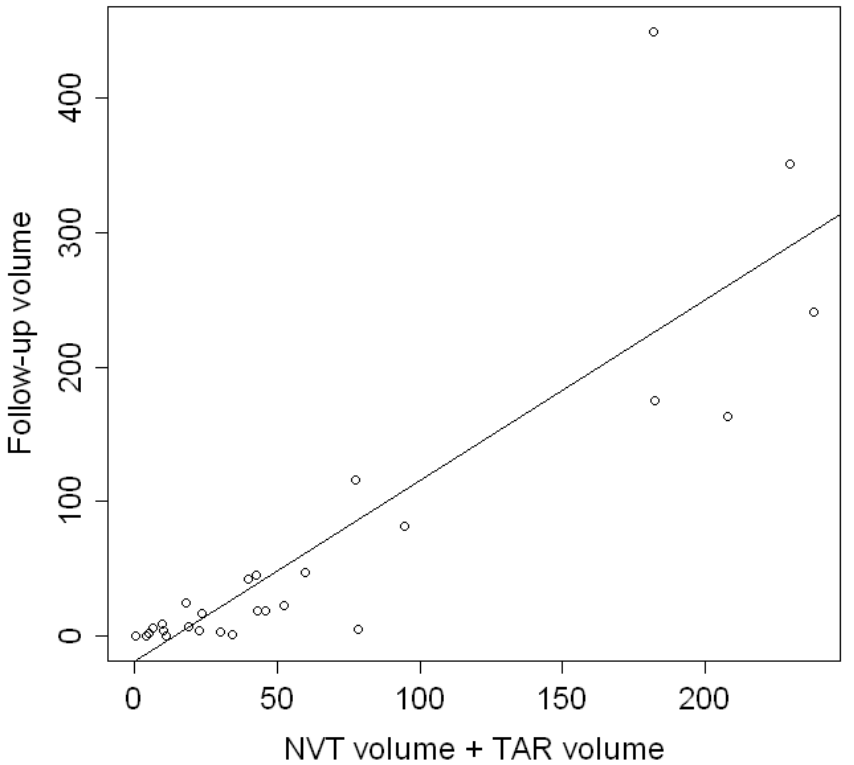

Abbildung 21: Follow-up-Messung in Abhängigkeit von NVT (A) und NVT + TAR (B). 


\subsubsection{Korrelation der Prädiktoren mit dem Follow-up-Volumen bei Patienten mit/ ohne Gefäßverschluss:}

Ein zervikaler oder intrakranieller arterieller Gefäßverschluss resultiert häufig aus einer dekompensierten arteriosklerotischen Gefäßstenose oder einer arteriellen Embolie und verursacht einen zerebralen Insult ischämischer Genese. Bei Patienten

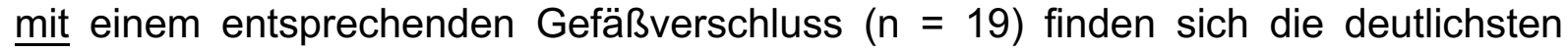
positiven Korrelationen mit dem Follow-up-Volumen bei dem nach dem MaximumSlope-Modell berechneten CBV $\left(\mathrm{R}^{2}=0,71\right)$ und bei der Kombination aus NVT + TAR $\left(R^{2}=0,72\right)$ (siehe Tabelle 5). Die Korrelationswerte sind den Werten ohne Aufteilung in zwei Patientengruppen annähernd konform.

Bei Patienten ohne Gefäßverschluss ( $n=9$ ) findet sich hingegen bei der voxelbasierten NVT-Messung mit einer Regressionsgüte von $R^{2}=0,84$ die größte positive Korrelation. Die Regressionsgüte des CBV entspricht mit $\mathrm{R}^{2}=0,71$ dem Wert der Patientengruppe mit Gefäßverschluss (siehe Tabelle 6). Der Korrelationswert der Kombination aus NVT + TAR ist allerdings im Vergleich zur Patientengruppe mit Gefäßverschluss verringert $\left(R^{2}=0,63\right)$.

Auch hier weist das Läsionsvolumen anhand der TTP-Karte die ungünstigste Korrelation mit dem Follow-up-Volumen auf. Die Prädiktoren der Gruppe der Patienten ohne Gefäßverschluss zeigt keinen Zusammenhang mit dem Follow-upVolumen (Patienten mit Gefäßverschluss: TTP Volumen: $R^{2}=0.50$, Patienten ohne Gefäßverschluss: TTP Volumen: $\left.\mathrm{R}^{2}=0,08\right)$. 


\begin{tabular}{|c|c|c|c|c|c|}
\hline \multirow[t]{3}{*}{ Prädiktor } & \multicolumn{3}{|c|}{ Regressionskoeffizienten } & \multirow{3}{*}{$\begin{array}{l}\text { Adjustiertes } \\
\mathbf{R}^{\mathbf{2}}\end{array}$} & \multirow{3}{*}{$\begin{array}{l}\text { Mittlere } \\
\text { absolute } \\
\text { Abweichung }\end{array}$} \\
\hline & \multirow{2}{*}{$\begin{array}{l}\text { Achsenabschnitt } \\
\text { Schätzwert }\end{array}$} & \multicolumn{2}{|l|}{ Steigung } & & \\
\hline & & Schätzwert & $\mathbf{P}$ & & \\
\hline TTP Vol & -47.02 & 0.64 & $\begin{array}{l}< \\
0.01\end{array}$ & 0.50 & 63.99 \\
\hline CBF Vol & -12.35 & 1.10 & $\begin{array}{l}< \\
0.01\end{array}$ & 0.67 & 43.08 \\
\hline CBV Vol & -4.65 & 1.30 & $\begin{array}{l}< \\
0.01\end{array}$ & 0.71 & 30.61 \\
\hline CBV(P) Vol & 5.27 & 1.00 & $\begin{array}{l}< \\
0.01\end{array}$ & 0.63 & 38.46 \\
\hline NVT Vol & 1.51 & 2.02 & $\begin{array}{l}< \\
0.01\end{array}$ & 0.66 & 38.14 \\
\hline $\begin{array}{l}\text { NVT Vol + } \\
\text { TAR Vol }\end{array}$ & -22.87 & 1.38 & $\begin{array}{l}< \\
0.01\end{array}$ & 0.72 & 41.89 \\
\hline
\end{tabular}

Tabelle 5: Geschätzte Regressionsparameter für die einzelnen Prädiktoren und Beschreibung der Regressionsgüte für Patienten mit Gefäßverschluss ( $n=19)$. 


\begin{tabular}{|c|c|c|c|c|c|}
\hline \multirow[t]{3}{*}{ Prädiktor } & \multicolumn{3}{|c|}{ Regressionskoeffizienten } & \multirow{3}{*}{$\begin{array}{l}\text { Adjustiertes } \\
\mathbf{R}^{\mathbf{2}}\end{array}$} & \multirow{3}{*}{$\begin{array}{l}\text { Mittlere } \\
\text { absolute } \\
\text { Abweichung }\end{array}$} \\
\hline & \multirow{2}{*}{$\begin{array}{l}\text { Achsenabschnitt } \\
\text { Schätzwert }\end{array}$} & \multicolumn{2}{|l|}{ Steigung } & & \\
\hline & & Schätzwert & $\mathbf{P}$ & & \\
\hline TTP Vol & 7.14 & 0.05 & 0.24 & 0.08 & 7.43 \\
\hline CBF Vol & -11.71 & 1.26 & $\begin{array}{l}< \\
0.01\end{array}$ & 0.66 & 5.80 \\
\hline CBV Vol & -5.39 & 1.18 & $\begin{array}{l}< \\
0.01\end{array}$ & 0.71 & 5.01 \\
\hline $\mathrm{CBV}(\mathrm{P}) \mathrm{Vol}$ & -6.47 & 1.19 & $\begin{array}{l}< \\
0.01\end{array}$ & 0.69 & 5.32 \\
\hline NVT Vol & 0.13 & 1.26 & $\begin{array}{l}< \\
0.01\end{array}$ & 0.84 & 3.70 \\
\hline $\begin{array}{l}\text { NVT Vol + } \\
\text { TAR Vol }\end{array}$ & 0.22 & 0.58 & $\begin{array}{l}< \\
0.01\end{array}$ & 0.63 & 5.08 \\
\hline
\end{tabular}

Tabelle 6: Geschätzte Regressionsparameter für die einzelnen Prädiktoren und Beschreibung der Regressionsgüte für Patienten ohne Gefäßverschluss ( $n=9)$

\subsubsection{Korrelation der Prädiktoren mit dem Follow-up-Volumen bei Patienten mit einem NIHSS-Score $\geq 8 /<8$}

Bei Patienten mit einem NIHSS-Score von $\geq 8(n=21)$ wird ebenfalls die deutlichste positive Korrelation mit dem Follow-up-Volumen bei den Läsionsvolumina von CBV und der Kombination NVT + TAR sichtbar (CBV: $\mathrm{R}^{2}=0,72 ;$ NVT + TAR: $\mathrm{R}^{2}=0,73$ ) (siehe Tabelle 7).

Bei Patienten mit einem NIHSS-Score von $<8(n=7)$ hingegen zeigt sich ein insgesamt weniger deutlicher Zusammenhang zwischen den Prädiktoren und dem Follow-up-Volumen. Das CBV weist hier eine Regressionsgüte von $R^{2}=0,70$, die Kombination aus NVT und TAR allerdings nur ein Bestimmtheitsmaß von $\mathrm{R}^{2}=0,46$ auf. Die CBF und das CBV(P) zeigen hier eine bessere Korrelation mit dem Followup-Volumen $\left(R^{2}=0.69\right)$ (siehe Tabelle 8$)$. 
Die TTP stellt auch hier den am wenigsten korrelierenden Prädiktor in Bezug auf das spätere Follow-up-Volumen dar (NIHSS $\geq 8: R^{2}=0,41$; NIHSS < 8: $R^{2}=0,00$ ).

\begin{tabular}{|c|c|c|c|c|c|}
\hline \multirow[t]{3}{*}{ Prädiktor } & \multicolumn{3}{|c|}{ Regressionskoeffizienten } & \multirow{3}{*}{$\begin{array}{l}\text { Adjustiertes } \\
\mathbf{R}^{\mathbf{2}}\end{array}$} & \multirow{3}{*}{$\begin{array}{l}\text { Mittlere } \\
\text { absolute } \\
\text { Abweichung }\end{array}$} \\
\hline & \multirow{2}{*}{$\begin{array}{l}\text { Achsenabschnitt } \\
\text { Schätzwert }\end{array}$} & \multicolumn{2}{|l|}{ Steigung } & & \\
\hline & & Schätzwert & $\mathbf{p}$ & & \\
\hline TTP Vol & -37.90 & 0.56 & $\begin{array}{l}< \\
0.01\end{array}$ & 0.41 & 65.61 \\
\hline CBF Vol & -14.37 & 1.11 & $\begin{array}{l}< \\
0.01\end{array}$ & 0.69 & 38.61 \\
\hline CBV Vol & -6.02 & 1.30 & $\begin{array}{l}< \\
0.01\end{array}$ & 0.72 & 28.02 \\
\hline $\mathrm{CBV}(\mathrm{P}) \mathrm{Vol}$ & 3.39 & 1.01 & $\begin{array}{l}< \\
0.01\end{array}$ & 0.64 & 35.17 \\
\hline NVT Vol & 0.50 & 2.03 & $\begin{array}{l}< \\
0.01\end{array}$ & 0.67 & 34.37 \\
\hline $\begin{array}{l}\text { NVT Vol + } \\
\text { TAR Vol }\end{array}$ & -23.76 & 1.37 & $\begin{array}{l}< \\
0.01\end{array}$ & 0.73 & 39.56 \\
\hline
\end{tabular}

Tabelle 7: Geschätzte Regressionsparameter für die einzelnen Prädiktoren und Beschreibung der Regressionsgüte für Patienten mit NIHSS $\geq 8(n=21)$. 


\begin{tabular}{|c|c|c|c|c|c|}
\hline \multirow[t]{3}{*}{ Prädiktor } & \multicolumn{3}{|c|}{ Regressionskoeffizienten } & \multirow{3}{*}{$\begin{array}{l}\text { Adjustiertes } \\
\mathbf{R}^{\mathbf{2}}\end{array}$} & \multirow{3}{*}{$\begin{array}{l}\text { Mittlere } \\
\text { absolute } \\
\text { Abweichung }\end{array}$} \\
\hline & \multirow{2}{*}{\begin{tabular}{|l} 
Achsenabschnitt \\
Schätzwert
\end{tabular}} & \multicolumn{2}{|l|}{ Steigung } & & \\
\hline & & Schätzwert & $\mathbf{P}$ & & \\
\hline TTP Vol & 9.13 & 0.04 & 0.81 & 0.00 & 12.70 \\
\hline CBF Vol & -3.06 & 0.99 & $\begin{array}{l}< \\
0.01\end{array}$ & 0.69 & 5.13 \\
\hline CBV Vol & -1.79 & 1.01 & $\begin{array}{l}< \\
0.01\end{array}$ & 0.70 & 5.03 \\
\hline $\mathrm{CBV}(\mathrm{P}) \mathrm{Vol}$ & -1.92 & 0.96 & $\begin{array}{l}< \\
0.01\end{array}$ & 0.69 & 4.81 \\
\hline NVT Vol & 0.71 & 1.17 & $\begin{array}{l}< \\
0.01\end{array}$ & 0.40 & 8.44 \\
\hline $\begin{array}{l}\text { NVT Vol + } \\
\text { TAR Vol }\end{array}$ & -1.79 & 0.83 & $\begin{array}{l}< \\
0.01\end{array}$ & 0.46 & 7.81 \\
\hline
\end{tabular}

Tabelle 8: Geschätzte Regressionsparameter für die einzelnen Prädiktoren und Beschreibung der Regressionsgüte für Patienten mit einem NIHSS $<8(n=7)$.

\subsection{Zusammenhang zwischen weiteren klinischen Parametern und dem Follow-up-Volumen}

3.4.1 Zusammenhang zwischen dem Alter/ Geschlecht der Patienten und dem Follow-up-Volumen

Sowohl für das Alter als auch für das Geschlecht besteht kein statistisch signifikanter Zusammenhang mit dem Follow-up-Volumen ( $p=0,54$ bzw. $p=0,17$ ) (siehe Tabelle 9, Abb. 22). 
3.4.2 Zusammenhang zwischen Patienten mit einem Gefäßverschluss/ keinem Gefäßverschluss und dem Follow-up-Volumen

Es zeigt sich eine Tendenz zu einem höheren Follow-up-Volumen bei Patienten mit einem Gefäßverschluss ( $p=0,07$ ) (siehe Tabelle 9, Abb. 22).

\begin{tabular}{|l|l|l|}
\hline Parameter & $\begin{array}{l}\text { Follow-up-Volumen } \\
\text { Pearson's } \rho \text { bzw. } \\
\text { Median (Range) }\end{array}$ & P \\
\hline Alter & $\rho=-0.12$ & 0.54 \\
\hline $\begin{array}{l}\text { Geschlecht } \\
\text { männlich }(n=12) \\
\text { weiblich }(n=16)\end{array}$ & 0.17 \\
\hline $\begin{array}{l}\text { Gefäßverschluss } \\
\text { ja }(\mathrm{n}=19) \\
\text { nein }(\mathrm{n}=9)\end{array}$ & $23.59(0.00-449.30)$ & 0.07 \\
\hline
\end{tabular}

Tabelle 9: Zusammenhang zwischen klinischen Parametern und dem Follow-up-Volumen. 

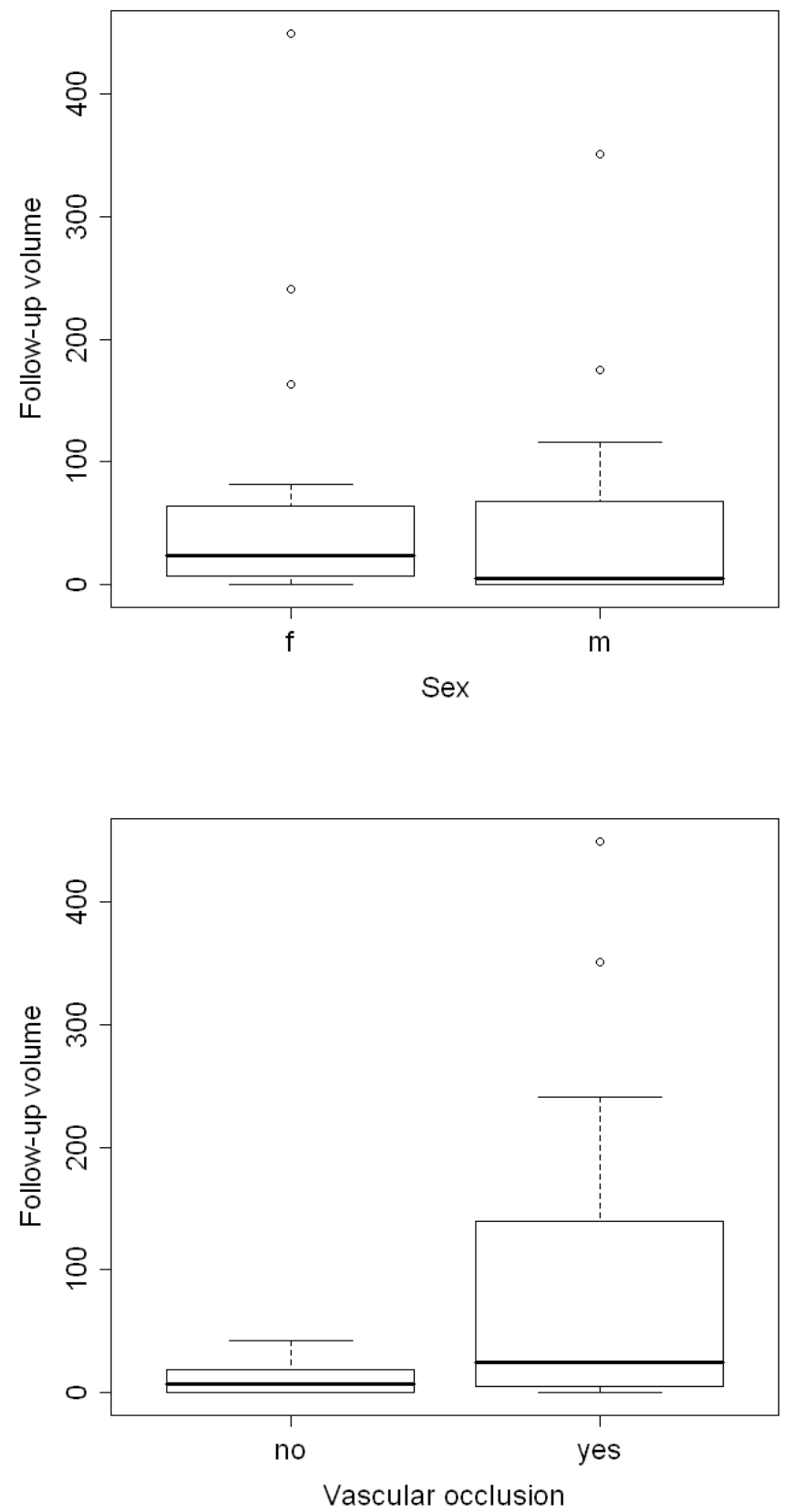

Abbildung 22: Verteilung des Follow-up-Volumens getrennt nach Geschlecht $(A)$ und nach Patienten mit und ohne Gefäßverschluss (B). 


\subsection{Korrelation der Kombination aus NVT + TAR mit dem CBF}

Die Läsionsgröße der Kombination aus TAR + NVT wird annähernd dem Läsionsvolumen der CBF-Karten gleichgesetzt.

Die im Rahmen der Dissertation durchgeführte statistische Untersuchung auf einen Zusammenhang zwischen NVT + TAR mit dem CBF ergab eine signifikante positive Korrelation (Pearson's $p=0.94, p<0,01$ ). 


\section{Diskussion}

\subsection{Patientenkollektiv und Studiengrundlagen}

In der prospektiven Studie erfolgte bei 28 Schlaganfallpatienten eine Auswertung der Bilddaten der Nativ-CT, der VPCT und der CTA. Zum direkten Vergleich wurde in den Follow-up-CT- oder Follow-up-MRT-Bildern der Patienten das endgültige Infarktvolumen bestimmt. Zur Analyse der Bilddaten aus der akuten Phase wurden die Parameterbilder TTP, CBF, CBV und CBV(P) der VPCT herangezogen und manuell ausgewertet. Außerdem erfolgte eine automatisierte Ermittlung der Läsionsgrößen NVT und TAR.

Zu den Einschlusskriterien für die Aufnahme eines Patienten in die Studie gehörte unter anderem, dass sich bei der notfallmäßigen Aufnahme des Patienten das klinische Bild einer akuten Ischämie bot. Um einen dem Routinealltag entsprechenden, möglichst großen Umfang an Patienten mit verschiedenen Formen und Schweregraden des Schlaganfalls zu erreichen, wurden im Gegensatz zu vielen bisher publizierten Studien nicht nur Patienten mit einem ausgeprägten Mediainfarkt in die Studie integriert, sondern auch Patienten, die im Follow-up-CT keine Demarkation eines Infarktes zeigten. Ferner wurden fünf wake-up strokes mit noch fehlender Demarkation im Nativ-CT und nur ungefähr anamnestizierbarem Zeitpunkt des Symptombeginns in die Datenanalyse mit eingeschlossen.

Die in dieser Studie zur Ischämiediagnostik verwendete Kombination aus Nativ-CT, PCT und CTA hat sich als nicht-invasives Verfahren bei einem akuten Schlaganfall bereits in der klinischen Routinediagnostik bewährt und findet in vielen Kliniken Anwendung (Schramm et al. 2004, Wintermark et al. 2007, Schrader et al. 2013).

Bei der Perfusions-CT gibt es methodisch bedingt ein limitiertes Scanvolumen. Seit der Einführung des Spiral-CT waren in den letzten Jahren weitere Ausführungen der Multislice-CT bis zu aktuell 128-, 256- und 320-Zeilen-Konfigurationen entwickelt worden, die für eine erhebliche Reduzierung der Scandauer und für ein größeres Scanvolumen bis hin zur Ganzhirndarstellung geeignet sind. Damit ist auch eine 
größere Volumenabdeckung bei der PCT möglich. Die VPCT ermöglicht anhand des Multispiralendatensatzes ein zeitaufgelöstes Volumenscanning mit Abdeckung des Hirnvolumens deutlich über der Detektorbreite (Morhard et al. 2010).

Der Einsatz eines 320-Zeilen-CT mit der Möglichkeit einer Ganzhirndarstellung wird in der Studie von Klingebiel et al. (2009) beschrieben. Die Detektorbreite von $16 \mathrm{~cm}$ ermöglicht bei diesen CT-Geräten die Erfassung des gesamten Hirnparenchyms ohne Patientenbewegung, sodass eine zeitaufgelöste CTA und PCT möglich sind. Zwar ist so ein größeres Scanvolumen erreichbar, Diekmann et al. (2010) konnten jedoch in ihren Studienergebnissen beim Vergleich eines 64- mit einem 320-ZeilenCT eine höhere Strahlenbelastung für den Patienten beim Einsatz eines 320-ZeilenCT-Scanners zeigen. Der behandelnde Arzt sollte somit zwischen dem diagnostischen Potential der neuen Technik und der Strahlenbelastung individuell abwägen. Aufgrund unterschiedlicher Aufnahmeprotokolle und Scanvolumina ist ein direkter Vergleich der Dosisprotokolle der beiden CT unterschiedlicher Detektorbreiten jedoch nur eingeschränkt möglich. Da jedoch bei der VPCT ein Multispiralendatensatz anstelle von repetitiven Einzelschichten zur Abbildung des gesamten Hirnvolumens notwendig ist und damit ein zeitaufgelöstes Volumenscanning möglich wird, ist nach Mori et al. (2006) bei der VPCT im Vergleich zu der Darstellung des gesamten Hirnvolumens mittels Standard-PCT eine Dosisreduktion zu erwarten.

\subsection{Diskussion der Ergebnisse}

Die Ergebnisse der vorliegenden Dissertationsarbeit zeigen, dass die Ganzhirn-PCT eine hohe prognostische Wertigkeit in Bezug auf die finale Infarktgröße gezeigt hat. Bei der Analyse der Bilddaten fand sich die signifikanteste Korrelation mit dem Follow-up-Volumen bei den Läsionsvolumina der Parameterkarten der CBV sowie der Kombination aus TAR und NVT. Dabei zeigte sich ein eindeutiger Zusammenhang zwischen der Größe der Läsionsvolumina und dem Schweregrad der akuten zerebralen Ischämie. 


\subsubsection{Prognostischer Wert der Perfusionsparameter im Bezug auf das Follow- up-Volumen}

Im Mittelpunkt der Dissertationsarbeit stand die Frage, welcher Prädiktor (TTP, CBF, CBV, CBV(P), NVT, TAR oder NVT + TAR) den höchsten prognostischen Wert im Bezug auf das finale Infarktvolumen besitzt. Das CBV und die Kombination aus NVT + TAR zeigten in der Frühphase der Ischämie die beste Voraussagekraft für die Ausdehnung des späteren Infarktgebietes $\left(R^{2}=0,75 ; R^{2}=0,75\right)$.

In der Literatur hat sich bisher noch kein eindeutiger Konsens über den am besten geeigneten CT-Perfusionsparameter als Prädiktor des finalen Läsionsvolumens gezeigt (Thierfelder et al. 2013). In älteren Studien wurden vor allem die Perfusionsparameter CBF und CBV gegenüber gestellt. Im Verlauf kamen mit der technischen Weiterentwicklung weitere Parameter wie die zeitbezogenen Parameter MTT und TTD (time to drain) hinzu.

Schrader et al. (2013) fanden passend zu den Studienergebnissen der vorliegenden Dissertation die größte Übereinstimmung zwischen den Volumina des CBV und dem definitiven Infarktvolumen. Nach zusätzlicher Dichotomisierung der Patienten in eine Gruppe mit erfolgreicher Rekanalisation und eine Gruppe, bei der keine Gefäßwiedereröffnung durchgeführt worden war, zeigte sich eine signifikante Korrelation der Volumenwerte in der Patientengruppe, bei der eine erfolgreiche Rekanalisation durchgeführt worden war. Dies passt zu der Studie von Muir et al. (2006), in der die in der Frühphase aufgenommenen Perfusionsbilder mit in einem Zeitrahmen von 24 bis 48 Stunden später aufgenommenen Bildern verglichen wurden. Das initiale Volumen der CBV-Parameterkarten zeigte bei Patienten mit erfolgter Rekanalisation ebenfalls signifikante Werte $(r=0,835 ; p=0,001)$ bezüglich der späteren Infarktvolumengröße. Bei Patienten ohne eine Wiedereröffnung des Gefäßes waren die Werte weniger repräsentativ $(r=0,793, p=0,110)$, die TTP hingegen erreichte hier eine höhere Korrelation ( $r=0,953, p=0,012)$.

In einer Studie von Schramm et al. (2004) hatte man zuvor hingegen eine signifikantere Korrelation zwischen dem CBV der PCT im Akutstadium und dem späteren Infarktvolumen bei Patienten ohne zuvor erfolgter medikamentöser Thrombolyse beobachtet $(r=1,0$ bei Patienten ohne Thrombolyse; $r=0,82$ bei Patienten mit erfolgter Thrombolyse). Gemäß Wintermark et al. (2006) seien zur 
Definition des Infarktkerns und der Penumbra die Perfusionsparameter CBV und relative MTT ebenfalls geeignet.

Sorensen et al. (1996) führten anhand einer MR-Perfusionsuntersuchung ebenfalls einen Vergleich der Perfusionsparameter durch. Es zeigte sich auch hier, dass das CBV einen besseren Prädiktor für das finale Infarktvolumen darstellt als der CBF. In dieser Studie wurden jedoch aufgrund der MRT-Bildgebungstechnik keine quantitativen Analysen durchgeführt, sondern es erfolgte lediglich eine visuelle Bewertung der Perfusionsbilder.

Thierfelder et al. (2013) untersuchten mit einem 128-Zeilen-CT anhand einer Ganzhirn-PCT-Untersuchung die Reliabilität und Reproduzierbarkeit der VPCT anhand diverser Ischämieparameter. In dieser Studie zeigte die TTD die höchste Reproduzierbarkeit. Die TTD stellt einen erst kürzlich mit kommerzieller Software bestimmbaren Parameter dar, der die Zeit des Kontrastmittelauswaschens aus dem Hirnparenchym angibt. Hier wurde jedoch nur eine limitierte Anzahl an Patienten ( $\mathrm{n}=$ 25) mit einer unilateralen Mediaischämie untersucht. Eine Follow-up-Untersuchung zum direkten Vergleich der Läsionsvolumina in Früh- und Spätphase war nicht erfolgt, sodass hier keine Aussage zur Prädiktion des Infarktes möglich war.

Auch Minnerup et al. (2011) führten eine Ganzhirn-PCT-Untersuchung mit einem 128-Zeilen-Detektor durch. Basierend auf der Annahme, dass das CBV den aussagekräftigsten Parameter zur Beschreibung des Infarktkerns darstellt, erfolgte hier eine Analyse des prädiktiven Wertes der Bestimmung der intrakraniellen Volumenreserve, hier in Milliliter des CSF (cerebrospinal fluid) angegeben, bei einem akuten zerebralen Infarkt. Die Bestimmung des Verhältnisses der Läsionsvolumina des CBV und der intrakraniellen Volumenreserve ergab dabei eine höhere Prognosegenauigkeit als bei der alleinigen Bestimmung des CBV. Auch hier wurden nur Patienten mit einem ausgeprägten Mediainfarkt sowie einem proximalen Gefäßverschluss retrospektiv in die Studie integriert.

Lee et al. (2008) analysierten den signifikantesten Prädiktor für das finale Infarktvolumen anhand des ASPECTS (Alberta Stroke Program Early CT Score). Das 10Punkte-System des ASPECTS wurde entwickelt, um die Zuverlässigkeit und den Nutzen einer Standard-CT-Untersuchung bei einem Mediainfarkt mit einem reproduzierbaren Grading bei frühen ischämischen Veränderungen zu versehen. Zu den Einschlusskriterien in die Studie gehörten hier das Vorhandensein einer zerebralen Ischämie im Bereich des Mediastromgebietes sowie eine CT-Perfusions- 
Untersuchung innerhalb von 24 Stunden nach erfolgter Rekanalisation. Das CBV ASPECTS zeigte hier einen hohen prognostischen Wert bezüglich des späteren Outcomes. Dies passt zu den Ergebnissen von Parsons et al. (2005). In jener Studie zeigte das CBV ASPECTS bei Patienten, bei denen es nach Intervention zu einer wesentlichen Reperfusion gekommen war, eine hohe prognostische Wertigkeit bezüglich des finalen Infarktvolumens. Psychogios et al. (2013) kamen im Rahmen einer VPCT-Untersuchung zu ähnlichen Ergebnissen, hier zeigte sich bei einem CBV ASPECTS von $>7$ (Scorebereich, bei dem Patienten von einer intravenösen Thrombolysetherapie in höherem Maße profitieren) die signifikanteste Korrelation.

Auch der CBF hat laut diverser Studien eine hohe prognostische Wertigkeit gezeigt. In einer Studie von Bivard et al. (2013) wurden sechs verschiedene Nachbearbeitungsprogramme zur Bestimmung der Penumbra und des Infarktkerns gegenübergestellt. Dabei wurden anhand eines 64-Zeilen-CT jeweils MTT-, CBF- und CBVKarten sowie je nach Softwareprogramm TTP-Karten erstellt. Die Parameterkarten der PCT wurden mit MRT-Bildern, die 24 Stunden nach der Akutdiagnostik angefertigt worden waren, verglichen. Die CBF-Parameterkarte zeigte dabei insgesamt die signifikanteste Korrelation zum Volumen des Infarktkerns. In dieser Studie wurden jedoch keine manuellen $\mathrm{ROI}$ angefertigt. Die entsprechend $\mathrm{zu}$ markierenden minderperfundierten Bereiche wurden im Follow-up-MRT-Bild durch festgelegte Grenzwerte in der Signalintensität automatisch markiert und zum Vergleich auf die Parameterkarten der Akutbilder transferiert. Des Weiteren wurden für die Berechnung der Läsionsvolumina nur MRT-Bilder als Referenzbilder genommen. Um eine Ganzhirndarstellung zu erreichen, wurden jeweils über 60 Sekunden zwei Perfusionsserien in unterschiedlichen Hirnabschnitten durchgeführt. Dies könnte daher zu Überschneidungen von einzelnen Pixeln der Perfusionsserien führen, die bei der Auswertung Ungenauigkeiten der Läsionsvolumina auf den Parameterkarten zur Folge haben.

In einer Studie von Kloska et al. (2004) ist der CBF dem CBV-Wert in seiner prognostischen Wertigkeit minimal überlegen (CBF: $\left.R^{2}=0,71 ; C B V: R^{2}=0,69\right)$. In dieser Arbeit wurden Patienten mit einem NIHSS $<5$ allerdings separat beurteilt und nicht in die oben erwähnte Statistik eingeschlossen. In unserer Studie hingegen sind vier Patienten mit einem NIHSS $<5$ inbegriffen sowie drei Patienten mit einem Follow-up-Volumen von 0 (bei denen im weiteren Verlauf keine Infarktdemarkation erfolgte). Es wurden bewusst alle Patienten mit Symptomen für eine akute zerebrale 
Ischämie eingeschlossen, da nicht nur Patienten mit großen Infarkten behandlungsbedürftig sind.

König et al. (2001) fanden heraus, dass die Messergebnisse des CBV und auch des CBF in den unterschiedlichen Zuständen der Hypoperfusion von dem verwendeten Algorithmus zur Bildberechnung abhängig sind. Laut einer Studie von Kudo et al. (2010) ging man ferner davon aus, dass vor allem die Darstellung der ischämischen Läsion im CBF-Bild im Gegensatz zur CBV-Parameterkarte bei der Verwendung unterschiedlicher Computerprogramme variiert. Die Auswertungsprogramme wiesen dabei einen deutlichen Unterschied bezüglich ihrer Sensitivität für die Hämodynamik auf.

Die TTP zeigte in unserer Studie die schlechteste Korrelation mit dem Follow-upVolumen. Dies passt zu den Ergebnissen der Studien von König et al. (2001) und Schramm et al. (2004) und liegt daran, dass die TTP Infarktgewebe nicht genau von reversibel geschädigtem Gewebe unterscheiden kann. Die TTP ist sehr sensitiv für Verzögerungen des Kontrastmittel-/Blutzuflusses im Hirngewebe, aber nicht spezifisch für reversible oder irreversible Ischämien. TTP-Läsionen sind daher in den meisten publizierten PCT-Studien signifikant größer als das spätere Ischämieareal und die initiale CBV-Läsion.

Der Aussagewert der verschiedenen Ischämieparameter für die Darstellung des Infarktareals in der Akutphase ist bislang trotz vieler Studien noch nicht eindeutig geklärt worden (Thierfelder et al. 2013). Hierbei muss allerdings erwähnt werden, dass sich ein Großteil der bisher publizierten Studien auf die Verwendung der PCTUntersuchung mit statischem Detektor beziehen.

Weitere Studien zur Bestimmung der Reliabilität und Reproduzierbarkeit der volumetrischen Beurteilung von Perfusionsdefiziten sowie die Standardisierung einer kommerziellen Perfusion- und Penumbra-Bildgebungsmethode, wären daher in Zukunft von entscheidendem Wert (Wintermark et al. 2002a, Thierfelder et al. 2013).

\subsubsection{Dichotomisierung des Patientenkollektivs}

Die Patienten der Studie wurden zur präziseren Datenanalyse in verschiedene Untergruppen eingeteilt. So wurden Gruppen mit und ohne Gefäßverschluss 
unterschieden. Auch erfolgte eine Einteilung nach Schweregrad der zerebralen Ischämie.

Durch die Aufteilung der Patienten in zwei Untergruppen je nach Präsenz eines Gefäßverschlusses wurden die prädiktiven Werte der einzelnen untersuchten Parameter nicht verbessert. Die Regressionsgüte von CBV zeigte sich weitgehend unabhängig von einem Gefäßverschluss. In der Literatur sind einige Studien beschrieben, in denen das Patientenkollektiv in eine Gruppe nach erfolgter Rekanalisation und eine ohne Gefäßwiedereröffnung unterteilt wurde. In der Studie von Schrader et al. (2013) sowie Muir et al. (2006) zeigte sich eine signifikantere Korrelation des CBV zum finalen Läsionsvolumen bei Patienten nach erfolgreicher Rekanalisation. Schramm et al. (2004) hatten hingegen eine größere Korrelation bei Patienten ohne medikamentöse Thrombolyse festgestellt.

Das Patientenkollektiv wurde darüber hinaus nach dem Grad der Schwere der Ischämiesymptomatik in eine Gruppe mit einem NIHSS-Score $\geq 8$ sowie eine Gruppe mit einem NIHSS-Score $<8$ aufgeteilt. Bei Patienten mit einem NIHSS-Score $\geq 8$ und damit einer ausgeprägteren Ischämie-Symptomatik zeigte sich eine höhere Korrelation zum Follow-up-Volumen als bei Patienten mit einem NIHSS-Score < 8 . Innerhalb der Patientengruppe mit einem NIHSS-Score < 8 konnte prinzipiell zudem statt eines Infarktereignisses auch eine TIA angenommen werden.

Interessanterweise zeigte sich der Vorhersagewert der Prädiktoren in der vorliegenden Dissertationsarbeit beim Vergleich der Läsionsvolumina von der Größe des Infarktgebietes abhängig. Je größer das zu bestimmende Ischämieareal war, desto höher war die Abweichung von der Regressionsgeraden. In anderen zum Vergleich herangezogenen Studien (wie etwa von Gasparotti et al. 2009) wurden jedoch nur Patienten mit höhergradigen Ischämien (v.a. im Mediastromgebiet) in die Studien integriert und Patienten mit leichteren Ischämien in anderen Versorgungsgebieten damit nicht untersucht.

Die statistische Überprüfung eines Zusammenhanges zwischen dem Follow-upVolumen und den Läsionsvolumina der Akutphase abhängig nach Alter und Geschlecht des Patienten ergab keine signifikante Korrelation. 


\subsubsection{Limitationen der Methodik}

Eine mögliche Limitation der Studie stellt die Heterogenität des Patientenkollektivs dar. Da auch Patienten mit einer weniger ausgeprägten zerebralen Ischämie behandlungsbedürftig sind, wurde ein breites Spektrum an Patienten mit verschiedenen Ausprägungen des Schlaganfalls in die Studie integriert. So wurden auch zwei Patienten eingeschlossen, die im Follow-up-Bild keine Infarktdemarkation aufwiesen. Bei diesen Patienten zeigte sich ein Follow-up-Volumen von 0. Die statistische Datenanalyse wurde dadurch jedoch nicht signifikant beeinflusst.

Des Weiteren wurden für die Bestimmung des finalen Infarktgewebes auf einem Follow-up-Bild nicht einheitlich Nativ-CT-Bilder, sondern in zwei Fällen auch MRTBilder verwendet. Dadurch kann es potentiell zu Ungenauigkeiten bei der volumetrischen Auswertung gekommen sein. Schellinger et al. (1999) konnten jedoch belegen, dass die Volumetrie von z.B. Hirnblutungen zwischen CT- und MRT-Bildern des Gehirns nicht signifikant unterschiedlich ist.

Ferner ist eine visuell bedingte Ungenauigkeit durch die manuelle Festlegung der ROI auf den Parameterkarten möglich. Bereits König et al. (2001) gingen von einer interindividuellen Variabilität bei der Bestimmung von CBF und CBV von > 20\% aus.

Im Gegensatz zu einer aktuellen Studie von Thierfelder et al. (2013) wurden in der vorliegenden Arbeit nur die Parameterkarten TTP, CBF, CBV und CBV(P) untersucht. In der von Thierfelder et al. (2013) publizierten Studie wurden zudem auch zeitbezogene Parameter wie MTT und TTD ausgewertet. Die TTD wies dabei eine hohe prognostische Wertigkeit für die Beurteilung des finalen Infarktvolumens auf. Die Parameter CBV und CBF waren in der Vergangenheit jedoch bereits häufig als signifikante Prädiktoren des finalen Infarktgewebes in einzelnen Perfusionsschichten diskutiert worden, sodass die Integration der Perfusionsparameter MTT und TTD ergänzend möglicherweise sinnvoll gewesen wäre, jedoch nicht zwingend notwendig war.

Bei der statistischen Überprüfung der Softwareparameter NVT + TAR und dem CBF hatte sich eine signifikante Korrelation zwischen diesen ergeben. Da statistisch jedoch auch die Summe aus NVT + TAR neben dem CBV die signifikanteste Korrelation zum finalen Infarktgewebe gezeigt hatte und diese dem CBF in ihrem Läsionsvolumen annähernd gleichzusetzen ist, ist nach dieser Herleitung damit auch der CBF weitgehend, wenn auch nicht im gleichen Umfang, signifikant. Die 
statistische Analyse zum prognostischen Wert der Parameter im Bezug auf das Follow-up-Infarktvolumen hatte bei den Parametern CBV und CBF zudem annähernd übereinstimmende Werte gezeigt $\left(C B V: R^{2}=0,75 ; C B F: R^{2}=0,74\right)$.

\subsection{Schlaganfall-CT versus Schlaganfall-MRT}

In der akuten Schlaganfalldiagnostik werden als Schnittbildverfahren sowohl die CT als auch die MRT verwendet, wobei die CT-Diagnostik eine breitere Verfügbarkeit bietet. In der Literatur bestehen unterschiedliche Ansichten zur diagnostischen Effektivität beider Verfahren.

Im Folgenden werden die Vor- und Nachteile beider Schnittbildverfahren tabellarisch vorgestellt und im Textverlauf weiter diskutiert.

\begin{tabular}{|c|c|c|}
\hline & Vorteile & Nachteile \\
\hline MRT & $\begin{array}{l}\text { - keine Strahlenbelastung } \\
\text { - Ganzhirndarstellung unabhängig von } \\
\text { Detektorbreite }\end{array}$ & $\begin{array}{l}\text { - eingeschränkte Verfügbarkeit } \\
\text { - höhere Anschaffungs- und Unterhaltungs- } \\
\text { kosten } \\
\text { - Kontraindikationen (z.B. Herzschrittmacher) } \\
\text { - nur relative Werte (Perfusionsdiagnostik) }\end{array}$ \\
\hline CT & $\begin{array}{l}\text { - kurze Untersuchungszeiten } \\
\text { - gute Verfügbarkeit } \\
\text { - Überwachungsmöglichkeiten } \\
\text { gegeben }\end{array}$ & $\begin{array}{l}\text { - Strahlenbelastung } \\
\text { - Kontrastmittelunverträglichkeit möglich }\end{array}$ \\
\hline
\end{tabular}

Tabelle 10: Vor- und Nachteile der Schnittbildverfahren MRT und CT.

Das MRT-Verfahren ist in der akuten Schlaganfalldiagnostik seit Anfang der neunziger Jahre etabliert (Le Bihan et al. 1986) und hat vor allem seit Anwendung von diffusions- und perfusionsgewichteten EPI-Sequenzen diverse Befürworter gefunden.

Ein unumstrittener Vorteil ist, dass MRT-Untersuchungen keine ionisierende Strahlung benötigen und somit keine Strahlenbelastung des Patienten zur Folge haben. Im Gegensatz zu der Nativ-CT werden laut Schellinger et al. (2001) mit der 
MRT-Diagnostik infratentoriell gelegene lakunäre Infarkte auf diffusionsgewichteten Bildern gut erkannt. Auch kleine lakunäre Infarkte von wenigen Millimetern Durchmesser können mit dem diffusionsgewichteten MRT mit hoher Sensitivität entdeckt werden.

Der notfallmäßige Zugang zu MRT ist in vielen Krankenhäusern jedoch nicht rund um die Uhr verfügbar. Gründe dafür sind nicht zuletzt die hohen Anschaffungs- und Unterhaltungskosten.

Zudem sind MRT-Untersuchungen nicht für jeden Patienten geeignet. Herzschrittmacher, Metallimplantate und andere magnetisierbare Fremdkörper stellen Kontraindikationen für eine Untersuchung mit dem MRT dar. Auch kann es notwendig sein, bei klaustrophoben, nicht kooperativen sowie überwachungspflichtigen Patienten eine andere Untersuchungsmethode zu bevorzugen.

MRT-Geräte liefern zwar eine bildliche Darstellung der Perfusionsparameter, in der klinischen Routine übliche Perfusions-MRT-Verfahren vermögen jedoch meist nur relative Werte darzustellen. Im Gegensatz dazu werden bei der Berechnung der CTPerfusionsparameter absolute Werte bestimmt. Damit können bei der CT-Untersuchung Grenzwerte festgelegt werden, die bei einer Über- oder Unterschreitung der Schwelle einen Hinweis auf ein ischämisches Ereignis geben können. Ein Vergleich der einzelnen Perfusionsparameter auf ihren prognostischen Wert im Akutstadium ist mit dem MRT-Verfahren nicht im gleichen messtechnischen Umfang möglich.

CT-Untersuchungen haben den Vorteil, dass sie erheblich einfacher verfügbar sind und eine schnelle Untersuchung ermöglichen (Brazzelli et al. 2009). Im Falle des akuten Schlaganfalls lässt die CT-Diagnostik ferner eine zügige und effektive Unterscheidung zwischen Hirnblutung und akuter zerebraler Ischämie zu (Bamford 1992). Auch intensivmedizinische Überwachungsmöglichkeiten während der Untersuchung sind hier einfacher gegeben.

Wie bereits erwähnt, wurden infratentoriell gelegene lakunäre Infarkte bei der SingleSlice-PCT-Untersuchung häufig übersehen. In einer Studie von Eckert et al. (2011) wurden Patienten mit Symptomatik, aber unauffälliger Nativ-CT, konventioneller PCT und CTA zusätzlich mit dem MRT untersucht. Dabei stellte sich heraus, dass 16 Patienten ( $n=107$ ) einen lakunären Infarkt hatten, der nur im MRT-Bild zu sehen war (Eckert et al. 2011). Die CT-Untersuchung dieser Erhebung umfasste allerdings bei einer Detektorbreite von $4 \mathrm{~cm}$ nur einen begrenzten Ausschnitt des Gehirns. Bei der Ganzhirn-PCT ist nun bei einer Hirnvolumenabdeckung von 9,6 cm in der Z- Achse 
(bei einem 128-Zeilen-CT) eine ausreichende Darstellung der Gehirnstrukturen möglich.

Zwar hat sich die Strahlenbelastung bei der Ischämie-Diagnostik mit dem CT im Gegensatz zu den früheren Geräten mit modernen Multisclice-CT-Scannern und neuen Detektoren deutlich verringert, generell ist die Strahlenbelastung durch die Röntgenstrahlung bei der CT-Diagnostik jedoch zu beachten. Schwangere und Kinder sind damit meist nicht für eine computertomographische Diagnostik geeignet. Auf Basis der während der Untersuchung angefertigten Patientenprotokolle ergab sich insgesamt pro Patient eine effektive Dosis von $11 \mathrm{mSv}$. Die Nativ-CTUntersuchung erforderte dabei eine Dosis von 2,3 mSv, für die VPCT wurden 5,3 mSv und für die CTA 3,4 mSv benötigt (siehe Tabelle 11). Die geschätzte Augenlinsendosis bei der Standardlagerung des Patienten liegt bei 100 mGy.

\begin{tabular}{|l|l|}
\hline \multicolumn{2}{|l|}{ Strahlenbelastungsprotokoll: } \\
\hline Effektive Dosis gesamt & $11,0 \mathrm{mSv}$ \\
\hline Nativ- CT & $2,3 \mathrm{mSv}$ \\
\hline VPCT & $5,3 \mathrm{mSv}$ \\
\hline CTA & $3,4 \mathrm{mSv}$ \\
\hline Augenlinsendosis (Standardlagerung) & $100 \mathrm{mGy}$ \\
\hline
\end{tabular}

Tabelle 11: Strahlenbelastung durch die CT-Untersuchungen im Rahmen der Dissertationsarbeit.

Im Rahmen der CT-Perfusionsdiagnostik ist eine intravenöse Kontrastmittelinjektion notwendig. Zu den prinzipiellen Risiken einer konventionellen Kontrastmittelgestützten Untersuchung gehören dabei die Verschlechterung einer Nierenfunktionsstörung, eine thyreotoxische Krise bei einer Hyperthyreose sowie eine Kontrastmittelallergie.

Das für die PCT eingesetzte intravenöse jodhaltige Kontrastmittel ist laut diverser Studien insgesamt gut verträglich. In einer Studie zur PCT beim akuten Schlaganfall von Smith et al. (2003) fand sich bei 51 von insgesamt 53 Patienten (wobei 2 Patienten Dialyse-Patienten waren), dass das Kontrastmittel keinen negativen Einfluss auf die Nierenfunktion hat. Auch allergische Reaktionen wurden nicht 
beobachtet. Knauth et al. (1997) konnten bei ihren Studienteilnehmern ebenfalls keinerlei Unverträglichkeitsreaktionen auf das Kontrastmittel feststellen.

Darüber hinaus konnten Doerfler et al. (1998) nachweisen, dass nichtionische Kontrastmittel den zerebralen Infarkt nicht statistisch signifikant beeinflussen oder sogar vergrößern.

In der Literatur finden sich unterschiedliche Ansichten bezüglich des effektiveren diagnostischen Schnittbildverfahrens bei der akuten zerebralen Ischämie.

Fiebach et al. (2002) zeigten anhand einer Studie, dass sich eine günstigere Interund Intraobserver-Variabilität bei der Diagnostik mit dem MRT findet und kamen zu dem Schluss, dass die MRT der akuten Schlaganfalldiagnostik mit dem Nativ-CT vorzuziehen sei. Damit hätten auch Ärzte mit weniger Berufserfahrung eine höhere diagnostische Sicherheit, wenn sie die Schlaganfalldiagnostik anhand von diffusionsgewichteten Bildern anstatt mit der nativen CT durchführten. Auch Lansberg et al. (2000) berichten über eine der Nativ-CT überlegene, höhere Sensitivität von 57\% und $86 \%$ bei zwei Beobachtern bezüglich der Detektion von Infarkten im Mediastromgebiet. Die Sensitivität der CT-Untersuchung betrug in ihrer Studie nur 14\% und $43 \%$. Es ist jedoch wichtig zu erwähnen, dass auch hier lediglich Nativ-CTAufnahmen mit diffusionsgewichteten MRT-Bildern verglichen wurden.

Das mit dem Perfusions-CT ermittelte Infarktgebiet der Untersuchungsschicht unterscheidet sich laut diverser Studien von dem mit der MRT ermittelten in der Größe nicht wesentlich.

Wintermark et al. (2002 b) verglichen die multimodale CT-Untersuchung bestehend aus Nativ-CT, PCT und CTA mit einer sich anschließenden DWI, PWI und MRA bei Patienten mit akuter zerebraler Ischämie und einem Untersuchungszeitpunkt von $<3$ Stunden nach Symptombeginn. Die Größe der ischämischen Läsion der CBVQuellbilder der Perfusions-CT und die DWI ergaben bezüglich des Infarktareals die signifikanteste Korrelation.

Auch die Läsionsgrößen auf den CTA-Quellbildern und die Diffusions-MRT unterscheiden sich nicht signifikant. Schramm et al. (2002) bewiesen, dass die CTAQuellbildanalyse der diffusionsgewichteten MRT bezüglich Größe und Volumen des Infarktgebietes gleichzusetzen ist. Nach Schramm (2004) und Wintermark et al. 
(2002 b) ist bei einem akuten Schlaganfall die Kombination aus Nativ-CT, PCT und CTA der DWI und PWI annähernd äquivalent.

Wintermark et al. (2002 b) gingen außerdem davon aus, dass selbst die begrenzte Volumenabdeckung bisher kein Hindernis für die Bestimmung der Ausdehnung der akuten Ischämie mit Hilfe der CT war, da der Hauptanteil des ischämischen Gebietes laut ihrer Studie im Detektorfeld bereits mit eingeschlossen war. Dennoch zeigte eine Studie von Morhard et al. (2010), dass anhand der konventionellen volumenbegrenzten Methode im Vergleich zu einer PCT mit einem größeren Scanbereich (ZAchse 9,6 cm) 24,1\% der Pathologien übersehen wurden. Dies führte daher in 34,7\% der Fälle zu unterschiedlichen Enddiagnosen.

Wie in der Einleitung erwähnt, kann mit der VPCT des 128-Zeilen-CT ein größeres Hirnvolumen untersucht werden. Somit besteht nicht mehr die Gefahr, ischämische Läsionen zu übersehen.

Die geringe Volumenabdeckung war nach Tomandl et al. (2003) bisher einer der Hauptnachteile einer CT-Untersuchung und ein möglicher Grund für die Wahl einer anderen Diagnostikmethode beim akuten Schlaganfallereignis. Dieser Nachteil ist nunmehr mit dem repetitiven Spiralscan egalisiert.

\subsection{Ausblick}

Durch die Einführung einer Ganzhirn-VPCT hat die Schlaganfalldiagnostik mit der Computertomographie an entscheidenden Vorteilen dazu gewonnen.

In Zukunft erscheint es allerdings notwendig - und dies gilt nicht nur für die CTDiagnostik - einen einheitlichen Algorithmus zur Akutdiagnostik zu finden (Bivard et al. 2013). Insbesondere fehlte es bisher an einer einheitlichen Definition der Penumbra anhand der verschiedenen Messparameter.

Frölich et al. (2012) hatten in ihrer Arbeit bezüglich der Darstellung von großen, intrakraniellen Gefäßverschlüssen eine hohe Sensitivität und einen positiven prädiktiven Wert der durch die VPCT rekonstruierbaren zeitaufgelösten 4D-CTA festgestellt. Weitere Studien zum potentiellen Wert sowie der diagnostische und therapeutische Nutzen von früh- und spätarterieller Phase der 4D-CTA wären hier von großer Relevanz. 


\section{$5 \quad$ Zusammenfassung}

Thema der Dissertation ist die Untersuchung der Wertigkeit der Volumen-PerfusionsComputertomographie mit dem 128-Zeilen-Multidetektor-CT bei Patienten mit einer akuten zerebralen Ischämie in einem Zeitrahmen von weniger als sechs Stunden nach Symptombeginn.

Gegenstand der Untersuchung war, ob die VPCT die Diagnostik einer akuten zerebralen Ischämie innerhalb der therapeutisch relevanten Frühphase zulässt und ob mit diesem Verfahren das gesamte Ausmaß der ischämischen Penumbra identifiziert werden kann. Zudem sollte der Ischämieparameter mit der besten prognostischen Aussagekraft bezüglich der späteren Infarktgröße ermittelt werden. Geprüft wurde die Hypothese, dass die Ganzhirn-Perfusions-CT bei einem akuten Schlaganfallereignis einen hohen prognostischen Wert in Bezug auf die finale Infarktgröße aufweist.

Für die Studie wurden 28 Patienten mit akuter zerebraler Ischämie untersucht. Dabei wurden im Akutstadium zerebrale Volumen-Perfusionsbilder angefertigt und diese mit CT- oder MRT-Bildern, die durchschnittlich drei Tage später angefertigt wurden, verglichen. Zur Subgruppen-Analyse wurden die Patienten dichotomisiert: Patienten mit einem in der CTA sichtbaren intrakraniellen arteriellen Gefäßverschluss wurden von solchen, bei denen kein Gefäßverschluss zu sehen war, unterschieden. Darüber hinaus waren die Patienten je nach Schwere der Symptomatik in eine Gruppe mit einem NIHSS-Score von $<8$ oder $\geq 8$ eingeteilt.

Die prognostische Wertigkeit wurde anhand der Perfusions-Parameterkarten für time to peak (TTP), cerebral blood flow (CBF), cerebral blood volume (CBV) und cerebral blood volume nach der Patlak-Methode $(\mathrm{CBV}(\mathrm{P}))$ überprüft. Außerdem wurden die anhand von absoluten Schwellenwerten bestimmten Parameter tissue at risk (TAR) und non-viable tissue (NVT) ausgewertet. Die Auswertung der Parameterkarten erfolgte nach einer manuellen Festlegung der region of interest. Die daraus bestimmten Volumina konnten damit zum unmittelbaren Vergleich mit den Follow-upBildern herangezogen werden. 
Die Größe der ischämischen Läsion auf den Parameterkarten des CBV und die Kombination aus TAR und NVT ergaben dabei den prognostisch höchsten Wert. Die Aufteilung in Untergruppen hatte keinen Einfluss auf die statistische Signifikanz.

In der Literatur herrschte bisher Uneinigkeit, welcher Prädiktor in Bezug auf das finale Infarktvolumen der aussagekräftigste ist. Von den meisten Autoren werden sowohl das CBV als auch der CBF als prognostisch wertvolle Parameter angesehen. Den Studien waren jedoch unterschiedliche Kriterien sowie verschiedene Algorithmen der Bildbearbeitung zugrunde gelegt, sodass ein direkter Vergleich nur annähernd möglich ist.

Bisher wurden in vielen diagnostischen Zentren diffusionsgewichtete MRT-Untersuchungen der CT-Diagnostik vorgezogen, da mit dem PCT nur Teile des Gehirns in einem Scandurchgang untersucht werden konnten. Durch die Verwendung des repetitiven Spiralscan ist es nunmehr möglich, eine Ganzhirn-PCT durchzuführen.

Bei der Anwendung der CT ergeben sich gegenüber einer MRT-Untersuchung entscheidende Vorteile. CT-Geräte sind besser verfügbar, sie sind außer in der Schwangerschaft und bei Kindern uneingeschränkt einsetzbar und liefern überdies absolut quantifizierbare Werte. Schließlich kann die bisher nachteilige Strahlenbelastung durch die fortgeschrittene Technik erheblich reduziert werden. 


\section{$6 \quad$ Literaturverzeichnis}

Astrup J, Branston NM, Lassen NA: Thresholds of cerebral ischemia. In Schmiedek P, Gratzl O, Spetzler RF (Hrsg.): Microsurgery for Stroke Springer, Berlin 1976, 16-21

Astrup J, Symon L, Branston NM, Lassen NA (1977): Cortical evoked potential and extracellular $\mathrm{K}+$ and $\mathrm{H}+$ at critical levels of brain ischemia. Stroke $\underline{8}, 51-57$

Astrup J, Siesjo BK, Symon L (1981): Thresholds in cerebral ischemia- the ischemic penumbra. Stroke $\underline{12}, 723-725$

Axel L (1980): Cerebral blood flow determination by rapid-sequence computed tomography: a theoretical analysis. Radiology $\underline{137}, 679-686$

Baird AE, Warach S (1998): Magnetic resonance imaging of acute stroke. J Cereb Blood Flow Metab 18, 583-609

Bamford J (1992): Clinical examination in diagnosis and subclassification of stroke. Lancet $\underline{339}, 400-402$

Baron JC (1999): Mapping the ischaemic penumbra with PET: implications for acute stroke treatment. Cerebrovasc Dis $\underline{9}, 193-201$

Baron JC (2001): Mapping the ischaemic penumbra with PET: a new approach. Brain $\underline{124}$, 24

Bastinanello S, Pierallini A, Colonnese C, Brughitta G, Angeloni U, Antonelli M, Fantozzi LM, Fieschi C, Bozzao L (1991): Hyperdense middle cerebral artery CT sign. Comparison with angiography in the acute phase of ischemic supratentorial infarction. Neuroradiology $\underline{33}, 207-$ 211 
Beauchamp NJ, Jr., Barker PB, Wang PY, van Zijl PC (1999): Imaging of acute cerebral ischemia. Radiology 212, 307-324

Bivard A, Levi C, Spratt N, Parsons M (2013): Perfusion ct in acute stroke: A comprehensive analysis of infarct and penumbra. Radiology $\underline{267}, 543-550$

Bogousslavsky J, Kaste M, Skyhoj Olsen T, Hacke W, Orgogozo JM (2000): Risk factors and stroke prevention. European Stroke Initiative (EUSI). Cerebrovasc Dis 10 Suppl 3, 12-21

Brazzelli M, Sandercock PA, Chappell FM, Celani MG, Righetti E, Arestis N, Wardlaw JM, Deeks JJ (2009): Magnetic resonance imaging versus computed tomography for detection of acute vascular lesions in patients presenting with stroke symptoms. Cochrane Database Syst Rev CD007424

Bryan RN, Levy LM, Whitlow WD, Killian JM, Preziosi TJ, Rosario JA (1991): Diagnosis of acute cerebral infarction: comparison of CT and MR imaging. Am J Neuroradiol $\underline{12}, 611-620$

Crain MR, Yuh WT, Greene GM, Loes DJ, Ryals TJ, Sato Y, Hart MN (1991): Cerebral ischemia: evaluation with contrast-enhanced MR imaging. Am J Neuroradiol 12, 631-639

Diekmann S, Siebert E, Juran R, Roll M, Deeg W, Bauknecht HC, Diekmann F, Klingebiel R, Bohner G (2010): Dose exposure of patients undergoing comprehensive stroke imaging by multidetector-row CT: comparison of 320-detector row and 64-detector row CT scanners. Am J Neuroradiol 31, 1003-1009

Doerfler A, Engelhorn T, von Kummer R, Weber J, Knauth M, Heiland S, Sartor K, Forsting M (1998): Are iodinated contrast agents detrimental in acute cerebral ischemia? An experimental study in rats. Radiology $\underline{206}, 211-217$

Eckert B, Küsel T, Leppien A, Michels P, Müller-Jensen A, Fiehler J (2011): Clinical outcome and imaging follow-up in acute stroke patients with normal perfusion CT and normal CT angiography. Neuroradiology $\underline{53}, 79-88$

Fiebach JB, Schellinger PD, Jansen O, Meyer M, Wilde P, Bender J, Schramm P, Juttler E, Oehler J, Hartmann M (2002): CT and diffusion-weighted MR imaging in randomized order: 
diffusion-weighted imaging results in higher accuracy and lower interrater variability in the diagnosis of hyperacute ischemic stroke. Stroke $\underline{33}, 2206-2210$

Frölich AM, Psychogios MN, Klotz E, Schramm R, Knauth M, Schramm P (2012): Angiographic reconstructions from whole-brain perfusion $\mathrm{CT}$ for the detection of large vessel occlusion in acute stroke. Stroke $\underline{43}, 97-102$

Garcia JH, Mitchem HL, Briggs L, Morawetz RB, Hudetz AG, Hazelrig JB, Halsey JH, Conger KA (1983): Transient focal ischemia in subhuman primates. Neuronal injury as a function of local cerebral blood flow. Neuropathol of Exp Neurol $\underline{42}, 44-60$

Gasparotti R, Grassi M, Mardighian D, Frigerio M, Pavia M, Liserre R, Magoni M, Mascaro L, Padovani A, Pezzini A (2009): Perfusion CT in patients with acute ischemic stroke treated with intra-arterial thrombolysis: Predictive value of infarct core size on clinical outcome. Am J Neuroradiol. $\underline{30}, 722-727$

Grotta JC, Chiu D, Lu M, Patel S, Levine SR, Tilley BC, Brott TG, Haley EC, Jr., Lyden PD, Kothari R et al. (1999): Agreement and variability in the interpretation of early CT changes in stroke patients qualifying for intravenous rtPA therapy. Stroke $\underline{30}, 1528-1533$

Hacke W, Kaste M, Fieschi C, Toni D, Lesaffre E, von Kummer R, Boysen G, Bluhmki E, Höxter G, Mahagne MH, Hennerici M, for the ECASS Study Group (1995): Intravenous thrombolysis with recombinant tissue plasminogen activator for acute hemispheric stroke. The European Cooperative Acute Stroke Study (ECASS). JAMA 274, 1017-1025

Hacke W, Albers G, Al-Rawi Y, Bogousslavsky J, Davalos A, Eliasziw M, Fischer M, Furlan A, Kaste M, Lees KR (2005): The Desmoteplase in Acute Ischemic Stroke Trial (DIAS): a phase II MRI-based 9-hour window acute stroke thrombolysis trial with intravenous desmoteplase. Stroke $\underline{36}, 66-73$

Hacke W, Kaste M, Bluhmki E, Brozman M, Davalos A, Guidetti D, Larrue V, Lees KR, Medeghri Z, Machnig T (2008): Thrombolysis with alteplase 3 to 4.5 hours after acute ischemic stroke. N Engl J Med $\underline{359}, 1317-1329$ 
Hacke W, Furlan AJ, Al-Rawi Y, Davalos A, Fiebach JB, Gruber F, Kaste M, Lipka LJ, Pedraza S, Ringleb PA et al. (2009): Intravenous desmoteplase in patients with acute ischaemic stroke selected by MRI perfusion-diffusion weighted imaging or perfusion CT (DIAS-2): a prospective, randomised, double-blind, placebo-controlled study. Lancet Neurol $\underline{8}, 141-150$

Handschu R, Garling A, Heuschmann PU, Kolominsky-Rabas PL, Erbguth F, Neundörfer B (2001): Acute stroke management in the local general hospital. Stroke $\underline{32}, 866-870$

Heiss WD (2000): Ischemic penumbra: evidence from functional imaging in man. J Cereb Blood Flow Metab 20, 1276-1293

Heiss WD, Rosner G (1983): Functional recovery of cortical neurons as related to degree and duration of ischemia. Ann Neurol $\underline{14}$, 294-301

Heuschmann PU, Busse O, Wagner M, Endres M, Villringer A, Röther J, Kolominsky-Rabas PL, Berger K (2010): Schlaganfallhäufigkeit und Versorgung von Schlaganfallpatienten in Deutschland. Akt Neurol $\underline{37}, 333-340$

Hjort N, Christensen S, Sølling C, Ashkanian M, Wu O, Røhl L, Gyldensted C, Andersen G, Østergaard L (2005): Ischemic injury detected by diffusion imaging 11 minutes after stroke. Ann Neurol $\underline{58}, 462-465$

Jones TH, Morawetz RB, Crowell RM, Marcoux FW, FitzGibbon SJ, DeGirolami U, Ojemann RG (1981): Thresholds of focal cerebral ischemia in awake monkeys. J Neurosurg $\underline{54}, 773-$ 782

Kalender WA, Polacin A (1991): Physical performance characteristics of spiral CT scanning. Med Phys $\underline{18}, 910-915$

Katayama H, Yamaguchi K, Kozuka T, Takashima T, Seez P, Matsuura K (1990): Adverse reactions to ionic and nonionic contrast media. A report from the Japanese Committee on the Safety of Contrast Media. Radiology $\underline{175}$, 621-628 
Kertesz A, Black SE, Nicholson L, Carr T (1987): The sensitivity and specificity of MRI in stroke. Neurology $\underline{37}, 1580-1585$

Kleindorfer D, Panagos P, Pancioli A, Khoury J, Kissela B, Woo D, Schneider A, Alwell K, Jauch E, Miller R, Moomaw C, Shukla R, Broderick JP (2005): Incidence and short-term prognosis of transient ischemic attack in population-based study. Stroke $\underline{36}, 720-723$

Klingebiel R, Siebert E, Diekmann S, Wiener E, Masuhr F, Wagner M, Bauknecht HC, Dewey M, Bohner G (2009): 4-D Imaging in cerebrovascular disorders by using 320slice CT: feasibility and preliminary clinical experience. Acad Radiol 16 (2), 123-129

Klingenbeck-Regn K, Schaller S, Flohr T, Ohnesorge B, Kopp AF, Baum U (1999): Subsecond multi-slice computed tomography: basics and applications. Eur J Radiol $\underline{31}, 110$ 124

Kloska SP, Nabavi DG, Gaus C, Nam EM, Klotz E, Ringelstein EB, Heindel W (2004): Acute stroke assessment with CT: do we need multimodal evaluation? Radiology $\underline{233}, 79-86$

Klotz E, König M (1999): Perfusion measurements of the brain: using dynamic CT for the quantitative assessment of cerebral ischemia in acute stroke. Eur J Radiol $\underline{30}, 170-184$

Knauth M, von Kummer R, Jansen O, Hahnel S, Dorfler A, Sartor K (1997): Potential of CT angiography in acute ischemic stroke. Am J Neuroradiol $\underline{18}, 1001-1010$

König M, Klotz E, Heuser L (2000): [Cerebral perfusion CT: theoretical aspects, methodical implementation and clinical experience in the diagnosis of ischemic cerebral infarction]. Rofo $\underline{172}, 210-218$

König M, Kraus M, Theek C, Klotz E, Gehlen W, Heuser L (2001): Quantitative assessment of the ischemic brain by means of perfusion-related parameters derived from perfusion $\mathrm{CT}$. Stroke $\underline{32}, 431-437$

Kudo K, Sasaki M, Yamada K, Momoshima S, Utsunomiya H, Shirato H, Ogasawara K (2010): Differences in CT perfusion maps generated by different commercial software: 
quantitative analysis by using identical source data of acute stroke patients. Radiology $\underline{254}$, 200-209

Lago A, Geffner D, Tembl J, Landete L, Valero C, Baquero M (1998): Circadian variation in acute ischemic stroke: a hospital-based study. Stroke $\underline{29}, 1873-1875$

Lansberg MG, Albers GW, Beaulieu C, Marks MP (2000): Comparison of diffusion-weighted $\mathrm{MRI}$ and CT in acute stroke. Neurology $\underline{54}, 1557-1561$

Lassen NA, Perl W. (1979): Tracer kinetic methods in medical physiology. New York:

Raven Press, 1- 186

Lassen NA (1990): Pathophysiology of brain ischemia as it relates to the therapy of acute ischemic stroke. Clin Neuropharmacol 13 Suppl 3, S1-8

Le Bihan D, Breton E, Lallemand D, Grenier P, Cabanis E, Laval-Jeantet M (1986). MR imaging of intravoxel incoherent motions: application to diffusion and perfusion in neurologic disorders. Radiology 161:401-407

Lee DH, Kang DW, Ahn JS, Choi CG, Kim SJ, Suh DC (2005): Imaging of the ischemic penumbra in acute stroke. Korean J Radiol $\underline{6}, 64-74$

Lee JY, Kim SH, Lee MS, Park SH, Lee SS (2008): Prediction of clinical outcome with baseline and 24-hour perfusion CT in acute middle cerebral artery territory ischemic stroke treated with intravenous recanalization therapy. Neuroradiology $\underline{50}$, 391-396

Leiva-Salinas C, Provenzale JM, Wintermark M (2011): Responses to the 10 most frequently asked questions about perfusion CT. Am J Roentgenol 196, 53-60

Leys D, Pruvo JP, Godefroy O, Rondepierre P, Leclerc X (1992): Prevalence and significance of hyperdense middle cerebral artery in acute stroke. Stroke $\underline{23}, 317-324$

Miles KA, Hayball M, Dixon AK (1991): Colour perfusion imaging: a new application of computed tomography. Lancet $\underline{337}, 643-645$ 
Minnerup J, Wersching H, Ringelstein EB, Heindel W, Niederstadt T, Schilling M, Schäbitz WR, Kemmling A (2011): Prediction of malignant middle cerebral artery infarction using computed tomography-based intracranial volume reserve measurements. Stroke $\underline{42}, 3403-$ 3409

Mohr JP, Biller J, Hilal SK, Yuh WT, Tatemichi TK, Hedges S, Tali E, Nguyen H, Mun I, Adams HP Jr et al. (1995): Magnetic resonance versus computed tomographic imaging in acute stroke. Stroke $\underline{26}, 807-812$

Morhard D, Wirth CD, Fesl G, Schmidt C, Reiser MF, Becker CR, Ertl-Wagner B (2010): Advantages of extended brain perfusion computed tomography: $9.6 \mathrm{~cm}$ coverage with time resolved computed tomography-angiography in comparison to standard stroke-computed tomography. Invest Radiol $\underline{45}$, 363-369

Mori S, Endo M, Nishizawa K, Murase K, Fujiwara H, Tanada S (2006): Comparison of patient doses in 256-slice CT and 16-slice CT scanners. Br J Radiol $\underline{79}, 56-61$

Muir KW, Halbert HM, Baird TA, Mc Cormick M, Teasdale E (2006): Visual evaluation of perfusion computed tomography in acute stroke accurately estimates infarct volume and tissue viability. J Neurol Neurosurg Psychiatry $\underline{77}$, 334-339

Parsons MW, Pepper EM, Chan V, Siddique S, Rajaratnam S, Bateman GA, Levi CR (2005): Perfusion computed tomography: prediction of final infarct extent and stroke outcome. Ann Neurol $\underline{58}, 672-679$

Psychogios MN, Schramm P, Frölich AM, Kallenberg K, Wasser K, Reinhardt L, Kreusch AS, Jung K, Knauth M (2013): Alberta stroke program early ct scale evaluation of multimodal computed tomography in predicting clinical outcomes of stroke patients treated with aspiration thrombectomy. Stroke $\underline{44}, 2188-2193$

Reichenbach JR, Röther J, Jonetz-Mentzel L, Herzau M, Fiala A, Weiller C, Kaiser WA (1999): Acute stroke evaluated by time-to-peak mapping during initial and early follow-up perfusion CT studies. Am J Neuroradiol 20, 1842-1850 
Rosen BR, Belliveau JW, Chien D (1989): Perfusion imaging by nuclear magnetic resonance. Magn Reson Q $\underline{5}, 263-281$

Röther J (2001): CT and MRI in the diagnosis of acute stroke and their role in thrombolysis. Thromb Res 103 Suppl 1, S125-133

Sakai F, Nakazawa K, Tazaki Y, Ishii K, Hino H, Igarashi H, Kanda T (1985): Regional cerebral blood volume and hematocrit measured in normal human volunteers by singlephoton emission computed tomography. J Cereb Blood Flow Metab $\underline{5}$, 207-213

Schellinger PD, Köhrmann M (2012): Current acute stroke trials and their potential impact on the therapeutic time window. Expert Rev Neurother 12, 169-177

Schellinger PD, Jansen O, Fiebach JB, Hacke W, Sartor K (1999): A standardized MRI stroke protocol: comparison with CT in hyperacute intracerebral hemorrhage. Stroke $\underline{30}, 765-$ 768

Schellinger PD, Jansen O, Fiebach JB, Pohlers O, Ryssel H, Heiland S, Steiner T, Hacke W, Sartor K (2000): Feasibility and practicality of MR imaging of stroke in the management of hyperacute cerebral ischemia. Am J Neuroradiol 21, 1184-1189

Schellinger PD, Fiebach JB, Jansen O, Ringleb PA, Mohr A, Steiner T, Heiland S, Schwab S, Pohlers O, Ryssel H et al. (2001): Stroke magnetic resonance imaging within 6 hours after onset of hyperacute cerebral ischemia. Ann Neurol $\underline{49}, 460-469$

Schlaug G, Benfield A, Baird AE, Siewert B, Lövblad KO, Parker RA, Edelman RR, Warach $S$ (1999): The ischemic penumbra: operationally defined by diffusion and perfusion MRI. Neurology $\underline{53}, 1528-1537$

Schrader I, Wilk D, Jansen O, Riedel C (2013): Whole-brain perfusion CT using a toggling table-technique to predict final infarct volume in acute ischemic stroke. Rofo $\underline{185}, 975-982$

Schramm P (2004): Mehrzeilen-CT: Anwendung beim Schlaganfall. Radiologie up2date $\underline{4}$, 183-197 
Schramm P (2005): CT Diagnostik bei acuter zerebraler Ischämie. Der Radiologe $\underline{45}$, 420429

Schramm P, Schellinger PD, Fiebach JB, Heiland S, Jansen O, Knauth M, Hacke W, Sartor K (2002): Comparison of CT and CT angiography source images with diffusion-weighted imaging in patients with acute stroke within 6 hours after onset. Stroke $\underline{33}, 2426-2432$

Schramm P, Schellinger PD, Klotz E, Kallenberg K, Fiebach JB, Külkens S, Heiland S, Knauth M, Sartor K (2004): Comparison of perfusion computed tomography and computed tomography angiography source images with perfusion-weighted imaging and diffusionweighted imaging in patients with acute stroke of less than 6 hours' duration. Stroke $\underline{35}$, 1652-1658

Smith WS, Roberts HC, Chuang NA, Ong KC, Lee TJ, Johnston SC, Dillon WP (2003): Safety and feasibility of a CT protocol for acute stroke: combined CT, CT angiography, and CT perfusion imaging in 53 consecutive patients. Am J Neuroradiol 24, 688- 690

Sorensen AG, Buonanno FS, Gonzalez RG, Schwamm LH, Lev MH, Huang-Hellinger FR, Reese TG, Weisskoff RM, Davis TL, Suwanwela N et al. (1996): Hyperacute stroke evaluation with combined multisection diffusion-weighted and hemodynamically weighted echo-planar MR imaging. Radiology 199, 391-401

The National Institute of Neurological Disorders and Stroke (NINDS) rt-PA Stroke Study Group (1995): Tissue plasminogen activator for acute ischemic stroke. N Engl J Med $\underline{333}$, $1581-1587$

Thierfelder KM, Sommer WH, Baumann AB, Klotz E, Meinel FG, Strobl FF, Nikolaou K, Reiser M, von Baumgarten $L$ (2013): Whole-brain ct perfusion: reliability and reproducibility of volumetric perfusion deficit assessment in patients with acute ischemic stroke. Neuroradiology $\underline{55}, 827-835$

Tomandl BF, Klotz E, Handschu R, Stemper B, Reinhardt F, Huk WJ, Eberhardt KE, FatehMoghadam S (2003): Comprehensive imaging of ischemic stroke with multisection CT. Radiographics $\underline{23}, 565-592$ 
Tomsick T, Brott T, Barsan W, Broderick J, Haley EC, Spilker J, Khoury J (1996): Prognostic value of the hyperdense middle cerebral artery sign and stroke scale score before ultraearly thrombolytic therapy. Am J Neuroradiol $\underline{17}, 79-85$

Truwit CL, Barkovich AJ, Gean-Marton A, Hibri N, Norman D (1990): Loss of the insular ribbon: another early CT sign of acute middle cerebral artery infarction. Radiology $\underline{176}$, 801806

Unger EC, Gado MH, Fulling KF, Littlefield JL (1987): Acute cerebral infarction in monkeys: an experimental study using MR imaging. Radiology $\underline{162}, 789-795$

von Kummer R, Holle R, Rosin L, Forsting M, Hacke W (1995): Does arterial recanalization improve outcome in carotid territory stroke? Stroke $\underline{26}, 581-587$

von Kummer R, Holle R, Gizyska U, Hofmann E, Jansen O, Petersen D, Schumacher M, Sartor K (1996): Interobserver agreement in assessing early CT signs of middle cerebral artery infarction. Am J Neuroradiol $\underline{17}, 1743-1748$

Warach S, Chien D, Li W, Ronthal M, Edelman RR (1992): Fast magnetic resonance diffusion-weighted imaging of acute human stroke. Neurology $\underline{42}, 1717-1723$

Warach S, Gaa J, Siewert B, Wielopolski P, Edelman RR (1995): Acute human stroke studied by whole brain echo planar diffusion-weighted magnetic resonance imaging. Ann Neurol. $\underline{37}, 231-241$

Wardlaw JM (2001): Overview of Cochrane thrombolysis meta-analysis. Neurology $\underline{57}, 69-76$

WHO (1988): The World Health Organization MONICA Project (monitoring trends and determinants in cardiovascular disease): a major international collaboration. WHO MONICA Project Principal Investigators. J Clin Epidemiol 41, 105-114

WHO (1989): Recommendations on stroke prevention, diagnosis, and therapy. Report of the WHO Task Force on Stroke and other Cerebrovascular Disorders. Stroke 20, 1407-1431 
Wintermark M, Reichhart M, Thiran JP, Maeder P, Chalaron M, Schnyder P, Bogousslavsky J, Meuli R (2002 a): Prognostic accuracy of cerebral blood flow measurement by perfusion computed tomography, at the time of emergency room admission, in acute stroke patients. Ann Neurol $\underline{51}, 417-432$

Wintermark M, Reichhart M, Cuisenaire O, Maeder P, Thiran JP, Schnyder P, Bogousslavsky J, Meuli R (2002 b): Comparison of admission perfusion computed tomography and qualitative diffusion- and perfusion-weighted magnetic resonance imaging in acute stroke patients. Stroke $\underline{33}, 2025-2031$

Wintermark M, Flanders AE, Velthuis B, Meuli R, van Leeuwen M, Goldsher D, Pineda C, Serena J, van der Schaaf I, Waaijer A et al. (2006): Perfusion-CT assessment of infarct core and penumbra: receiver operating characteristic curve analysis in 130 patients suspected of acute hemispheric stroke. Stroke $\underline{37}, 979-985$

Wintermark M, Meuli R, Browaeys P, Reichhart M, Bogousslavsky J, Schnyder P, Michel P (2007): Comparison of ct perfusion and angiography and MRI in selecting stroke patients for acute treatment. Neurology $\underline{68}, 694-697$

Xyda A, Haberland U, Klotz E, Jung K, Bock HC, Schramm R, Knauth M, Schramm P (2012): Diagnostic performance of whole brain volume perfusion CT in intra-axial brain tumors: preoperative classification accuracy and histopathologic correlation. Eur J Radiol $\underline{81}, 4105-$ 4111

Yadav JS, Roubin GS, lyer S, Vitek J, King P, Jordan WD, Fisher WS (1997): Elective stenting of the extracranial carotid arteries. Circulation $\underline{95}, 376-381$

Yuh WT, Crain MR, Loes DJ, Greene GM, Ryals TJ, Sato Y (1991): MR imaging of cerebral ischemia: findings in the first 24 hours. Am J Neuroradiol 12, 621-629 


\section{$7 \quad$ Abbildungsverzeichnis}

Abbildung 1: Zonen der zerebralen Ischämie ................................................... 4

Abbildung 2: Veränderung des Infarktgebietes im zeitlichen Verlauf ...................... 5

Abbildung 3: Zeit-Dichte-Kurve im normalen Hirngewebe zur Bestimmung von CBF,

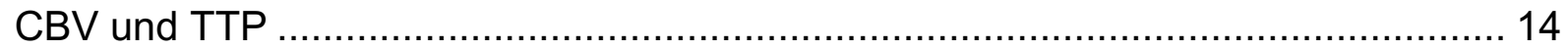

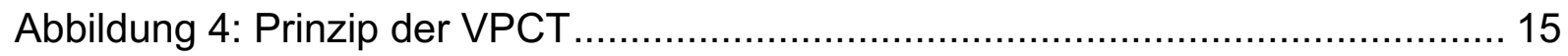

Abbildung 5: Protokoll aller CT Untersuchungen .......................................... 21

Abbildung 6: Schritt 1- Bewegungskorrektur. .............................................. 23

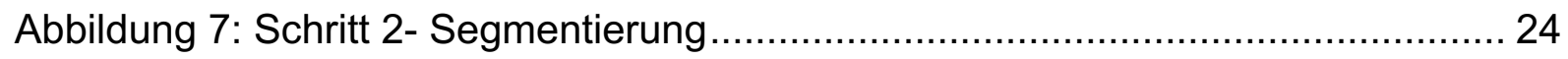

Abbildung 8: Schritt 3- Festlegung der arteriellen und venösen Referenzgefäße für die spätere Datenberechnung. .................................................................. 25

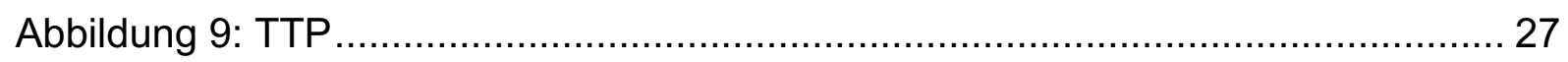

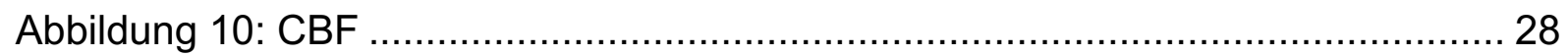

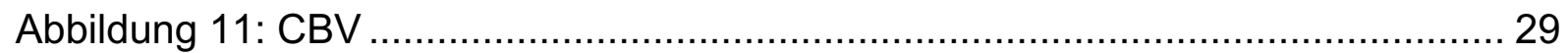

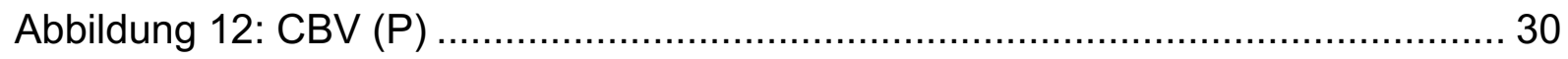

Abbildung 13: Einzeichnen der region of interest (ROI) in der axialen Schicht......... 31

Abbildung 14: Vergleich der beiden Hemisphären anhand einer ROI...................... 32

Abbildung 15: Tabelle der Parameterdaten im Hemisphärenvergleich ................... 33

Abbildung 16: Die erweiterte ROI-Analyse .................................................... 35

Abbildung 17: Das Follow-up-Bild ............................................................... 36

Abbildung 18: Vergleich der Kenngrößen zwischen gesunder Seite und Infarktseite40

Abbildung 19: Follow-up-Messung in Abhängigkeit von TTP $(A)$ und CBF (B)....... 43

Abbildung 20: Follow-up-Messung in Abhängigkeit von $\mathrm{CBV}(\mathrm{A})$ und $\mathrm{CBV}(\mathrm{P})(\mathrm{B})$... 44

Abbildung 21: Follow-up-Messung in Abhängigkeit von NVT (A) und NVT + TAR (B).

Abbildung 22: Verteilung des Follow-up-Volumens getrennt nach Geschlecht $(A)$ und nach Patienten mit und ohne Gefäßverschluss (B). 


\section{Tabellenverzeichnis}

Tabelle 1: Protokoll der Infusionen.... 20

Tabelle 2: Protokoll der Infusionen bei der CTA 21

Tabelle 3: Parameter der regionalen zerebralen Perfusion. 26

Tabelle 4: Geschätzte Regressionsparameter für die einzelnen Prädiktoren und Beschreibung der Regressionsgüte.

Tabelle 5: Geschätzte Regressionsparameter für die einzelnen Prädiktoren und Beschreibung der Regressionsgüte für Patienten mit Gefäßverschluss ( $n=19)$

Tabelle 6: Geschätzte Regressionsparameter für die einzelnen Prädiktoren und Beschreibung der Regressionsgüte für Patienten ohne Gefäßverschluss ( $n=9) \ldots \ldots . .48$

Tabelle 7: Geschätzte Regressionsparameter für die einzelnen Prädiktoren und Beschreibung der Regressionsgüte für Patienten mit NIHSS $\geq 8 \quad(n=21)$.

Tabelle 8: Geschätzte Regressionsparameter für die einzelnen Prädiktoren und Beschreibung der Regressionsgüte für Patienten mit einem NIHSS $<8(n=7)$. 50

Tabelle 9: Zusammenhang zwischen klinischen Parametern und dem Follow-upVolumen.

Tabelle 10: Vor-und Nachteile der Schnittbildverfahren MRT und CT. 62

Tabelle 11: Strahlenbelastung durch die CT-Untersuchungen im Rahmen der Dissertationsarbeit. 64 


\section{$9 \quad$ Formelverzeichnis}

Formel 1: Berechnung der Perfusion anhand der Zeit-Dichtekurve ......................... 12

Formel 2: Formel zur Berechnung des zerebralen Blutvolumens .......................... 13 


\section{Danksagung}

Zuallererst danke ich meinem Doktorvater, Herrn Prof. Dr. med. Peter Schramm, für die Überlassung des Dissertationsthemas, das Ermöglichen der Studie und die stets hilfreiche und unermüdliche Betreuung dieser Arbeit.

Ich danke Herrn Prof. Dr. med. Michael Knauth für die Möglichkeit, die Studie in seiner Abteilung durchführen zu können, sowie für die wertvolle Unterstützung und Förderung, auch im Rahmen meines Vortrags auf der DGNR-Tagung 2010 in Köln.

Des Weiteren möchte ich mich bei Frau Ramona Schramm und den Mitarbeitern der neuroradiologischen Abteilung der Universitätsmedizin Göttingen für die technische und praktische Unterstützung bei der Anfertigung der Studie herzlich bedanken.

Ein Dank gilt auch Frau Ulrike Haberland und Herrn Ernst Klotz von der Siemens AG, Medical Solutions, für die kompetente Beratung und Unterstützung bei der technischen Durchführung der Studie.

Auch möchte ich mich bei Herrn PD Dr. Klaus Jung vom Institut für Medizinische Statistik der Universitätsmedizin Göttingen für die wertvolle Begleitung bei der statistischen Auswertung der Studienergebnisse bedanken. 


\section{Anhang}

Auswertungstabelle 